\title{
Common infections, work-related factors, and fatigue
}

Citation for published version (APA):

Mohren, D. C. L. (2002). Common infections, work-related factors, and fatigue. [Doctoral Thesis, Maastricht University]. Datawyse / Universitaire Pers Maastricht. https://doi.org/10.26481/dis.20030131dm

Document status and date:

Published: 01/01/2002

DOI:

10.26481/dis.20030131dm

Document Version:

Publisher's PDF, also known as Version of record

\section{Please check the document version of this publication:}

- A submitted manuscript is the version of the article upon submission and before peer-review. There can be important differences between the submitted version and the official published version of record.

People interested in the research are advised to contact the author for the final version of the publication, or visit the DOI to the publisher's website.

- The final author version and the galley proof are versions of the publication after peer review.

- The final published version features the final layout of the paper including the volume, issue and page numbers.

Link to publication

\footnotetext{
General rights rights.

- You may freely distribute the URL identifying the publication in the public portal. please follow below link for the End User Agreement:

www.umlib.nl/taverne-license

Take down policy

If you believe that this document breaches copyright please contact us at:

repository@maastrichtuniversity.nl

providing details and we will investigate your claim.
}

Copyright and moral rights for the publications made accessible in the public portal are retained by the authors and/or other copyright owners and it is a condition of accessing publications that users recognise and abide by the legal requirements associated with these

- Users may download and print one copy of any publication from the public portal for the purpose of private study or research.

- You may not further distribute the material or use it for any profit-making activity or commercial gain

If the publication is distributed under the terms of Article $25 \mathrm{fa}$ of the Dutch Copyright Act, indicated by the "Taverne" license above, 
Common Infections,

Work-related Factors, and Fatigue 
ISBN: 9052783632

Lay-out: Cobie Martens, Epidemiologie, Universiteit Maastricht Cover: Marlies Crooijmans | Danielle Mohren

Production: Datawyse | Universitaire Pers Maastricht

(c) 2002, D.C.L. Mohren

All rights reserved. No part of this thesis may be reproduced or transmitted in any form or by any means, electronic or mechanical, including photacopying, recording or any information storage or retrieval system, without pernission in writing from the author, or, when appropriate, from the publishers of the publications. 


\title{
Common Infections, Work-related Factors, and Fatigue
}

\author{
PROEFSCHRIFT \\ ter verkrijging van de graad van doctor aan \\ de Universiteit Maastricht, \\ op gezag van de Rector Magnificus, \\ Prof. dr. A.C. Nieuwenhuijzen Kruseman, \\ volgens het besluit van het College van Decanen, \\ in het openbaar te verdedigen \\ op vrijdag 31 januari 2003 om 12.00 uur \\ door
}

Danielle Catharina Leonie Mohren

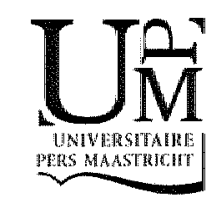




\section{Promotores}

Prof. dr. C.P. van Schayck

Prof. dr. J.M.D. Galama (Katholieke Universiteit Nimmegen)

\section{Co-promatores \\ Dr. G.M.H. Swaen \\ Dr. ing. IJ. Kant}

\section{Beoordelingscommissie}

Prof. dr. J.A. Knottnerus (voorzitter)

Prof. dr. G. Bleijenberg (Katholieke Universiteit Nijmegen)

Prof. dr. ir. P.A. van den Brandt

Dr. J.A. Landeweerd

Prof. dr. J.W.M van der Meer (Katholieke Universiteit Nijmegen)

The Maastricht Cohort Study is part of the Netherlands concerted research action on "Fatigue at Work" granted by the Netherlands Organization for Scientific Research (NWO). The study presented in this thesis was supported by the Netherlands Organization for Scientific Research (NWO grant no. 580-02.254).

The study presented in this thesis was conducted at the Maastricht Health Research Institute for Prevention and Care (HEALTH), Maastricht University, the Netheriands. HEALTH participates in the Netherlands School of Primary Care Research (CaRe), which was acknowledged in 1995 by the Royal Netherlands Academy of Arts and Sciences (KNAW). 


\section{Contents}

1 Introduction

2 Psychological Job Demands as a risk factor for common cold in a Dutch working population

$3 . \quad J o b$ insecurity as a risk factor for common infections, and health complaints 31

4 Prevalence of common infections among employees in different work schedules

$5 \quad$ Associations between infections and fatigue in a Dutch working population: Results of the Maastricht Cohort Study on Fatigue at Work

6 Common infections and the role of Burnout in a Dutch working population

$7 \quad$ Fatigue and job stress as predictors for sickness absence during common infections

8. Epilogue

Summary

Samenvatting

Dankwoord

About the author 



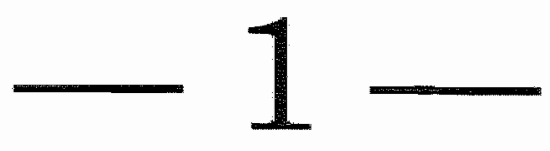

\section{Introduction}

Acute common infections, such as common cold, influenza-like illnesses, and gastroenteritis are very prevalent in the general population, and cause considerable discomfort and absenteeism. Not every person exposed to a virus responsible for a common infection, will acquire the infection. Also, severity and duration can vary widely among those who do fall ill." Psychosocial factors might be involved in the susceptibility to and manifestation of an infection, including its duration.

\section{Acute common infections}

\section{Causes and symptoms}

Colds can be caused by over 200 viruses, among which the rhinoviruses predominate, ${ }^{2}$ and is the most prevalent disease in humans. Adults typically get two to five colds a year. In households with young children, the incidence is even higher. ${ }^{3}$ Influenza is primarily caused by two types of viruses ( $A$ and $B$ ), each with several subtypes and antigenic variants. Influenza-like diseases can also be caused by other viruses, for example, adenoviruses, enteroviruses, and respiratory syncytical virus (RS-virus). Both, common colds and flu-like illnesses are characterized by sore throat ${ }_{\text {congestion, and mucus }}$ secretion. Cold and influenza-like illnesses are different in that colds produce mainly local symptoms confined to the upper respiratory tract (nasal secretion) whereas influenza gives also rise to systemic effects, ${ }^{4}$ such as an elevated body temperature, and muscle pain. The major causes of gastroenteritis are either viral or bacterial. Rotaviruses, astroviruses, enteric adenoviruses, ${ }^{5}$ and caliciviruses are the main viral causes of gastroenteritis in the general population. The primary manifestation of gastroenteritis is diarrhea, but it may be accompanied by nausea, vomiting, and abdominal pain. In Table 1, the viruses commonly responsible for acute common infections in the general population are shown.

\section{Impact}

The common cold, although not a severe disease in healthy subjects, is one of the main causes of absenteeism at work. ${ }^{6}$ As an example, about 30 million days of work are lost every year in the United States as a result of colds, which also cause 250 million days of restricted activity. ${ }^{7}$ Also influenza and flu-like illnesses have a substantial effect on both the worker and the employers. The major impact is related to the disruption of dailly life caused by the symptoms, resulting in tens of millions of workdays absenteeism and health care provider visits each year. Data from the National Health Survey ${ }^{9}$ for persons aged 18 to 64 years, indicate that influenza was responsible for more than 200 million 
Tabie 1 Viruses commonly responsibie for acute common infections

\begin{tabular}{ll}
\hline Common infections & Responsible viruses \\
\hline Comimon cold & Adenovirus* \\
& Enterovirus $^{*}$ \\
& Influenza A-virus* \\
& Influenza B-virus* \\
& Influenza C-virus \\
& Mycoplasma pneumoniae* \\
& Parainfluenza virus* \\
& Rhinovirus* \\
& RS-virus* \\
\hline Flu-like illness & Chlamydia pneumoniae \\
& Enterovirus* \\
& Influenza A-virus* \\
& Influenza B-virus* \\
& Mycoplasma pneumoniae* \\
& RS-virus \\
\hline Gestroenteritis & Astrovirus \\
& Caliciavirus \\
& Enterovirus* \\
& Rotavirus \\
\hline
\end{tabular}

* yiruses included in the Virological Weekly Reports

days of restricted activity, 100 million days of bed disability, 75 million workdays absenteeism, and 22 million health care provider visits in 1995. In industrialized countries, gastroenteritis is still one of the most common diseases ${ }^{10}$ although morbidity and mortality have declined as the economy and sanitation have improved. Most episodes of gastroenteritis are brief and do not require medical attention, but the social and economic burdens due to absenteeism are substantial because of the high incidence. $^{1 /}$

\section{Stress and infections}

Over the years evidence has accumulated that stress, caused by psychosocial factors influences, the immune system and subsequently the susceptibility to infections and the duration of symptoms. ${ }^{2-16}$ in a 4-year prospective epidemiological study of infectious mononucleosis $(\| \mathrm{M})$ among cadets at West Point Military Academy, it was shown that psychosocial factors significantly increased the risk of clinical IM among seroconverters. ${ }^{17}$ A large body of evidence indicating that stress influences the susceptibility to infections has been provided by the Common Cold Studies. In these studies, healthy subjects were intentionally exposed to either rhinoviruses, respiratory syncytical viruses or coronavirus, ${ }^{16,18-20}$ in order to determine whether psychological factors influence susceptibility to upper respiratory tract infections (URTI). These studies showed that persons with high levels of perceived stress or life events showed higher rates of upper respiratory tract infections.

Research into the relationship between stress and infectious diseases began approximately 100 years ago. Pasteur abserved that chickens normally resistant to anthrax became susceptible following immersion in cold water. ${ }^{12}$ This discovery probably 
marked the beginning of research on the relationship between stress and infectious pathology. Recent thinking is heavily influenced by the observations of Alexander " ${ }^{24} \mathrm{He}$ related psychological factors to seven disease entities (peptic ulcer, ulcerative colitis. hyperthyroidism, regional enteritis, rheumatoid arthritis, essential hypertension, and bronchial asthma). ${ }^{22}$ It was thought that a specific psychological conflict was an underlying basis for each of these illnesses, and thus linking psychosocial factors to health. Research, most of which has been conducted over the past 25 years, has revealed that immunoregulatory processes are influenced by the brain and, conversely, that neural and endocrine functions and behavior are influenced by the immune system. Two pathways link the brain and the immune system: the autonomic nervous system and the neuroendocrine outflow via the pituitary. ${ }^{23}$ Changes in behavioral and emotional states that accompany the perception of, and the effort to adapt to, environmental circumstances are associated with complex patterns of neuroendocrine changes. ${ }^{23}$ Researchers have observed that acute and chronic stressors are associated with in witro changes in immune parameters. The biological relevance of these changes, however, are still unclear. The immune system may manifest changes, which not have any apparent clinical effect on health because of compensatory mechanisms. This implies that not every individual exposed to these or acute or chronic stressors may show obvious health effects, but that effects may only be detectable on a population level, for example, as an increased prevalence of common infections. ${ }^{24}$

\section{The role of work-related factors}

The work environment can be seen as a source of stress caused by several work-related factors. These factors may have an impact on the development of an infection, possibly through the effect on the immune system. Although there are a number of studies which demonstrate a link between the experience of work stress and changes in the immune system, in only a few studies the relationship between work stress and the risk for infections has been investigated. In several studies the possible effects of these longterm stressors have been investigated. In a study of Cluff, ${ }^{14}$ the effect of mental demands, in a group of 480 men working for a military research institute, was investigated. This investigation took place three to six months before the onset of an epidemic of Asian influenza in Maryland (USA). This naturally accurring event gave the researchers the opportunity to study the possible relationship between mental demands and the occurrence of infections. It was found that employees who reported high mental demands, showed a three times higher morbidity of influenza in comparison with a group of employees reporting low levels of emotional demands. In other studies, the focus has been on the effect of work-related stressors on immune parameters. Cross-sectional studies among teachers and nurses revealed that immunoglobuline levels were negatively correlated with self-reports of work stress. ${ }^{25,26}$ in a study of Nakano et al ${ }^{27}$ among taxi-drivers, blood samples were collected at two different time-points. At baseline no differences were found in the levels of several immune parameters between taxi-drivers and a group of controls. One year later, the lymphocyte response to mitogen and production of interleukine-2 was lower in taxi-drivers compared to the control group. In contrast, an increase in interleukine-4 production was found among taxi-drivers. The daily experienced stress of taxi-driving, and a decrease in income due to economic recession, was given as possible explanation for the findings. The above mentioned 
studies show that demands in the job can influence the immune system. Whether the changes in immune parameters result in an increased susceptibility for infections has not been subject of these studies.

\section{Role of fatigue}

Work-related stressors are also risk factors for fatigue, ${ }^{20}$ for this reason fatigue may also act as an intermediate factor between work-related stressors and common infections. Besides this, fatigue may play a role in the susceptibility to acute viral infections. ${ }^{29}$ This relationship has not been supported by a substantial body of scientific evidence, and it is more a piece of conventional wisdom that people think they caught a virus because the felt tired or run down ${ }^{30}$ Viral infections are usually accompanied by fatigue. ${ }^{31}$ in several retrospective studies a link was found between abnormal fatigue and severe infections. ${ }^{32-}$ ${ }^{35}$ Certain infections can trigger long-term fatigue and chronic fatigue syndrome (CFS). For instance, longuterm fatigue, CFS, or both, have been reported after infectious mononucleosis, ${ }^{33,36,37}$ viral hepatitis, ${ }^{38}$ viral meningitis ${ }^{39}$ and $\mathrm{Q}$ fever. ${ }^{40}$ Wessely et al. ${ }^{41}$ studied a sample of primary care altenders, categorized by whether or not they had been clinically diagnosed as suffering from an infection, mainly upper respiratory tract infections. In this study no excess fatigue was found in those clinically diagnosed as having an infection six months earlier. Cope et al, ${ }^{42}$ studied a simillar sample in primary care, consisting of patients who had been clinically dliagnosed as suffering from a viral infection. They did not find an association with fatigue six months later. From these prospective studies it has been suggested that it is unlikely that common upper respiratory tract infections trigger CFS, and that the relationship between common viral infections and fatigue 6 months later may be unrelated to the virus itself. ${ }^{41.42}$

\section{Study aim and research questions}

As already mentioned the effect of work-related factors on the immune system has not been subject of a lot of research, and the effect of these factors on the occurrence of infections is still unclear. Evidence that links psychosocial factors to the immune system is largely based on cross-sectional studies, mainly under experimental conditions. In respect to the role of fatigue, a lot of information is available concerning its connection with infections. But in these particular studies, mostly severe infections with a low prevalence in the generall population, were investigated.

The aim of this thesis was to explore the relationship between several work-related factors and the occurrence of acute common infections, and the possible role of fatigue. This study was performed within the framework of a large prospective cohort study among employees, in order to establish longitudinal relationships within a nonexperimental setting. We hypothesized that work-related factors causing stress, can result in increased susceptibility to common infections, as measured by an increase in the prevalence of infections. Infections can lead to the activation of the immune system, resulting in fatigue. Since fatigue is also influenced by work-related factors, there may be a complex interaction between work-related factors, common infections, and fatigue. Figure 1 shows a conceptual model that has been used as the basis for the research 
questions of this thesis. A potential outcome of common infections is sickness absence. Common infections can also result in absenteeism from work, possibly, influenced by work-related factors, and fatigue.

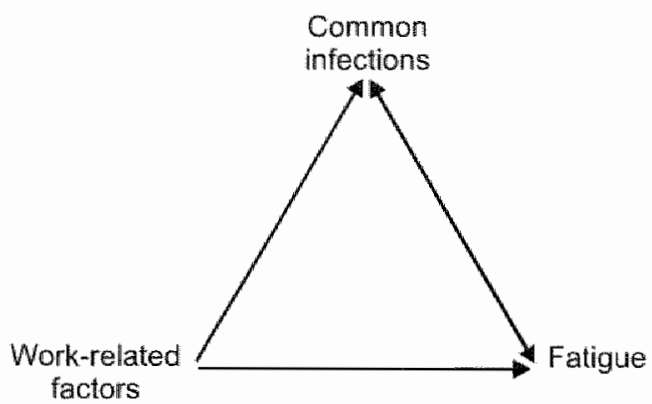

Figure 1 Conceptual model for the possible relationships between infections, work-related factors and fatigue

In order to study the complex relationships between common infections, work-related factors and fatigue, the following questions were formulated:

1. What is the effect of different work-related stressors on the occurrence of common infections?

2. What is the relationship between common infections and different expressions of fatigue?

3. Which work-related factors play a role in the decision to be absent from work when experiencing a common cold?

\section{Methodological considerations}

\section{Maastricht Cohort Study}

To investigate the causal relationships between stressors in the work environment and the occurrence of common infections, and to disentangle the relationships between fatigue and infections, it is necessary to follow a group of employees prospectively. The Maastricht Cohort Study on "Fatigue at Work", started in 1998, was used as a sampling frame to further elucidate these relationships. This cohort study is part of a national research program on "Fatigue at Work", which was started in 1996. This multidisciplinary program includes psychological and medical research and is financially supported by the Netherlands Organization for Scientific Research (NWO). 


\section{Study population}

At baseline $(n=12,140)$ the Maastricht Cohort Study surveyed a large heterogeneous population of employees in 687 different professions ${ }^{43}$ working in 45 different companies and organizations and followed this group for three years. ${ }^{44.45}$

\section{The questionnaire}

The participants of the Maastricht Cohort Stuidy received nine questionnaires in total, at four-monthly interval $s_{i}$ and a total observation period of three years (1998-2001). Once a year the participants received a questionnaire with both exposures (work-related factors, individual characteristics, domestic and sacial factors) as well as outcomes (fatigue, need for recovery, burnout, etc.) measured on an individual level using self-administered questionnaires. The participants received a short questionnaire twice a year, measuring mainly outcomes.

\section{Determination of common infections}

The main health outcome in this thesis was the occurrence of common infections. The occurrence of common cold, flu-like illness and gastroenteritis was inventoried in each questionnaire, using self-reported information on common infection symptoms. In large scale cohort studies the use of questionnaires, which may lead to possible over or under reporting of the effect, is inevitable. Furthermore, it is technically difficult to confirm viral infections, using a specific test, when the particular virus is not known, which is typically the case in the natural observational studies.

At four-monthly intervals the employees in the Maastricht Cohort Study were asked to fill in a questionnaire. The following items on the occurrence of common infections were part of these questionnaires:

1. Did you experience a common cold in the past four months? The symptoms for a common colld include: clogged or running nose, a sore throat, caughing, and slight or no fever (temperature less than $38^{\circ} \mathrm{C}$ ).

2. Did you experience a flu in the past four months? The symptoms for a flu include: fever (temperature $38^{\circ} \mathrm{C}$ or more), with a least four of the following six complaints: muscular pain, fatigue, sore throat, clogged or running nose, coughing, headache

3. Did you experience gastroenteritis in the past four months? The symptoms for gastroenteritis include: slight or no fever, gastritis, nausea, vomiting, and/or diarrhea.

A smail pillot study was performed among a group of five general practitioners (GPS), to test the validity of the common infection items, used in our study. Patients were asked to fill out the infection items in the questionnaire, in order to complare the subjective experience of infection symptoms of the patients, with the GPS diagnosis. A good correspondence between the answers filled out by the patients, and the GPs diagnosis was found. Another comparison was made between, data from the virological weekly reports, ${ }^{46}$ which covers laboratory diagnoses from all clinical virology laboratories in the Netherlands, and the prevalence of common infections derived from the questionnaires from the Maastricht Cohort Study. Because infections recur in cycles, peaks of common infections should be found in comparable periods, established by virology tests, and in 
the Maastricht Cohort Study. In Figures 2,3 , and 4 , the results of the comparison between the prevalence of common infections in the Maastricht Cohort Study and the data based on the virology weekly reports of the viruses isolated commonly responsible for these acute common infections are shown. To make these comparisons, we grouped the different viruses that were isolated in the virology laboratories, in order to compare the results with the prevalence of acute common infections in the cohort. In Table 1 , viruses commonly responsible for acute common infections were shown. The viruses that were part of the virological weekly reports were indicated. The respiratory syncytical virus, although responsible for influenza-like illnesses among the general population. was not included as a cause for flu-like illness in an adult working population. This virus is the chief cause of hospitalization for respiratory tract illnesses in children, ${ }^{47}$ in adults this virus mainly causes common cold symptoms. A striking simularity (figure 2,3, and 4), between the trend of the prevallence of the common infections and the viruses isolated responsible for these infections, was found. This comparison should be interpreted with some caution, because data based on the virologicall weekly reports were based on the determination of infections among patients, in contrast to the occurrence of common infections among "healthy" employees in the Maastricht Cohort Study.

Adding the results of the detection of bacterial pathogens (Saimonellas, Shigellas and Campylobacter), which can also be responsible for symptoms of gastroenteritis to the viruses isolated, resulted in a comparison as shown in Figure 5 . Several reasons can account for the difference found in Figure 5 between the trend in reported infections within the cohort and the viruses isolated and bacteria commonly responsible for these infections. Probably severity and duration of symptoms for gastroenteritis play a role in health-care seeking behavior. Because these factors are also related to the pathogen causing the symptoms, the relative importance of the various pathogens will differ ${ }^{11}$ between patients and the employees within the cohort. A difference in prevalence of gastroenteritis, either contributable to a virus or bacteria, could account for the difference between Figure 4 (only viruses responsible for gastroenteritis were included) and Figure 5 (both viruses and bacteria responsible for gastroenteritis were included). In a prospective population-based cohort study in the general Dutch population, it was found that bacterial pathogens accounted for only $5 \%$ of gastroenteritis cases, and viral pathogens for $21 \% . "$ But also a difference in age between employees in the cohort and the patients, because of the high incidence of gastroenteritis among young children, may have accounted for the found differences in Figure 5. Based on these data it was assumed that the questionnaire is a suitable instrument to measure the occurrence of common cold and flu-like illness and to a lesser extent gastroenteritis, in the cohort. 


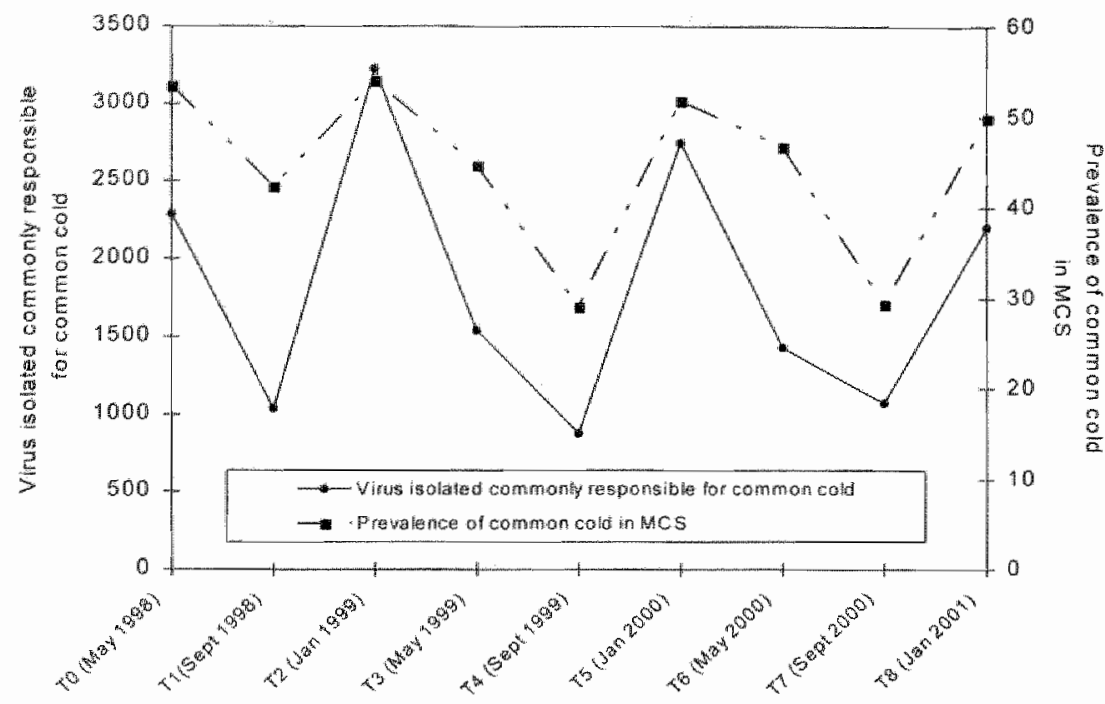

Figure 2 Comparison of occurrence of common cold in MCS with data based on the virological weeklly reports irom the Working Committee on Clinical Virology

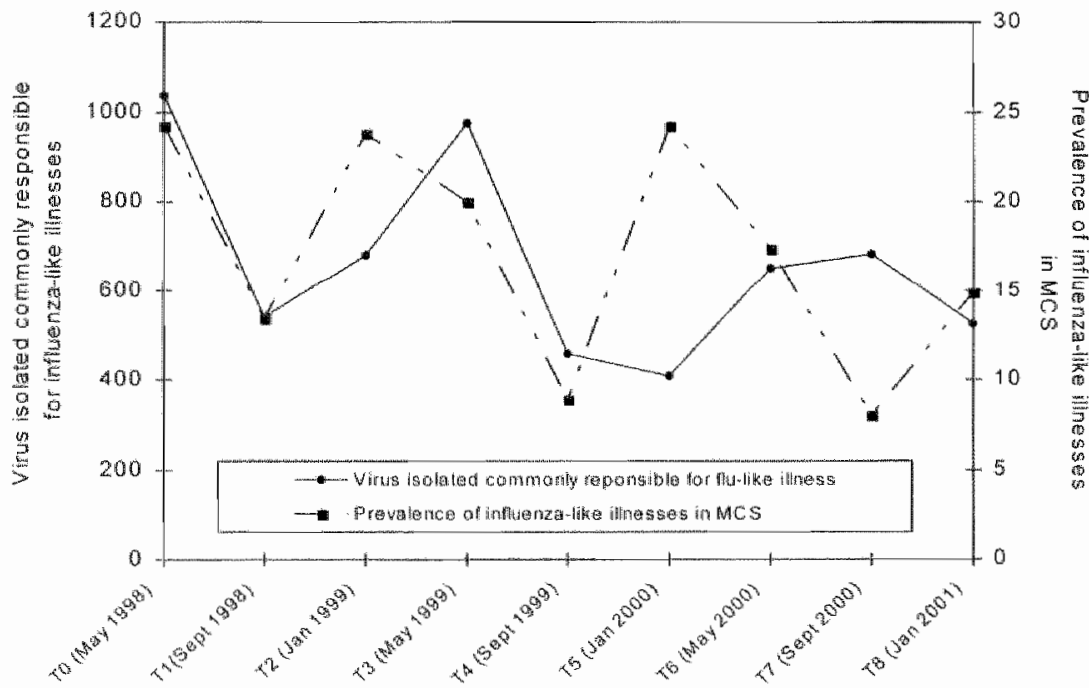

Figure 3 Comparison of occurrence of influenza-like illnesses in MCS with dala based on the virological weekly reports from the Working Committee on Clinical Virology 


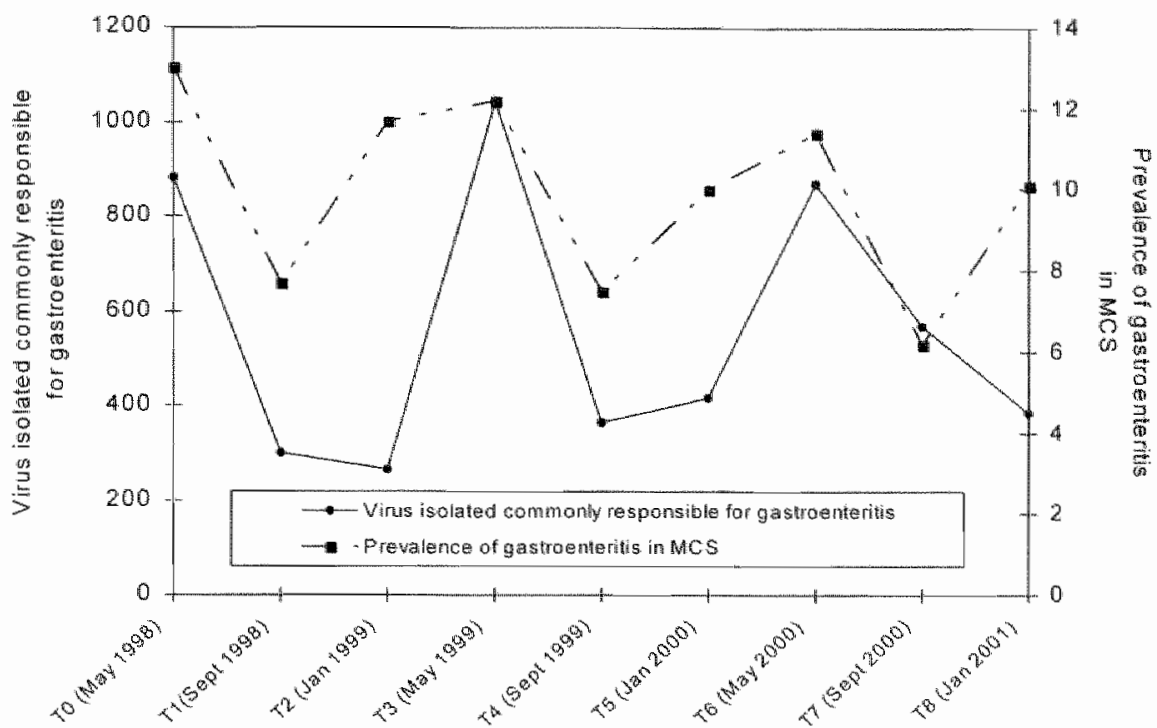

Figure 4 Comparison of occurrence of gastroenteritils in MCS with data based on the virological weekly reports from the Working Committee on Clinical Virology

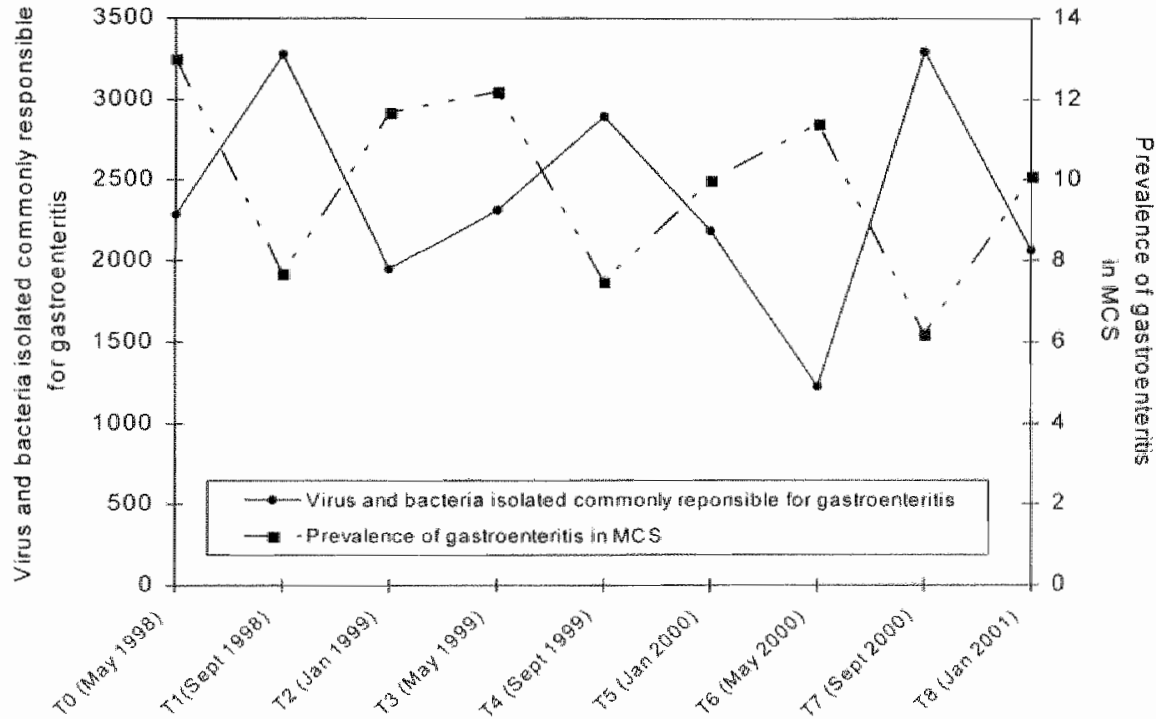

Figure 5 Camparison of occurrence of gastroenteritis in MCS with data based on the virological Weekly reports from the Working Committee on Clinical Virology and data based on the Laboralory Surveillance infectious diseases 


\section{Outline of the thesis}

In chapter 2,3 , and 4 , the role of work-related factors on the occurrence of infections are subject of study. A distinction was made between subjective factors (psychological job demands, and job insecurity) and objective factors related to work (work schedules). In chapter 2 the results of a cross-sectional study at baseline are presented, in which the effect of psychological job demands on the occurrence of common cold is studied. In chapter 3 the cross-sectional as well as the longitudinal effect of job insecurity on the occurrence of common infections, and health complaints is discussed. Chapter 4 describes the relationship between working in different work schedules and common infections. For this particular study employees in day shift were compared with employees in three shifts, five shift and irregular shift with night work.

In chapter 5 and 6 we studied the effect of two different expressions of fatigue on the occurrence of infections. In chapter 5, the complex relationship between fatigue (measured with the Checklist Individual Strength), as a more general complaint, and infections is studied. Three different relationships are subject of study: a cross-sectional relationship, fatigue as predictor of infections, and infections as predictor of fatigue. Chapter 6 describes the effect of burnout on the occurrence of common infections. Burnout is a more work-related syndrome, caused by stressful work conditions. In this study, the burnout concept is measured with the Maslach Burnout Inventory Generall Survey (MBI-GS).

In chapter 7, a potential outcome of common infections, this is absence due to these infections, is subject of study. The goal was to determine factors that play a role in the decision to be absent from work when reporting an infection.

Chapter 8 is the epilogue, which presents a general discussion and the conclusions of this research

\section{References}

1. Cohen $S$, Williamson GM. Stress and infectious disease in humans. Psychol Bull $1991 ; 109(1): 5-24$.

2. Gwaltney JM. Rhinowirus. In: Mandell GL, Bennett JE, Dolin R, editors. Mandell, Douglas and Bennett's Principles and practice of infectious disease. New York: Churchill Livingstone; 1995. p. $1656-63$.

3. Cohen S. Psychological stress and susceptibility to upper respiratory infections. Am I Respir Crit Care Med 1995; 152 (4 Pt 2):553-8.

4. Smith AP. Respiratory virus infections and performance. Philos Trans R Sac Lond B Biol Sci $1990 ; 327(1241): 519-28$

5. Koopmans $M_{n}$ Vinje $J$, de Wit $M$, Leenen I, van der Poel $W$, van Duynhoven $Y$. Molecular epidemiology of human enteric caliciviruses in The Netherlands. J Infect Dis 2000;181 Suppi 2:\$262-9.

6. Takkouche B, Regueira C. Gestal Otero JJ. A cohort study of stress and the common cold. Epidemiology. 2001:12(3):345-9.

7. Couch RB. The common cold: control? J Infect Dis 1984;150:167-73. 
8. Nichol KL. Cost-benefit analysis of a strategy to vaccinate healthy working adults against influenza. Arch Intern Med 2004:161(5):749-59.

9. Benson V, Marano MA. Current estimates from the National Health Interview Survey, 1995. Vital Health Stat 1998(199):1-428

10. Guerrant RL, Hughes JM, Lima NL. Crane J. Diarrhea in developed and developing countries: magnitude, special settings, and etiologies. Rew lifect Dis 1990;12 Suppl 1:S41-50.

11. de Wit MA, Koopmans MP, Kortbeek LM, Wannet WJ, Vinje J, van Leusden F, et al. Sensor, a population-based cohort study on gastroenteritis in the Netherlands: incidence and etiology. Am J Epidemiol 2001; 154(7):666-74.

12. Biondi M. Zannino LG. Psychological stress, neuroimmunomodulation, and susceptibility to infectious diseases in animals and man a review. Psychother Psychosom 1997;66(1):3-26.

13. Meyer RJ, Haggerty RJ. Streptococcal infections in families. Pediatrics 1962;29:539-49.

14. Cluff LE, Canter A, Imboden $\unlhd B$. Asian influenza. Infection, disease, and psychological factors. Arch Intern Med 1966;117(2):159-63.

15. Clover RD, Abell T, Becker LA, Crawford $S$, Ramsey $C N$, Jr. Family functioning and stress as predictors of influenza $B$ infection. J Fam Pract 1989:28(5):535-9.

16. Cohen $S$, Tyrrell DA, Smith AP. Psychological stress and susceptibility to the common cold. N Engl J Med 1991;325(9):606-12.

17. KasI SV, Evans AS, Niederman JC. Psychosocial risk factors in the developmental of infectious manonucleosis. Psychasom Med 1979;41(6):445-66.

18. Cohen S, Tyrrell DA, Smith AP. Negative life events perceived stress, negative affect, and susceptibility to the common cold. J Pers Soc Psychol 1993;64(1):131-40.

19. Stone AA, Bovbjerg DH, Neale JM, Napoli A, Valdimarsdottir $H_{*}$ Cox D, et al. Development of common cold symptoms following experimental rhinovirus infection is related to prior stressful life events. Behav Med 1992;18(3):115-20.

20. Cohen S. Psychological stress and susceptibility to upper respiratory infections. Am J Respir Crit Care Med 1995:152:S53-S58.

21. Alexander F. Psychosomatic Medicine. New York: Norton; 1950

22. Plaut $S M$, Friedman SB. Psychosocial factors in infectious disease. In: Ader $R$, editor. Psychoneuroimmunology: Academic press, INC.; 1981. p. 3-30.

23. Ader $R$, Cohen $N$, Felten $D$. Psychoneuroimmunology: interactions between the nervous system and the immune system. Lancet 1995;345(8942):99m 103 .

24. van Loveren $H$, Germolec D, Koren HS, Luster MH, Nolan C, Repetto R, et al. Report of the Bilthoven symposium: Advancement of epidemiological studies in assessing the human health effects of immunotoxic agents in the environment and the workplace. Bilthoven, The Netherlands: National Institute of Public Health and the Environment; 1998. Report No.: RIVM report 640070001

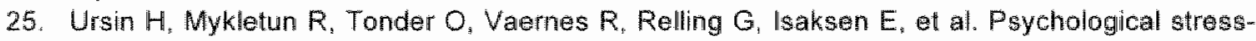
factors and concentrations of immunoglobulins and complement components in humans. Scand I Psychol 1984:25(4):340-7

26. Endresen $I M$, Vaernes $R$, Ursin $H_{n}$ Tönder $O$. Psychological stress-factors and concentration of immunoglobulins and complement components in Norwegian nurses. Work Stress 1987:1:36576.

27. Nakano $Y$, Nakamura $S$, Hirata $M$, Harada $K$. Ando $K$ "Tabuchi $T$, et al. Immune function and lifestyle of taxi drivers in Japan. Ind Health 1998;36(1):32-9.

28. Bültmann U, Kant IJ, Van den Brandt PA, KasI SV. Psychosocial work characteristics as risk factors for the onset of fatigue and psychological distress: Prospective results from the Maastricht Cohort Study. Psychol Med 2002;32:333-45

29. Smith $A$, Thomas $M$, Borysiewicz $L$, Llewelyn $M$. Chronic fatigue syndrome and susceptibility to upper respiratory tract illness. Br J Health Psychol 1999;4(Part 4):327-35.

30. Cope H. David A, Mann A. 'Maybe it's a virus?': beliefs about viruses, symptom attributional style and psychological health. $J$ Psychosom Res 1994;38(2):89-98

31. Bennett BK, Hickie IB, Vollmer Conna US, Quigley B, Brennan CM, Wakefield D, et al. The relationship between fatigue, psychological and immunological variables in acute infectious illness. Aust N Z J Psychiatry 1998;32(2):180-6. 
32. Benjamin JE, Hoyt RC. Disability following postvaccinal (yellow fever) heaptitis: a study of 200 patients manifesting delayed convalescence. JAMA 1945;128:319-24.

33. Lambore S. McSherry J, Kraus AS. Acute and chronic symptoms of mononucleosis. J Fam Pract 1991,33(1):33-7.

34. Muller R. Nylander I, Larsson LE, Widen L, Frankenhaeuser M. Sequelae of primary aseptic meningo-encepalitis. A clinical, sociomedical, electroencephalographic and psychological study. Acta Psychiatr Neurol Scand 1958;33 Suppl 126:1-115.

35. Lepow ML, Coyne $\mathbb{N}$, Thompson LB, Carver DH, Robbins FC. A clinical, epidemiological and laboratory investigation of aseptic meningitis during the four-year period, 1955-1958. II. The

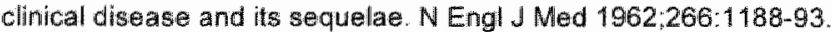

36. Buchwald DS, Rea TD, Katon WJ. Russo JE, Ashley RL. Acute infectious mononucleosis: characteristics of patients who report failure to recover. Am J Med 2000;109(7):531-7.

37. White PD, Thomas JM, Amess J, Crawford DH, Grower SA, Kangro HO, et all. Incidence, risk and prognosis of acute and chronic fatigue syndromes and psychiatric disorders after glandular fever. Br J Psychiatry 1998;173:475-81.

38. Berelowitz GJ, Burgess AP, Thanabalasingham T, Murray Lyon IM, Wright DJ. Post-hepatitis syndrome revisited. J Viral Hep 1995;2(3):133-8.

39. Hotopf $M$, Noah $N$, Wessely $S$. Chronic fatigue and minor psychiatric morbidity after viral meningitis: a controlled study. J Neurol Neurosurg Psychiatry 1996;60(5):504-9.

40. Ayres JG, Flint $N$, Smith EG, Tunnicliffe WS, Fletcher $T J$, Hammond $K$, et al. Post-infection fatigue syndrome following $Q$ fever. QJM 1998;91(2):105-23.

41. Wessely $S$, Chalder $T$, Hirsch $S$, Pawlikowska $T$, Wallace P, Wright DJ. Postinfectious fatigue: prospective cohort study in primary care. Lancet 1995;345(8961):1333-8.

42. Cope $H$, David A, Pelosi A, Mann A. Prediclors of chronic "postviral" fatigue. Lancet $1994 ; 344(8926) ; 864-8$.

43. Bültmann $U$, Kant IJ Van Amelsvoort LGPM, Van den Brandt PA, Kasi SV. Differences in fatigue and psychological distress across occupations: Results from the Maastricht cohort study an fatigue at work. J Occup Environ Med 2001:43(11):976-83.

44. Beurskens AJ, Bultmann U, Kant $W_{\text {, Vercoulen }} \mathrm{JH}$, Bleijenberg $\mathrm{G}$, Swaen GM. Fatigue among working people: validity of a questionnaire measure. Occup Environ Med 2000;57(5):353-7.

45. Kant IJ, Beurskens AJHM, Schröer CAP, Nijhuis FJN, Van Schayck CP, Van den Elzen HJ, et al. De Maestrichtse Cohort Studie naar langdurige psychische vermoeidheid in de arbeidssituatie [The Maastricht Cohort Study on fatigue at work]. TBV 2000;8(8):226-32.

46. van den Brandhof WE, Kroes ACM, Bosman A, Peeters MF, Heijnen MLA. Rapportage van virologische diagnostiek in Nederland. Representativiteit van de gegevens uit de virologische weekstaten. [Reporting virus diagnostics in the Netherlands: representativeness of the virological weelkly reports. Infectieziekten Bulletin 2002;13(4):110-13.

47. Breese Hall C. Respiratory syncytial virus and parainfluenza virus. N Engl J Med $2001 ; 344(25): 1917-28$ 


\title{
$-2$
}

\section{Psychological Job Demands as a risk factor for common cold in a Dutch working population}

\author{
Danielle CL Mohren' \\ Gerard MH Swaen' \\ Paul JA Borm ${ }^{2}$ \\ Aalt Bast ${ }^{3}$ \\ Jochem MD Galama
}

\begin{abstract}
Objective. We investigated the effect of Psychological Job Demands (PJD) on the occurrence of the clinical symptoms of common cold. Methods. Subjects, participating in a large prospective cohort study on psychological determinants of fatigue at work, were asked to fill in a questionnaire on the occurrence of common colld during the previous four months. High PJD were considered as a potential risk factor. Other factors such as age, gender, and having young children were considered as potential confounders. Results. In logistic regression analysis the adjusted odds ratio (OR) for having a recent cold in subjects reporting high PJD ws. those reporting low PJD was 1.20 (95\% confidence interval (Cl) 1.08-1.33). A higher risk emerged among those with young children (OR $1.70 ; 95 \% \mathrm{Cl} 1.47-1.96$ ), those having a history of asthma (OR $1.69 ; 95 \%$

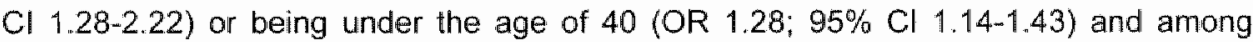
smokers (OR 1.23;95\% Cl 1.09-1.38). Conclusion. The results support an association between P.JD and common cold. In spite of the almost inevitable shortcoming of a large cohort study using questionnaires, this study gave us the opportunity to study the relationship between common cold and work-related factors in a nonexperimental setting with participants, observed in a natural environment with all the normal everyday hassles.
\end{abstract}

\footnotetext{
"Department of Epidemiology, Maastricht University, Maastricht, The Netherlands

${ }^{2}$ Department of Fibre \& Particle Toxicology, Medical Institute for Environmental Hygiene.

Düsseldorf, Germany

${ }^{3}$ Department of Pharmacology and Toxicology "Maastricht University, Maastricht. The Netherlands

'Department of Medical Microbiology. University Medical Center St. Radboud, Nijmegen,

The Netherlands
} 


\section{Introduction}

Common colds are endemic in the general population causing considerable amounts of discomfort and (even) absence from work. This highly infectious illness comprises a mild systemic upset with rhinitis, sneezing, cough, and pharyngeal discomfort as the most prominent complaints. 'Colds can be caused by more than 100 viruses, among which the rhinoviruses predominate. "Not every person exposed to one of these viruses will develop a cold. Also, severity and duration of symptoms can vary widelly among those who do fall ill. ${ }^{2}$ Psychosocial factors are suggested to be involved in the process of developing a cold and, maybe, also in its prevention. ${ }^{2}$

Several studies have been conducted where stress and the susceptibility to or prevalence of common cold were taken into consideration. In a 6-month prospective study, Graham et al. ${ }^{3}$ identified high and low stress groups; The high stress group defined by high levels of major life event and daily event stress over a 6-month period, suffered significantly more episodes and symptom days of respiratory illness. Also, Cobb and Steptoe ${ }^{4}$ reported a higher risk of upper respiratory tract illness in an adult population experiencing high life event stress both before and during the study period. Experimental inoculation of adult volunteers with respiratory viruses, revealed that psychological stress was associated in a dose-response manner with an increased risk of acute respiratory illness, and this risk was attributable to increased rates of infection rather than to an increased frequency of symptoms after infection. ${ }^{5}$ In a second study ${ }^{6}$ it was found that the rate of symptomatic illness did increase as well. Furthermore, a distinction was made between the effect of acute and chronic stressors. This study showed that acute stressful life events were not associated with developing colds, but chronic stressors were.

Work environment can be an important stressor, and should be taken into account when studying the relationship between psychological factors and common cold. For this reason, we investigated the effect of Psychological Job Demands (P.JD) on the occurrence of the common cold. It is obvious that PJD themselves cannot induce a cold. but PJD may operate as a co-factor in the pathogenesis of common cold. When exposed to an infectious agent, only a proportion of the people will develop illness, which may partially be attributed to psychologicall stress. PJD play an important role in the "Job Strain model" developed by Karasek, "which is a very important model in research on job stress and cardiovascular diseases. The model uses two dimensions: Decision Latitude (DL) and Psychological Job Demands. ${ }^{B}$ According to the model, workers exposed to the combination of high P.JD and low DL (high job strain) have an increased risk of psychological strain and a number of somatic diseases, notably cardiovascular diseases. Besides the main effects of PJD and DL on the incidence of common cold, we also studied this interaction between PJD and DL. In addition, other potential risk factors for common cold were studied in a large sample of the Dutch working population.

This study is part of the large scale Maastricht Cohort Study on "Fatigue at Work". Workrelated and nonwork-related factors are measured prospectively on an individual level by means of self-administered questionnaires. To determine the prevalence of common 
cold, we used self-reported experience of symptomatic colds that occurred during the previous four months.

\section{Methods}

In 1998, a large-scale epidemiological study was started at Maastricht University in order to (a) examine the psychosocial risk factors in the etiology and prognosis of fatigue and psychological distress at work and (b) to investiglate the effectiveness of different treatments of fatigue. This Maastricht Cohort Study is used as a framework for several different projects.

\section{The questionnaire}

The participants in the Maastricht Cohort Study will receive in total nine questionnaires at four-monthly intervals, and a total observation period of three years (1998-2001). Exposures (work, private situation, individual characteristics) are measured each year. outcomes (primary outcome parameter is fatigue) every four months. Exposures and outcomes are measured on an individual level using self-administered questionnaires. The questionnaire contained four items concerning acute or more persistent infections. For the purpose of the present study only the data concerning the common cold derived from the baseline questionnaire were used. In addition, the questionnaire contained questions on potential confounders, such as demographic factors, work-related and nonwork-related factors. An initial analysis (of which data are presented in the present study) is based on the cross-sectional data derived from the first (baseline) answers on the questionnaire.

\section{The study population}

At baseline, the Maastricht Cohort Study surveyed 12,140 employees with a wide range of jobs/educational level working in 45 different companies. All sectors were represented. Included were men and women with a minimum employment of $50 \%$. Temporary employees were excluded since they generally change frequently from jobs. The average age was 40.97 years ( 4 SD 8.93 ); $26.9 \%$ of the participants were women and $73.1 \%$ were men. Biecause of the specific inclusion criteria and the overrepresentation of the sector industry, women were underrepresented in our study population.

From this cohort, two different groups were selected, one group experiencing a high level of PJD and one group experiencing a low level of PJD. We used the PJD scale (Chronbach's alpha: 0.69) from the Job Content Questionnaire of Karasek ${ }^{10}$ to determine the level of PJD. This scale is a five-item indicator measuring job demands, time pressure and conflicting demands. ${ }^{11}$ We used the bottom and top quartile of the scores to compose two groups with enough contrast. The cut-off points for the quartiles are based on the PJD scores of the total population $(n=2,940)$. The reported incidence of common cold was compared between the two groups. In total these two groups included 6050 employees, after exclusion of subjects that had one or more missing values, the final study population contained 5896 individuals $(73.2 \%$ men and $26.8 \%$ were women). 


\section{Risk factors}

Several potential risk factors, either work-related or nonwork-related, were considered. We compited factors that were considered in other studies to be risk factors for common cold. These potential confounders were also inventoried in the Maastricht Cohort Study and were used to analyze the indiwidual effect of PJD and other work-related risk factors on the incidence of the common cold. We investigated onlly the factors that showed some effect in previous studies. ${ }^{2114}$ These factors were: age, gender, smoking, alcohol consumption, having young children and a history of hay fever. In the questionnaire no information concerning a history of hay fever was collected, but we did collect information about the presence of asthma, bronchitis and chronic non specific lung disease (CNSLD). Additional work-related factors were included in the logistic regression model that may act as risk factors for the common cold, including leadership and $\mathrm{DL}$. Leadership is measured using one single dichotomous item in the questionnaire (Do you fulfill an executive function?). Decision Latitude (Chronbach's alpha: 0.82), a scale from the Job Content Questionnaire of Karasek ${ }^{10}$ is defined as the sum of two sub-scales: Skill Discretion (six items; Chronbach's alpha: 0.73) and Decision Authority (three items; Chrombach's alpha: 0.73 ). It is an indicator measuring the subject's influence on or control over his or her work "job variety, and the possibilities for learning new skills. ${ }^{11}$

Karasek's model suggests that a relationship exists between PJD and DL. This combined effect has often been described as an "interaction" suggesting that the particular co-occurrence is associated with significantly lower well-being than would be expected from the simple additive combination of the two factors. ${ }^{15}$ We tested this interaction term (PJDX DL) in our dlata.

\section{Outcome measures}

The main health outcome for this particular part of the cohort study was the accurrence of a common cold during the previous four months. The questionnaire was sent to the participants in May 1998. The results are based on the inventory of self-reported infections. The questionnaire contains one item on the occurrence of the common cold. Symptoms that bellong to this infection, like clogged or running nose, a sore throat and coughing and slight or no fever (temperature less than $38^{\circ} \mathrm{C}$ ), were included in the questionnaire.

\section{Statistical methods}

The possible effect of PJD on the occurrence of the common cold was taken into consideration. The study population was divided into two groups: one group experiencing high PJD and another experiencing low PJD. The reported incidence of common cold was compared between the two groups. The adjusted odds ratio (OR) for having experienced a common cold in the high PJD group vs. the low PJD group and its $95 \%$ confidence interval $(\mathrm{Cl})$ were calculated by logistic regression. Potential confounders were dichotomized and included in the model. By using quartiles for the operationalization of the factor PJD we lost information, because we did not take the information from the two middle quartiles of four into consideration. Instead, in a second logistic model we used the PJD score also as a continuous variable and added the DL scalle from the Job Content Questionnaire of Karasek ${ }^{10}$ as a continuous variable to this 
model. For this analysis, we took the complete population into consideration, excluding those cases that had one or more missing values on either one of the variables. This resulted in a population of 11,452 employees. Finally, we included an interaction term (PJD and DL) to test if there was interaction between PJD and DL. All procedures were done using SPSS for windows 8.0 software.

\section{Results}

\section{Incidence of the common cold}

In our study population ( $n=5896), 53.4 \%$ of the employees reported having experienced a cold in the previous four months. Significantly more employees in the high PJD group reported a common cold $(55.6 \%$ vs. $51.3 \% ; P<0.05)$ compared to the low PJD group. In both groups of PJD, women reported (although not significantly) more common colds compared to men. Both men and women reported more common colds in the high PJD group, for men this difference was significant (Table 1).

There were significantly more men, more smokers, and more people in leadership positions in the high PJD group. No significant differences were found between the high and low PJD group with respect to age, alcohol use, the proportion of people having children of five years or younger or having asthma (Table 2).

Table 1 The prevalence of common cold during the past four months by the level of PJDa

\begin{tabular}{|c|c|c|c|c|c|c|}
\hline & & & & & & \\
\hline & & & & & & \\
\hline & & $N$ & $\%$ & $N$ & $\%$ & $P$ value \\
\hline Women & High PJD & 396 & 58.1 & 285 & 41.9 & .076 \\
\hline & Low PJD & 482 & 53.7 & 416 & 463 & \\
\hline Men & High PJD & 1180 & 54.7 & 976 & 45.3 & .004 \\
\hline & LOW PJD & 1088 & 50.3 & 1073 & 49.7 & \\
\hline Total & High PJD & 1576 & 55.6 & 1261 & 44.4 & .001 \\
\hline & Low PJD & 1570 & 51.3 & 1489 & 48.7 & \\
\hline
\end{tabular}

a PJD: Psychological Job Demands. 
Table 2 Characteristics of the study population in relation to the level of psychological job demands

\begin{tabular}{|c|c|c|c|c|c|c|}
\hline & \multicolumn{2}{|c|}{ High PJD } & \multicolumn{2}{|c|}{ Low PJD } & \multicolumn{2}{|c|}{ Total } \\
\hline & $\mathbb{N}$ & $\%$ & $N$ & $\%$ & $N$ & $\%$ \\
\hline Total & 2837 & 48.1 & 3059 & 51.9 & 5896 & 100 \\
\hline \multicolumn{7}{|l|}{ Gender } \\
\hline Men & 2156 & 76.0 & 2161 & 70.6 & 4317 & 73.2 \\
\hline Women & 681 & 24.0 & 898 & 29.4 & 1579 & 26.8 \\
\hline \multicolumn{7}{|l|}{ Age } \\
\hline$>40$ years & 1472 & 51.9 & 1538 & 50.3 & 3010 & $5: 1$ \\
\hline$\leq 40$ years & 1365 & 48.1 & 1521 & 49.7 & 2886 & 489 \\
\hline \multicolumn{7}{|l|}{ Asthma e.g. } \\
\hline Yes & 127 & 4.5 & 111 & 3.6 & 238 & 4.0 \\
\hline No & 2710 & 95.5 & 2948 & 96.4 & 5658 & 96.0 \\
\hline \multicolumn{7}{|l|}{ Smoking } \\
\hline Yes & 874 & 30.8 & 758 & 25.0 & 1632 & 27.7 \\
\hline No & 1963 & 69.2 & 2301 & 75.0 & 4264 & 72.3 \\
\hline \multicolumn{7}{|l|}{ Alcohol use } \\
\hline Yes & 2095 & 73.8 & 2196 & 71.8 & 4291 & 72.8 \\
\hline $\mathbb{N o}$ & 742 & 26.2 & 863 & 28.2 & 1605 & 27.2 \\
\hline \multicolumn{7}{|c|}{ Young children ( $\leq 5$ years) } \\
\hline Yes & 559 & 19.7 & 559 & 18.3 & 1118 & 19.0 \\
\hline No & 2278 & 80.3 & 2500 & 81.7 & 4778 & 81.0 \\
\hline \multicolumn{7}{|l|}{ Leadership } \\
\hline Yes & 875 & 30.8 & 452 & 14.8 & 1327 & 22.5 \\
\hline No & 1962 & 69.2 & 2607 & 85.2 & 4569 & 77.5 \\
\hline
\end{tabular}

Table 3 shows that the group of employees that reported to have caught a cold during the previous four months consisted of significantly more women, people under the age of 40 years, people having asthma, people having young children, and more smokers. In this group, people in leadership positions were significantly underrepresented. No significant differences were found between the two groups in respect to alcohol use.

Logistic regression analysis was used to adjust for potential confounding. The results of the first logistic model analysis are indicated in the equation:

$(\log ($ odds $)=-0.2756+0.0685$ gender +0.2479 age +0.5231 asthma + 0.2045 smoking +0.0608 alcohol +0.5295 young children +0.1800 PJD 0.1461 leadership).

After controlling for confounding it was found that employees reporting high PJD had a greater risk of having a common cold in the previous four months than those reporting low PJD (OR 1.20; $95 \%$ Cl 1.08-1.33) (Table 4). Parents of young children were significantly more likely reporting a cold (OR 1.70;95\% Cl 1.47-1.96) in contrast to employees having no children under the age of five. Also having a history of asthma (OR $1.69 ; 95 \% \mathrm{Cl} 1.28-2.22$ ) or being under the age of 40 (OR $1.28 ; 95 \% \mathrm{Cl} \mathrm{1.14-1.43)}$ increased the risk for catching a cold. 
Table 3 Characteristics of the study population in relation to the occurtence of common cold

\begin{tabular}{|c|c|c|c|c|}
\hline & \multicolumn{2}{|c|}{ Common cold } & \multicolumn{2}{|c|}{ No common cold } \\
\hline & $\mathbb{N}$ & $\%$ & $\mathbb{N}$ & $\%$ \\
\hline Total & 3446 & 53.4 & 2750 & 46.6 \\
\hline \multicolumn{5}{|l|}{ Gender } \\
\hline Men & 2268 & 72.1 & 2049 & 74.5 \\
\hline Women & 878 & 27.9 & 701 & 25.5 \\
\hline \multicolumn{5}{|l|}{ Age } \\
\hline$>40$ years & 1459 & 46.4 & 1551 & 56.4 \\
\hline$\leq 40$ years & 1687 & 53.6 & 1199 & 43.6 \\
\hline \multicolumn{5}{|l|}{ Asthma e.g. } \\
\hline Yes & 156 & 5.0 & 82 & 3.0 \\
\hline No & 2990 & 95.0 & 2668 & 97.0 \\
\hline \multicolumn{5}{|l|}{ Smoking } \\
\hline Yes & 927 & 29.5 & 705 & 25.6 \\
\hline No & 2219 & 70.5 & 2045 & 74.4 \\
\hline \multicolumn{5}{|l|}{ Alcohol use } \\
\hline Yes & 2278 & 72.4 & 2013 & 73.2 \\
\hline No & 868 & 27.6 & 737 & 26.8 \\
\hline \multicolumn{5}{|c|}{ Young children ( $\$ 5$ years) } \\
\hline Yes & 735 & 23.4 & 383 & 13.9 \\
\hline $\mathrm{No}$ & 2411 & 76.6 & 2367 & 86.1 \\
\hline \multicolumn{5}{|l|}{ Leadership } \\
\hline Yes & 672 & 21.4 & 655 & 23.8 \\
\hline No & 2474 & 78.6 & 2095 & 76.2 \\
\hline
\end{tabular}

The risk was also significantly increased among smokers (OR 1.23;95\% Cl 1.09-1.38). Drinking (OR 1.06;95\% Cl 0.94-1.20) and being female (OR 1.07;95\% Cl 0.95-1.21) increased the risk not significantly. As described, we constructed a logistic model with potential confounders and added the potential risk factors (PJD and leadership) to the model. Having a leadership position decreased the risk for catching a cold (OR 0.86 ; $95 \%$ C $\| .76-0.98$ ).

By using PJD as a dichotomous variable, we might have lost information. Therefore, a second logistic regression analysis using PJD and DL as continuous variables was performed. The results of the second logistic model analysis are indicated in the follawing equation:

$$
\begin{aligned}
(\log (\text { odds })= & -0.1025+0.0681 \text { gender }+0.2480 \text { age } * 0.5588 \text { asthma } \\
& +0.1272 \text { smoking }+ \text { alcohol }+0.5509 \text { young children }+0.0126 \text { PJD }- \\
& 0.0070 \mathrm{DL})
\end{aligned}
$$

The results of this analysis are shown in Table 4. After controlling for the same confounders as in the first analysis, the results are roughly similar to those reporled in the first analysis. Employees reporting high PJD reported significantly more common colds (OR 1.13; 95\% Cl 1.06-1.21). There was an inverse relationship between DL and 
Table 4 Determinants of experiencing a common cold. Adjusted odds ratios are from fogistic regression analysis \| and II

\begin{tabular}{|c|c|c|c|c|}
\hline \multirow[b]{2}{*}{ Determinant } & \multicolumn{2}{|c|}{ Regression analysis $\left.\right|^{\circledR}$} & \multicolumn{2}{|c|}{ Regression analysis $\|^{B}$} \\
\hline & Adjusted odds ratio & $95 \% \mathrm{Cl}$ & Adjusted odds ratio & $95 \% \mathrm{Cl}$ \\
\hline Age $\leq 40$ years & 1.28 & $1.14-1.43$ & 1.28 & $1.18-1.39$ \\
\hline Gender, female & 1.07 & $0.95-1.21$ & 1.07 & $0.98-1.17$ \\
\hline Smooking & 1.23 & $1.09-1.38$ & 1.14 & $1.04-1.24$ \\
\hline Drinking & 1.06 & $0.94-1.20$ & 1.03 & $0.95-1.13$ \\
\hline Asthma & 1.69 & $1.28-2.22$ & 1.75 & $1.43-2.14$ \\
\hline Young children ( $\leq 5$ years) & 1.70 & $1.47-1.96$ & 1.73 & $1.56-1.92$ \\
\hline Leadership position & 0.86 & $0.76-0.98$ & - & - \\
\hline $\begin{array}{l}\text { Psychological Job Demands, } \\
\text { high }(>36)\end{array}$ & 1.20 & $1.08-1.33$ & - & - \\
\hline $\begin{array}{l}\text { Psychological Job Demands } \\
10 \text { points increase }\end{array}$ & - & - & 1.13 & $1.06-1.21$ \\
\hline $\begin{array}{l}\text { Decision Latitude } \\
10 \text { points increase }\end{array}$ & - & 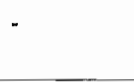 & 0.93 & $0.90-0.96$ \\
\hline
\end{tabular}

the risk for the common cold. Employees reporting more DL. had a significantly lower risk for common cold (OR $0.93 ; 95 \% \mathrm{Cl} \quad 0.90-0.96$ ). The reported ORs for the continuous variables relate to an increase of 10 points on the PJD and DL scales. To see if $\mathrm{DL}$ is an effect modificator, we build the full model, including the interaction term (PJD $\times$ DL). Including this term, did not improve the model significantly, and the OR for PJD did not change substantially. Therefore, we concluded that there is no interaction between DL and PJD. In accordance with the first analysis parents of children of five years or younger were significantly more likely to catch a cold (OR 1.73; 95\% $\mathrm{Cl} 1.56-1.92)$ in contrast to employees having no children. Also, having a history of asthma YOR 1.75; $95 \% \mathrm{Cl} 1.43-2.14$ ), and being under the age of 40 years (OR 1.28; 95\% $\mathrm{Cl} 1.18-1.39$ ). increased the risk for catching a cold. The risk was also significantly increased among smokers (OR 1.14; 95\% Cl 1.04-1.24). Drinking (OR 1.03; 95\% Cl 0.95-1.13) and being female (OR $1.07 ; 95 \% \mathrm{Cl} 0.98-1.17$ ) did not increase the risk significantly. The factor leadership did not improve the model significantly and for this reason was excluded from further analysis. 


\section{Discussion}

In this study, we found that employees reporting high PJD (either measured dichotomous or continuous) have a higher risk for catching a common cold than those reporting a lower level of PJD. Although the effect of PJD on common cold prevalence is not very big, this finding supports the hypothesis that PJD can operate as a co-factor in the pathogenesis of common cold. We adjusted these results for the effect of a number of known confounders. In a second analysis, we also included DL and showed that this determinant was inversely related to common cold. This means that a low level of $\mathrm{DL}$ increases the risk for catching a clinical cold and can be seen as a stressor in the same way as the high PJD. Karasek's "Job Strain model" states that the greatest risk to physical and mental health from stress occurs to workers facing high psychological workload demands or pressures combined with low control or DL. We did not find supportive evidence for this "interaction hypothesis" in our model. Having a leadership position was another factor included in the first analysis. The results showed a significant decrease in the risk for catching a cold. A possible, though indirect, explanation could be that people in leadership positions have more abilities to control there own tasks. The results of the second logistic regression analysis showed that a higher level of DL was inversely related to the occurrence of common cold. Comparing the means of the variable DL of people in leadership positions (77.84 $\pm S D$ 9.75) to those without leadership positions $(69.34 \pm \mathrm{SD} 12.14)$ showed a clear difference in the level of $\mathrm{DL}$. This may be the reason why people in leadership position reported less collds in the previous four months. As mentioned earlier, having a higher level of DL reduced the risk. for catching a clinical cold.

Several possible mechanisms to explain the relationship between psychological factors and infections in general or particularly common cold have been mentioned in other studies. When demands imposed by events exceed individuals abilities to cope, a psychological stress response composed of negative cognitive and emotional states is ellicited. ${ }^{16}$ These responses are thought to influence immune function through their effects on behavioral coping and neuro-endocrine responses. Another possibility may be that the self-reported illnesses reflect influences of stress, cognitive processes and selfperceptions that are not associated with an infectious disease. ${ }^{5}$ The occurrence of common cold in our study population was determined by using self-reported illness. The item in the questionnaire concerning common cold covers representative symptoms of common cold, such as sore throat, nasal stuffiness, mucus weight increase, cough and little or no fever. ${ }^{17}$ We are aware of the fact that using self-reported illness may llead to an over or under reporting. However, a study on the comparison between self-assessed and observer assessed presence of colds showed a high degree of validity of the volunteers' self-assessments in relation to the physician's assessments. ${ }^{10}$ However, it remains possible that people experiencing high PJD reported differently as compared to the other employees. Because we used a large sample of employees working in different companies, it was not possible to use another method for the determination (clinical examination or biological analysis) of the existence of a common cold than by selfreports. Evans et al. ${ }^{19}$ showed, using a self-report methodology, that the reporting of a cold episode is not correlated with neuroticism (often taken as a measure of "complainer 
syndrome") whereas the reporting of aches and pains and general body symptoms is correlated. Epidemiological studies and viral-challenge studies showed that persons reporting psychological stress have both, a higher incidence and a greater severity of illness. ${ }^{20}$ Hence, it might be easier for stressed people to recollect the information about common cold episodes in the previous four months. Another mechanism could be that there are stress-elicited differences in health practices such as smoking, and alcohol consumption, poor diets and poor sleeping habits. Increased smoking, drinking, and changes in diet may all influence the immune response. ${ }^{21}$ in the analysis we corrected for these confounders. This means that the higher risk for common cold in the high P.JD group can not be explained by a difference in life style. Thus, psychological stress as such will be a determinant of the modified susceptibility to the common cold, possibly through altering innate resistance and immune function. It has been suggested that chronic stressors may influence more than one aspect of the disease process (i.e., extent of viral replication as well as the processes that modulate signs and symptoms of a cold) ${ }^{6}$ It has, for instance, been reported that psychological stress can have an effect on the magnitude of specific immune mechanisms (e.g., the amount of secretory antibody) after the experience with common cold viruses has been mentioned. ${ }^{22}$ The above mechanisms can be part of a more complex pathologic pathway ${ }^{5,16}$ which is based on the fact that psychological variables may influence immunity through a direct nervous connection between the central nervous system and the immune system and through neuro-endocrine-immune pathways. ${ }^{23}$ Behavioural changes that are associated with personality characteristics or that occur as adaptations or coping responses in the face of stressful events or negative emotional states may influence immunity, for example poor health practices, such as smoking, poor diets and poor sleeping habits. ${ }^{5,23}$

Our data demonstrate that employees having younger children have a significantly higher risk of catching a cold. This finding is in accordance with other studies. ${ }^{24}$ The incidence of common colds is highest in infants and children, who suffer from four to eight colds each year. Adults typically get two to five colds, except in houselholds with children, where the incidence is higher. ${ }^{24}$ Furthermore the results showed an increased risk in smokers, which is in line with the literature. ${ }^{14}$ The current paradigm is that smoking has deleterious effects on non-specific mucosal properties, such as cilliary movement that provide front-line barriers against infection. Alternative explanations may be that smoking has a negative effect on first-line defence mechanisms that limit viral replication, or that smoking may influence inflammatory processes involved in the production of symptoms. ${ }^{14}$

The data presented in this study are the result of a large-scale cohort study using employees from 45 different companies as the study population. In spite of the almost inevitable shortcoming of a large cohort study using questionnaires, this study gave us the opportunity to study the relationship between the common cold and work-related factors in a nonexperimental setting with participants observed in a natural environment with all the normal everyday hassles. Despite its limitations ${ }_{*}$ the specific approach revealed a clear relationship between PJD and symptomatic common colds. The use of a questionnaire covering a wide range of items gave us the opportunity to control for important factors. 
In summary, this study extends previous evidence for an association between psychosocial factors and common cold and is consistent with the fact that high PJD can acts as a co-factor in the pathogenesis of the common colld. Because cross-sectionall data were used it was not possible to establish causal relationships. By using future longitudinal results from the Maastricht Cohort Study, we expect to further our understanding of the possible causal relationship between psychosocial factors and illnesses such as infections. It is obvious that the measuring of immune parameters in combination with the results from the questionnaires is hellful to resolve the mechanisms that mediate a relationship between psychosocial stress and infections, not only those of the upper respiratory tract. Such studies are currently in progress.

\section{Acknowledgements}

This study is part of the large scale Maastricht Cohort Study on "Fatigue at Work". The Maastricht Cohort Study participates in the Netherlands concerted research on "Fatigue at Work" granted by the Netherlands Organisation for Scientific Research (NWO).

\section{References}

1. Gwaltney JMM. Rhinowirus. In: Mandell GL, Bennett JE, Dolin R, eds. Mandell, Douglas and Bennett's Principles and practice of infectious disease. New York: Churchill Livingstone; 1995. p. $1656-63$

2. Cohen $\mathrm{S}$, Williamson $\mathrm{GM}$. Stress and infectious disease in humans. Psychol Bull 1991;109(1):5-24.

3. Graham NM, Douglas RM, Ryan P. Stress and acute respiratory infection. Am J Epidemiol 1986;124(3):389-401.

4. Cobb JM, Steptoe A. Psychosocial stress and susceptibility to upper respiratory tract illmess in an adult population sample. Psychosom Med 1996:58(5):404-12.

5. Cohen S, Tyrrell DA, Smith AP. Psychological stress and susceptibility to the common cold. N Engl J Med 1991,325(9):606-12.

6. Cohen $\mathrm{S}$, Frank E, Doyle WJ, Skoner DP, Rabin BS, Gwaltney JM, $\Perp \mathrm{r}$. Types of stressors that increase susceptibility to the common colld in healthy adults. Health Psychol 1998:17(3):21423.

7. Karasek RA. Job Demandis, Job Decision Latitude, and mental strain: Implications for job redesign. Adm Sci Q 1979;24:285-311.

8. Kristensen TS. Job stress and cardiovascular disease: A theoretic critical review. J Occup Health Psychol 1996:" (3):246-60.

9. Kant IJ, Beurskens AJHM, Schröer CAP, Nijhuis FJN, Van Schayck CP, Van den Elzen HJ. Swaen GMH. De Maastrichtse Cohort Studie naar langdurige psychische vermoeidheid in de arbeidssituatie [The Maastricht Cohort Stuidy on fatigue at work]. TBV 2000; 8(8): 226-32.

10. Karasek RA. The Job Content Questionnaire and User's Guide (version 1. 1). Los Angeles: Department of Industrial and Systems Engineering, University of Southern California; 1985

11. Niedhammer 1 , Goldberg $M_{s}$ Leclerc A, Bugell I, David S. Psychosocial factors at work and subsequent depressive symptoms in the Gazel cohort. Scaind J Work. Environ Health $1998 ; 24(3): 197-205$.

12. Tumer Cobb JM, Steptoe A. Psychosocial influences on upper respiratory infectious illness in children. J Psychosom Res 1998;45(4):319.30.

13. Jaakkola $\mathrm{JJ}$, Heinonen $\mathrm{OP}$. Shared office space and the risk of the common cold. Eur $J$ Epidemiol 1995:11(2):213-6. 
14. Cohen S, Tyrrell DA, Russel MA, Janis MJ, Smith AP. Smoking, alcohol consumption, and susceptibility to the common cold. Am J Public Health 1993;83(9):1277-83.

15. War PE. Decision latitude, job demands, and employee well-being. Work Stress $1990 ; 4(4): 285-94$

16. Cohen S, Herbent TB. Health psychology: psychological factors and physical disease from the perspective of human psychoneuroimmunology. Annu Rev Psychol 1996:47:113-42.

17. Tyrrell DA, Cohen S, Schlarb JE. Signs and symptoms in common colds. Epidemiol Infect $1993 ; 111(1)+43-56$

18. Macintyre $S$, Pritchard $C$. Comparisons between the selfwassessed and obsenerwassessed presence and severity of colds. Soc Sci Med 1989;29(11):1243-8.

19. Evans PD. Pitts MK. Smith K. Minor infection, minor life events and the four day desirability dip. J Psychosom Res 1988;32(4-5):533-9.

20. Cohen S, Doyle WJ "Skoner DP. Psychological stress "cytokine production, and severity of upper respiratory illness. Psychosom Med 1999;61(2):175-80.

21. Kiecolt Glaser $J K$, Glaser $R$. Methodological issues in behavioral immunology research with humans. Brain Behav Immun 1988:2(1):67-78.

22. Bovbjerg DH, Stone AA. Psychological stress and upper respiratory iliness. In: Friedman $H$, Klein TW. Friedman AL, eds. Psychoneuroimmunology, stress, and infection. Boca Raton: CRC Press, 1996:195-213.

23. Cohen S. Psychological stress and susceptibility to upper respiratory infections. Am J Respir Crit Care Med 1995:152(4 Pt 2):S53-8.

24. Hall C. McBride J. Ulpper respiratory tract infections: The common cold, pharyngitis, croup, bacterial tracheitis and epiglottis. In: Pennington $J_{n}$ ed. Respiratory infections: Diagnosis and management. New York: Raven Press; 1994. p. 101-24. 


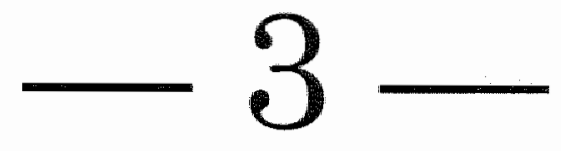

\title{
Job insecurity as a risk factor for common infections, and health complaints
}

\author{
Danielle CL Mohren ${ }^{\mathrm{i}}$ \\ Gerard MH Swaen" \\ Ludlovic GPM van Amelsvoort' \\ Paull JA Borm² \\ Jochem MD Galama ${ }^{3}$
}

\begin{abstract}
The aim of this present study was to investigate the cross-sectional and longitudinal effect of job insecurity on common infections and health complaints. Self-administered questionnaire data from the Maastricht Cohort Study $(n=12,140)$ were used. We used Generalized Estimating Equations (GEE) analyses to calculate pooled odds ratios (ORs) and $95 \%$ confidence intervals (Cl). A cross-sectional relationship between job insecurity and common infections or health complaints was found. For the longitudinal, the largest effect was found for flu-like illness (OR 1.39; $\mathrm{Cl} 1.22-1.57$ ) and health complaints (OR 1.51 ; Cl 1.39-1.64). We additionally corrected for health behavior, the presence of a longstanding disease, and work-related demands, resulting in lower ORs. An increase in common infections or health complaints has a substantial impact on the employees wellbeing and may result in economic consequences for the company.
\end{abstract}

\footnotetext{
${ }^{4}$ Department of Epidemiology, Maastricht University, Maastricht, The Netherlands

"Department of Fibre \& Particle Toxicology Medical Institute for Environmentall Hygiene, Düsseldorf, Germany

"Department of Medical Micrabiology, University Medicall Center St. Radboud, Nijmegen. The Netherlands
} 


\section{Introduction}

Driven by international competition and the rapid rate of technological change, corporate mergers, acquisitions, and downsizing have become an important part of day to day business in the last decade of the $20^{\text {th }}$ century. " Job insecurity is a particularly potent stressor in manufacturing companies that are in the process of substantial downsizing. During a reorganization, employees will perceive job insecurity due to the uncertainty about their job in the future. Job insecurity due to downsizing and the closure of facilities has been connected to negative changes in self-rated health, increases in longstanding illiness, adverse sleep patterns, minor psychiatric morbidity, ${ }^{2}$ increase in sickness absence ${ }^{3.4}$ and somatic symptoms (changes in health and blood pressure). ${ }^{5}$ Generally, during the process of downsizing or organizational change there is a period during which the fate of the company or department, and the position of the employee is uncertain. This period of job insecurity can pose an extra strain on top of the intrinsic burden of a particular job. Besides job insecurity due to downsizing or reorganization, an individual emiployee may experience a different kind of job insecurity. This feeling of job insecurity is not directly connected to an upcoming reorganization or downsizing, and might be due to different factors. For instance, uncertainty about own capabilities to function in a specific company, or a secure employment in an unsatisfactory job when no alternatives are available, ${ }^{\theta}$ can be causes of job insecurity.

On top of the health effects and the increase in sickness absence found in other studies, job insecurity may lower the employee's resistance to infections and consequently increase the incidence of infections. Unemployment has already been reported to have an effect on some aspects of the immune system. ${ }^{7}$ It was found that Phytohemagglutinin reactivity of lymphocytes decreased significantly in women after nine months of unemployment. Reactivity to purified protein derivative of tuberculin also decreased significantly. In another study a substantial increase in the incidence of colds was reported to be primarily attributable to under- or unemployment. ${ }^{B}$

Several mechanisms that link job insecurity to health have been described. Alternations in work characteristics, for instance increasing job demands and decreasing job control during a period of downsizing, but also behavior prejudicial to health, for example smoking and excessive alcohol consumption, ${ }^{4}$ may be more prevalent among employees experiencing job insecurity. Changes in work characteristics and health behavior may on their turn influence the accurrence of common infections. In one of our earlier studies, using the same cohort data as this current study, ${ }^{9}$ we showed that psychological job demands, a work rellated stressor, was positively related with the incidence of common cold. it is known that increased smoking and drinking ${ }^{10}$ can influence the immune response.

We used the Maastricht Cohort study on "Fatigue at Work" as a framework to study the cross-sectional and longitudinal effect of job insecurity on the employees susceptibility to common infections (common cold, flu-like illness, and gastroenteritis) and the occurrence of health complaints using self-administered questionnaires. To gain insight in possible underlying mechanism in this relationship, we adjusted for several potential confounding 
factors (demographics, health behavior, health, and job characteristics) in consecutive steps in the analyses.

\section{Methods}

\section{The study population}

At baseline the Maastricht Cohort Study surveyed a large heterogeneous population of employees working in 45 different companies and organizations. ${ }^{11.12}$ A total of 12,161 employees completed the baseline questionnaire. Written consent was obtained from all participants. The overall response was $45 \%$. Twenty-one questionnaires were discarded because of technical reasons, ${ }^{13}$ resulting in a study population of 12,140 employees. The average age was 40.97 years ( \pm SD 8.93 ), 26.9\% of the participants were women and $73.1 \%$ were men. On T3 and T6, $9655(79.5 \%$ compared to the baseline response) and $8070(66.5 \%)$ employees respectively returned the questionnaire.

\section{The questionnaire}

The participants of the Maastricht cohort study received questionnaires at four-monthly intervals, and a total observation period of three years (1998-2001). Each year an extensive questionnaire was sent to the participants, containing both exposure and effect measures, and two short questionnaires, mainly containing effect measures. The results of the cross-sectional analysis are based on the first two years of this study, using three successive extensive questionnaires. In the baseline questionnaire (TO), the fourth (T3) and seventh (T6), exposures and outcomes were measured on an individual level using self-administered questionnaires. For the longitudinal analysis, we used information from the extensive questionnaires (TO, $\mathrm{T}_{\mathrm{n}}$ and $\mathrm{T} 6$ ) to determine job insecurity, and from the short questionnaires ( $T 1, T 4$, and $T 7)$ to determine the presence of common infections and health complaints, one time point later as job insecurity.

\section{Job insecurity}

Job insecurity was measured with a single dichotomous item derived from the Questionnaire on psychosocial job demands and job stress (VBBA) "(Do you fear losing your job an short notice?"). This item was measured in the extensive questionnaires which were sent out once a year. This means that the results about job insecurity were based on three successive large questionnaires (T0, $\mathrm{T} 3$, and T6). We compared employees reporting job insecurity with the group of employees not reporting job insecurity, in respect to the occurrence of common infections, and health complaints.

\section{Infections and health complaints}

Infections and health complaints were determined using self-administered questionnaires. The occurrence of infections in the previous four months was measured in each questionnaire. We used the information on the prevalence of these infections from the three extensive successive questionnaires ( $T O, T 3$, and T6), for the crosssectional analysis. For the longitudinal analysis we used the information from the short questionnaires (T1, T4, and T7) to determine the presence of these infections. Three different infections: common cold, flu-like illness, and gastroenteritis were inventoried as 
individual dichotomous items in the questionnaires. A description of the infections was included in the question. This description mainly concerned the typical symptoms of the infection, which made it easier for individual employees to determine the occurrence of one of the infections in the previous four months. For common cold these symptoms were: clogged or running nose, a sore throat, coughing, and slight or no fever (temperature less than $38^{\circ} \mathrm{C}$ ), for flu-like illness: fever (temperature $38^{\circ} \mathrm{C}$ or more), with at least four of the following six complaints, muscular pain, fatigue, sore throat, clogged or running nose, coughing, headache. For gastroenteritis these symptoms included: slight or no fever, gastritis, nausea, vomiting and/or diarrhea.

The presence of health complaints were determined in the same questionnaires as used to determine the presence of common infections, using a single item: do you currently have health complaints (yes/no)?

\section{Demographics, health behavior, and health}

At baseline employees provided information on age, gendler, and health behavior variables. Smoking habits were determined with a single dichotomous item. Alcohol consumption was measured by weekly consumption in glasses and divided into four categories ( 0 glasses, 1 to 14 glasses, 15 to 21 glasses, $\geq 22$ glasses/week). The presence of a longstanding illness was measured with a single dichotomous item.

\section{Work characteristics}

For the present study, we measured psychological job demands and decision latitude using the information from the baseline questionnaire. The Psychological Job Demands scale from the Job Content Questionnaire of Karasek ${ }^{15}$ was used to determine the level of psychological job demands. This scale is a five-item indicator measuring job demands time pressure, and conflicting demands. ${ }^{16}$ Decision latitude is defined as the sum of two sub-scales, which are also measured with the Job Content Questionnaire: Skill Discretion (six items) and Decision Authority (three items). It is an indicator measuring the subject's influence on or control over his or her work, job variety, and the possibility for learning new skills. The response options for each item varied on a four-point scale from "strongly disagree" to "strongly aglee".

\section{Statistical methods}

Regression analysis using Generalized Estimating Equations (GEE), ${ }^{17}$, 18 were used to determine the cross-sectional effect of job insecurity on $T$ on the prevalence of infections, and health complaints on $T$, comparing employees reporting job insecurity and employees not reporting job insecurity, adjusted for seasonal variation, age and gender, and additionally for health behavior, the presence of a longstanding illiness and work characteristics. The results are based on the three extensive questionnaires (TO, T3, and T6). Pooled adjusted odds ratios (ORs) were calculated for the cross-sectional effect of subjective job insecurity on common infections and health complaints at three different time-points. Also for the longitudinal analysis we used regression analysis using GEE, to determine the relationship between job insecurity at $T$ and the presence of common infections or health complaints at $T+1$. We corrected for age, gender and seasonal variation. In the second step we adjusted for the presence of common 
infections or health complaints at $T$. After this step, we subsequently adjusted for health behavior, the presence of a longstanding illness and work characteristics. Additionally $T$. tests and Chi-square tests were used to test univariate differences between employees reporting job insecurity and reporting no job insecurity. All procedures were performed using SPSS for windows release 9.0.0. and Intercooled Stata 7.0 for Windows $98 / 95 / N T$ software.

\section{Results}

In Table 1, the descriptive characteristics of the study population at baseline are shown. Employees reporting job insecurity were on average older compared to employees reporting no job insecurity. With regard to health behavior, smoking was significantly more prevalent among employees reporting job insecurity, no significant differences were found for drinking habits between the two groups. With regard to work-related factors, substantial differences were found comparing the two groups of employees. Higher levels of psychological job demands and lower levels of decision latitude were found among employees reporting job insecurity. The presence of longstanding illness was significantly more prevalent among employees reporting job insecurity.

Table 1 Descriptive characieristics study population at baseline

\begin{tabular}{|c|c|c|c|}
\hline & \multirow[b]{3}{*}{$\mathbb{N}$} & \multicolumn{2}{|c|}{ Job insecurity } \\
\hline & & No & Yes \\
\hline & & 10,961 & 988 \\
\hline \multirow[t]{2}{*}{$\overline{\text { Demographics }}$} & Gender $\%$ female & 27.0 & 26.8 \\
\hline & Age mean & 40.76 & $42.94^{* * *}$ \\
\hline \multirow[t]{6}{*}{ Health behavior } & Smaking \% & 25.2 & $29.1^{*}$ \\
\hline & Alcohol use \% (glasseshulk) & & \\
\hline & - none & 26.2 & 29.0 \\
\hline & $-1-14$ & 62.4 & 59.2 \\
\hline & $-15-21$ & 8.7 & 8.8 \\
\hline & $-\geq 22$ & 2.7 & 3.0 \\
\hline \multirow[t]{2}{*}{ Work-rellated factors } & $\begin{array}{l}\text { Psychological job demands } \\
(12-48)^{\dagger}\end{array}$ & 33.17 & $34.29^{* * *}$ \\
\hline & $\begin{array}{l}\text { Decision latitude } \\
(24-96)^{\dagger}\end{array}$ & 72.12 & $66.63^{*: k x}$ \\
\hline Health & Longstanding illness \% & 22.9 & $36.7^{* * *}$ \\
\hline
\end{tabular}

Sigrificant difference with employees reporting no job insecurity: ${ }^{*} P<0.05,{ }^{* *} P<0.01,{ }^{* *} P<0.001$ + Scalle range

Table 2 shows the prevalence of common infections among employees with and without job insecurity. The highest prevalence for all three infections was found for employees reporting job insecurity. For flu-like illness this difference with employees reparting no job 
insecurity was statistically significant. For gastroenteritis the difference was borderline significant. Health complaints were significantly more prevalent among employees reporting job insecurity.

Table 2 Prevalence of common infections and thealth complaints among employees with and without job insecurity

\begin{tabular}{lll} 
& \multicolumn{2}{c}{ Job insecurity } \\
\cline { 2 - 3 } & No & Yes \\
\hline Common cold $\%$ & 53.2 & 55.9 \\
Flu-like illness \% & 23.6 & $30.3^{* * *}$ \\
Gastroenteritis \% & 12.7 & 14.9 \\
Health complaints \% & 29.3 & $46.5^{* * *}$ \\
\hline
\end{tabular}

Significant difference with employees reporting mo job insecurity:

${ }^{*} P<0.05,{ }^{*} P<0.01,{ }^{* * *} P<0.001$

The relationship between job insecurity and the occurrence of infections or health complaints is shown in Table 3 . In this table, the pooled ORs for the three infections and the presence of health complaints, comparing employees reporting job insecurity with a reference group not reporting job insecurity, are shown. Significant effects were found for the association between job insecurity and the occurrence of common infections, the highest $O R$ was found for flu-like illness (OR 1.33; $\mathrm{Cl} 1.21-1.45$ ). The strongest association was found between job insecurity and health complaints, resuiting in a pooled $O R$ of 1.56 ( $\mathrm{Cl} 1.44-1.68$ ). Additionally adjusting for smoking and drinking habits, resulted in only a slight decrease of the found ORs. After correcting for the presence of a longstanding illness the ORs decreased further, although the found effects were still statistically significant. In the final analysis, the ORs were additionally corrected for work characteristics (psychological job demands and decision latitude), which resulted in a larger decrease of the ORs. Still, the largest effect was found for the association between job insecurity and the presence of health complaints (OR 1.38; $\mathrm{Cl} 1.25-1.51$ ). In respect to common infections, the largest effect was again found for the relationship between job insecurity and flu-like illness (OR 1.24; $\mathrm{Cl} 1.12-1.36$ ).

Table 3 Adjusted odds ratios and $95 \%$ confidence intervals regarding the cross-sectional relationship between job insecurity, different infections and health complaints

\begin{tabular}{lcccccccc} 
& OR* & $95 \% \mathrm{Cl}$ & OR† & $95 \% \mathrm{Cl}$ & OR & $95 \% \mathrm{Cl}$ & ORß & $95 \% \mathrm{Cl}$ \\
\hline Common cold & 1.09 & $1.01-1.18$ & 1.09 & $1.01-1.19$ & 1.08 & $1.00-1.17$ & 1.05 & $0.97-1.14$ \\
Flu-like illness & 1.33 & $1.21-1.45$ & 1.31 & $1.19-1.44$ & 1.30 & $1.18-1.43$ & 1.24 & $1.12-1.36$ \\
Gastroenteritis & 1.24 & $1.11-1.39$ & 1.23 & $1.10-1.38$ & 1.20 & $1.07-1.35$ & 1.14 & $1.01-1.28$ \\
Health complaints & 1.56 & $1.44-1.68$ & 1.57 & 1.451 .70 & 1.50 & $1.37-1.65$ & 1.38 & $1.25-1.51$ \\
\hline
\end{tabular}

The reference group consisted of employees reporting no job insecurity

"corrected for age, gender, and seasonal wariation

$\uparrow$ additionally corrected for smoking and drinking habits

\$ additionally corrected for the presence of a longstanding illness

$\$$ additionally corrected for psychological job demands and decision latitude 
Table 4 shows the results of the longitudinal analysis between job insecurity at $T$ and common infections or health complaints at $T+1$. In this table, the pooled ORs for the three infections and the presence of health complaints at $T+1$, comparing employees reporting job insecurity at $T$ with a reference group of employees reporting no job insecurity at $T$, are shown. Significant effects were found for the longitudinal relationship between job insecurity at $T$ and flumlike illness and gastroenteritis and health complaints at $T+1$. The strongest relationship was found between job insecurity and flu-like illness (OR 1.39; $\mathrm{Cl} 1.22-1.57$ ) and health complaints (OR 1.51; Cll 1.39-1.64). No significant effect was found for the relationship between job insecurity and cornmon cold. Additionally correcting for the presence of common infections or health complaints at $T$ in the second step, resulted in a decrease of the found ORs. For flu-like illness and health complaints at $T+1$, the relationship with job insecurify at $T$, was still significant. Correcting for health behavior, and subsequently for the presence of a longstanding illness, resulted in a further decrease of the pooled ORs. In the final step, we corrected for work characteristics, resulting in a further decrease of the ORs. The relationship between flu-like illness (OR 1.15; 1.00-1.32), health complaints (OR 1.26; 1.14-1.40) at $T+1$ and job insecurity at $T$ was still significant.

Table 4 Adjusted odds ratios and $95 \%$ confidence intervals regarding the longitudinal relationship belween job insecurity at $T$, and different infections or health complaints at $T+1$

\begin{tabular}{lcccccccccc}
\hline & OR* & $95 \% \mathrm{Cl}$ & ORT & $95 \% \mathrm{Cl}$ & OR. & $95 \% \mathrm{Cl}$ & OR\& & $95 \% \mathrm{Cl}$ & OR & $95 \% \mathrm{Cl}$ \\
\hline Common cold & 1.04 & $0.95-1.13$ & 0.99 & $0.90-1.08$ & 0.99 & $0.90-1.08$ & 0.97 & $0.89-1.07$ & 0.96 & $0.87-1.06$ \\
Flu-like illness & 1.39 & $1.22-1.57$ & 1.31 & $1.15-1.49$ & 1.26 & $1.13-1.46$ & 1.23 & $1.08-1.41$ & 1.15 & $1.00-1.32$ \\
Gastroenteritis & 1.20 & $1.03-1.40$ & 1.15 & $0.98-1.35$ & 1.13 & $0.96-1.33$ & 1.11 & $0.94-1.31$ & 1.04 & $0.88-1.24$ \\
Health complaints & 1.51 & $1.39-1.64$ & 1.38 & $1.26-1.52$ & 1.38 & $1.26-1.52$ & 1.32 & $1.20-1.46$ & 1.26 & $1.14-1.40$ \\
\hline
\end{tabular}

The reference group consisted of employees reporting no job insecurity

corrected for age, gender, and seasonal varialion

$\uparrow$ additionally corrected for either common infections at $\pi$ or health complaints at $T$

\# additionally corrected for smoking and drinking habits

$\S$ additionally corrected for the presence of a longstanding illness

il additionally corrected for psychological job demands and decision latitude

\section{Discussion}

In this study we investigated the cross-sectional and longitudinal effect of job insecurity on health, resulting in the occurrence of common infections or general health problems. Our findings show that the prevalence of common infections and general health problems differed among employees reporting and not reporting job insecurity.

Although associations between organizational downsizing and the health of employees have been demonstrated in many studies, ${ }^{19-22}$ much remains to be discovered about the mechanisms through which downsizing affects health. ${ }^{4}$ We can only hypothesize how job insecurity, can influence the susceptibility to infections and cause general health problems. Job insecurity may be viewed as a classic work stressor with the expectation 
that continued exposure would result in impaired psychological and physiological health. ${ }^{5}$ As shown in Table 3 and 4, we additionally corrected for several factors when studying the relationship between job insecurity and common infections or general health problems, in order to disentangle possible mechanisms that play a role in this relationship. Kivimaki et al. discussed the mechanisms that may link job insecurity to health. Behavior prejudicial to health, for example, smoking and excessive alcohol consumption, may become more prevalent among employees reporting job insecurity. We found no significant differences in drinking habits among the two groups. In contrast, the prevalence of smokers was higher among the employees with job insecurity. Increased smoking may influence the immune response. ${ }^{10}$ Smoking may have deleterlous effects on the non-specific mucosal properties, such as cilliary movement that provide front-line barriers against infection. Alternative explanations may be that smoking has a negative effect on first-line defense mechanisms that limit viral replication, or that smoking may influence inflammatory processes involved in the production of symptoms. ${ }^{23}$ We also corrected our results for the presence of a longstanding illiness. The prevalence of a longstanding illness, was more prevalent among employees with job insecurity in our cohort. It is possible that the experience of job insecurity and subsequent events is a consequence, rather than a cause, of ill health. ${ }^{21}$ The presence of a longstanding illness may also result in a higher susceptibility for common infections and in a higher prevalence of general health problems. Employees having a longstanding illness may have more severe symptoms or complications, when having a mild infection like for instance common cold. Common colds often predispose patients with Chronic Obstructive Pulmonary Diseases (COPD) to develop lower airway infections, ${ }^{24 i}$ which are one of the most common causes of exacerbations in COPD patients. ${ }^{25}$ Alterations in characteristics of work as a result of upcoming reorganizations may increase job demands and decrease job control. Higher levels or psychological job demands and lower levels of decision latitude, were found among employees reporting job insecurity. Dala from the Maastricht Cohort Study earlier showed a cross-sectional relationship between psychological job demands and common cold, ${ }^{9}$ and also showed an inverse relationship between decision latitude and the occurrence of common cold.

It is possible that employees will be more on sick leave, due to an increase in common infections and health complaints. It is also possible that employees who report job insecurity may show withdrawal from work without medical reason as a way of coping. resulting in an increase in sick leave. ${ }^{26}$ An increase in sick leave, or reduced productivily from employees at work, as a result of health problems or common infections can have an important economic impact.

In this present study, the cross-sectional and longitudinal relationship between job insecurity and common infections or health complaints was investigated in a nonexperimental setting, with participants observed in a natural environment with all the normal every day hassles. An important issue concerns the assessment of both the dlependent (common infections and health complaints) and independent variables (job insecurity) through self-administered questionnaires. Although the items in the questionnaire concerning common infections cover representative symptoms for common cold, flu-like illness and gastroenteritis, we are aware of the fact that self- 
reported illnesses may lead to under of over reporting. Evans et al. ${ }^{27}$ showed that when using a self-report methodology, that reporting of a cold episode is not correlated with neuroticism (often taken as a measure of "complainer syndrome") whereas the reporting of aches and pain and general body symptoms is. Also job insecurity was measured with a single self-administered item. The potential underlying effects of negative affectivity on the self-reports nature of our measures have to be recognized. ${ }^{28}$ Individuals high on negative affectivity may perceive their environment more negatively, thereby creating spurious associations between job insecurity and common infections or health complaints. Therefore we corrected in our longitudinal analysis for the presence of common infections or health complaints at $T$, in order to reduce the possible influence of negative affectivity. ${ }^{29}$ Also the presence of jab insecurity was determined using selfreported questionnaires. We think that with this single item, the effect of an upcoming reorganization of closing a company can be measured. Within the Maastricht Cohort Study several organizations were in the process of a reorganization. As an example, at baseline $13.1 \%$ of the employees of an agency later threatened with closure, reported jab insecurity. In a reference group of employees in comparable organizations, $7 \%$ reported job insecurity. One year later, the percentage had increased to $62 \%$ in the agency threatened with closure and had decreased to $3 \%$ in the reference group. ${ }^{30}$ These data show that the report of job insecurity of the employees goes together with an actual increase of objective insecurity due to an upcoming closure or reorganization. It is now widely recognized that the definition of job insecurity as a threat of imminent job loss is too narrow in that it fails to include the threat from deteriorating employment conditions and career opportunities. ${ }^{31,32}$ The presented job insecurity in the questionnaire does probably not account for insecurity due to these conditions.

In this present study we found an assaciation between job insecurity and common infections or general health problems. We also found support for the longitudinal relationship between job insecurity and common infections or health complaints measured at a later time-point. In respect to the high prevalence of common infections and health problems, the found effects should be considered as quite large. The fact that in the Netherlands, employees that become redundant because of reorglanization activities or downsizing will receive substantial settlements from the company and/or get a benefit from the state, may have reduced the health effects.

\section{Acknowledgements}

The Maastricht Cohort Study is part of the Netherlands concerted research action on "Fatigue at Work" granted by the Netherlands Organization for Scientific Research. This present study was supported by a grant from the Netherlands Organization for Scientific Research (NWO grant no. 580-02.254). 


\section{References}

1. Hurrell $J J, J r$. Are you certain?-uncertainty, health, and safety in contemporary work. Am $J$ Public Health $1998,88(7): 1012-3$.

2. Ferrie JE, Shipley MU, Marmot MG, Stansfeld SA, Smith GD. An uncertain future: the health effects of threats to employment security in white-collar men and women. Am J Public Health $1988 ; 88(7): 1030-6$

3. Beale $\mathbb{N}$, Nethercot S. Certificated sickness absence in industrial employees threatened with redundancy. BrMed J Clin Res Ed 1988:296(6635):1508-10.

4. Kivimaki $M_{1}$ Vahtera $J$. Pentti $J$, Ferrie JE. Factors underlying the effect of organisational downsizing on health of employees: Iongitudinal cohort study. BMJ 2000;320(7240):971-5.

5. Barling J, Kelloway EK. Job insecurity and health: The moderating role of workplace control. Stress Med 1996; 12(4):253-9.

6. Ferrie JE. Health consequences of job insecurity. WHO Reg Publ Eur Ser 1999;81:59-99.

7. Arnetz BB, Wasseman J, Petrini $B$, et al. Immune function in unemployed women. Psychosom Med 1987:49(1):3-12

8. Cohen S, Frank E, Doyle WJ, Skoner DP. Rabin BS, Gwaltney JM, JP. Types of stressors that increase susceptibility to the common cold in healthy adults. Health Psychol 1998;17(3):21423.

9. Mohren DCL, Swaen GMH, Borm PJA, Bast A, Galama JMD. Psychological Job Demands as a risk factor for common cold in a Dutch working population. J Psychosom Res 2001;50:21-7.

10. Kiecolt Glaser JK, Glaser $\mathbb{R}$. Methodological issues in behavioral immunology research with humans. Brain Behav Immun 1988;2(1):67-78.

11. Beurskens AJ, Bultmann U, Kant IJ, Vercoulen JH, Bleijenberg G, Swaen GM. Fatigue among working people: validity of a questionnaire measure. Occup Environ Med 2000;57(5):353-7.

12. Kant IJ, Beurskens AJHM. Schröer CAP, et al. De Maastrichtse Cohort Studie naar langdurige psychische vermoeidheid in de arbeidssituatie. [The Maastricht Cohort Study on fatigue at work]. TBV 2000;8(8):226-32

13. Bültmann U, Kant $\| \mathrm{J}$, KasI SV, Beurskens A.JHM, Van den Brandt PA. Fatigue and psychological distress in the working population: Psychometrics, prevalence, and correlates. $J$ Psychosom Res 2002;52(6):445-52

14. Van Veldhoven M, Meijman TF. Het meten van psychosociaie arbeidsbelasting met een vragenlijst: de vragenlijst beleving en beoordeling van de arbeid (VBBA) The measurement of psychosocial job demands with a questionnaire (VBBA)]. Amsterdam: NIA; 1994.

15. Karasek RA. The Job Content Questionnaire and User's Guide (version 1.1). Los Angeles: Department of Industrial and Systems Engineering. University of Southern California; 1985 March.

16. Niedhammer I, Goldberg M, Leclerc A, Bugel I, David S. Psychosocial factors at work and subsequent depressive symptoms in the Gazel cohort. Scand J Work Environ Health $1998 ; 24(3) ; 197-205$

17. Liang $K-Y$, Zeger $S L$. Longitudinal analysis using generalized linear madels. Biometrika $1986 ; 73: 13-22$

18. Zeger SL, Liang KY. Longitudinal data analysis for discrete and continuous outcomes. Biometrics 1986;42(1):121:30.

19. Ferrie JE, Shipley MJ, Marmot MG. Stansfeld $S$, Davey Smith $G$. The health effects of major organisational change and job insecurity. Soc Sci Med 1998:46(2):243-54.

20. Vahtera $J$. Kivimaki $M$. Pentti $d$. Effect of organisational downsizing an health of employees. Lancet 1997;350(9085):1124-8.

21. Ferrie JE, Shipley Md, Marmot MG. Stansfeld S. Smith GD. Health effects of anticipation of job change and non-employment: longitudinal data from the Whitehall II study. BMJ $1995 ; 311(7015): 1264-9$.

22. Heaney $\mathrm{CA}$, Israel $B \mathrm{~A}_{3}$ House $\mathrm{US}$. Chronic job insecurity among automobile workers: effects on job satisfaction and health. Soc Soi Med 1994:38(10):1431-7.

23. Jaakkola JJ, Heinonen OP. Shared office space and the risk of the common cold. Eur J Epidemiol 1995:11(2):213-6. 
24. Smith $C B$, Golden CA, Kanner RE, Renzetti AD, Jr. Association of viral and Mycoplasma pneumoniae infections with acute respiratory illness in patients with chronic obstructive pulmonary diseases. Am Rev Respir Dis 1980;121(2):225-32.

25. Suzuki $T$, Yanai $M$, Yamaya $M$, Satoh Nakagawa $T$, Sekizawa $K$, Ishida $S$, et al. Erythromycin and common cold in COPD. Chest 2001:120(3):730-3.

26. Van Vuuren T. Onzekerheid over de arbeidsplaats en het psychisch welbevinden. Directe en indirecte effecten wan sociale en psychologische factoren. Job insecurity and psychological well-being: Direct and indirect effects of social and psychological factors. Gedrag Gezond 1991:19(4):191-204.

27. Evans PD, Pitts MK, Smith K. Minor infection, minor life events and the four day desirability dip. J Psychosom Res 1988:32(4-5):533-9.

28. Watson $D$, Clark. LA. Negative affectivity: the disposition to experience aversive motional states. Psychol Bull 1984;96:465-90.

29. Bütmann $U$, Kant IJ, Van den Brandt PA, KasI SV. Psychosocial work characteristics as risk factors for the onset of fatigue and psychological distress: Prospective results from the Maastricht Cohort Study. Psychol Med 2002;32:333-45.

30. Swaen GMH, wan Amelswoort LGPM, Bültmann U, Kant IJ. Effect of job insecurity on fatigue and psychological distress. Results from the Maastricht Cohort Study. (submitted for publication).

31. Heligren J, Sverke $M$, Isaksson $K$. A two-dimensional approach to job insecurity: Consequences for employee altitudes and well-being. Eur \& Work Organ Psychol 1999;8(2):179-95.

32. Ferrie JE, Shipley MU, Stansfeld SA, Marmot MG. Effects of chronic job insecurity and change in job insecurity on self-reported health, minor psychiatric morbidity, psychological measures and health-related behaviours in British civil servants:" the Whitehall II study, J Epidemiol Community Health $2002 ; 56(6): 450-4$. 


\title{
$-4-$
}

\section{Prevalence of common infections among employees in different work schedules}

\author{
Danielle CL Mohren" \\ Nicole WH Jansen " \\ IJmert Kant ${ }^{9}$ \\ Jachem MD Galama ${ }^{2}$ \\ Piet A van den Brandt \\ Gerard MH Swaen
}

\begin{abstract}
This study examined the prevalence of common infections, among employees in different work schedules. Self-administered questionnaire data from the Maastricht Cohort Study on "Fatigue at Work" $(n=12,140)$ were used. Job title was used as a matching variable between day and shift workers in order to control for their different work environment. We used a multilevel analysis of a two-level structure, in which employees (level 1) were nested within job titles (level 2), adjusted for demographics, longstanding disease, health behavior, work-related factors, fatigue and sleep quality. Results from the multilevel analyses showed that, compared to day work, shift work was associated with a higher risk for common infections, with the highest risk in three-shift workers. Compared to day work, shift work was further associated with differences in health, health behavior sleep, fatigue and perceived job characteristics, factors which may influence the occurrence of infections and should be taken into account in future studies as well.
\end{abstract}

'Department of Epidemiology, Maastricht University, Maastricht, The Netherlands

${ }^{2}$ Department of Medical Microbiology, University Medical Center St. Radboud, Nijmegen,

The Netherlands

Both authors made equall contributions to this article

Journal of Occupational and Environmental Medicine 2002;44(11):1003-1011 


\section{Introduction}

Common infections like common cold, flu-like illness, and gastroenteritis are endemic in the general population thereby causing considerable discomfort and absence from work. In a study by Feeney et al. ${ }^{4}$ it was found that respiratory disorders and gastroenteritis accounted for 50 to $60 \%$ of all spells of absence. In recent years, evidence has accumulated that stress influences the susceptibility to, and duration of infections. Several psychosocial factors have been linked to an increased risk for infections. Daily hassles and major life events have been connected to a higher risk for upper respiratory tract infections. ${ }^{2-6}$ Family functioning, measured with scales covering among others cohesion, adaptability and recent events within a family, has been associated with a higher risk for influenza-like illnesses. Also work-related stressors may play a role in the susceptibility to infections and several studies have demonstrated a link between the experience of work-related stressors and changes in immune activity. 10 Psychological job demands for example, have been described as a possible risk factor for common cold. ${ }^{11}$

Another work-related factor that is likely to be associated with common infections, constitutes shift work. Shift work can have a negative impact on the health and wellbeing of workers. ${ }^{12}$ Problems related to shift work fall into three main areas. ${ }^{13}$ First. biological disruption of physiological processes, including the sleep-wake cycle, ${ }^{14,15}$ can result from shift work. Second, the impairment of physical health and psychological wellbeing, ${ }^{16}$ and third the disruption of social and domestic life ${ }^{17.18}$ have been associated with shift work as well. Studies have shown that shift workers have an increased risk of cardio-vascular diseases. ${ }^{19-23}$ gastro-intestinal diseases, ${ }^{12.24 .25}$ and diminished wellbeing. ${ }^{12}$ A few studies have reported depressed immune function in relation to shift work, which may explain an increased susceptibility to infections ${ }^{26.27}$ Further, depression of immune function has been attributed to a disturbed circadian rhythm ${ }^{28}$ caused by periodic shifting of the light-dark, wake-sleep-cycles. ${ }^{26}$ Shift work may be a major cause of suboptimal sleep quality ${ }^{29}$ and has been rellated to a greater amount of insomnia, sleep deprivation, and daytime sleepiness. ${ }^{15}$ Cohen et al ${ }^{30}$ found that inefficient sleep is associated with an increased risk of colds. Moreover, we found that fatigue is associated with common infections. ${ }^{31}$ Fatigue can be regarded as a common complaint during infection, which aftenwards can persist for months. On the other hand, it was found that fatigue can also precede a common infection.

The prevalence of infections may further be influenced by health behavior like smoking, drinking habits, and limited exercise. Increased smoking, drinking, ${ }^{32}$ and limited exercise $^{33}$ can influence the immune response. Both smoking and alcohol consumption are believed to suppress host resistance and thereby increase the risk of upper respiratory tract infections. ${ }^{34}$ Health behavior may also differ between day and shift workers and may possibly account for differences in infection rates. One of the most important physiological problems associated with shift work and the night shift in particular, is that working, eating and sleeping phases are changed. ${ }^{25}$ Strong differences between day and shift workers have also been reported concerning other work conditions, such as, for example, decision latitude and conflicts at work, ${ }^{35}$ as well as 
emotional, physical and psychological job demands. ${ }^{36.37}$ This emphasizes the need to control for differences in the work environment when examining work schedules. Approaches to take into account these confounders, are to include measures of perceived job characteristics in the analysis of shift work effects ${ }^{38}$ and/or use job title as a matching variable in the analyses.

We are currently interested in the associations between work schedules and the prevalence of infections. The present study is part of the large scale Maastricht Cohort Study on "Fatigue at Work", in which work-related and nonwork-related factors as well as the occurrence of common infections were measured on an individual level by means of self-administered questionnaires. The aim of the present study was to investigate whether shift work is associated with a higher prevalence of common infections, such as common cold, flu-like illness, and gastroenteritis compared to day work, with day and shift workers matched on job title. We differentiated day workers from employees working three-shift, five-shift or irregular shift systems, while taking into account the role of demographics, health, health behavior, perceived job characteristics, sleep quality and fatigue.

\section{Methods}

\section{Maastricht Cohort Study}

At baseline the Maastricht Cohort Study surveyed a large heterogeneous population of employees working in 45 different companies and organizations. ${ }^{39.40}$ Temporary employees, as well as employees with an employment of less than $50 \%$, were excluded. A total of 12,161 employees completed the baseline questionnaire. Written consent was obtained from all participants. The overall response was $45 \%$. Twenty-one questionnaires were discarded because of technical reasons, ${ }^{44}$ resulting in a study population of 12,140 employees. Included were men and women, aged 18-65 years $(n=12,095)$.

The participants of the Maastricht Cohort Study received nine questionnaires at fourmonthly intervals, with a total observation period of three years (1998-2001). The results of the present study are based on the first (baseline) questionnaire (May 1998). At baseline, exposures (work-related factors, individual characteristics, domestic and social factors as well as information on job title) and outcomes were measured on an individual level using self-administered questionnaires.

\section{The study population}

For the present study we further excluded employees with multiple jobs ( $n=497)$, since we have no information available on the content and work schedule of the other job. To study the effects of work schedules, employees involved in day work, three-shift, fiveshift or irregular shift work were selected. All employees involved in other work schedules or those who did not provide information on their work schedule were excluded, resulting in a final study population of 8255 employees. 
The questions 'What is your job in the companylorganization?' and 'What is your most important task?' were used to assess an employees' job title in the current job. The responses to these open-ended questions were used by trained coders to assign a job title, with a five-digit code, based on The Netherlands Standard Classification of Occupations 1992. ${ }^{42}$ From the employees, 88 did not indicate their function or most important task. These employees were excluded from further analyses. At baseline in 1998, the Maastricht Cohort Study captured 687 different job titles. Job title was used to match the employees in the different work schedule groups. For example, employees working three-shift systems were matched with a reference group of day workers with similar job titles. For each distinguished job title, there was a minimum of two employees in each work schedule. For the comparison of three-shift workers with day workers, 47 job titles were identified ( $n=753$ for three-shift workers, $n=1114$ for day workers). Examples of job titles represented in both day work and three-shift systems were: production planner, operator, engine/bench fitter. For comparing five-shift workers and matched day workers, 58 job titles were identified ( $n=947$ for five-shift workers, $n=1609$ for day workers). Examples of job titles represented in both day work and five-shift systems were: machine operator, controller or tester electric-machinery, maintenance electrician. As regards irregular shift workers and matched day workers, 28 job titles were identified ( $n=329$ for irregular shift workers, $n=573$ for day workers). Examples of job titles represented in both day work and irregular shift systems were mailman, enrolled nurse, care taker of the mentally handicapped or elderly.

\section{Work schedules}

Regarding work schedules, employees were asked whether they were involved in irregular shifts, two-shift, three-shift, four-shift, or five-shift work, exclusively evening or night work, or whether they worked daytime only. In our study, the term shift work is used for a work schedule that includes night work. In the present study only day workers, three-shift, five-shift or irregular shift workers were included for investigating differences between the schedules. The direction of the shifts (clockwise, counterclackwise) varied between the companies. In the present study three-shift work involves three alternating learns, with a semi-continuous schedule, in which a weekly interruption of the production, mainly in the weekends, takes place. Five-shift work involves full continuous shift work, spread over seven days including five alternating teams. Concerning working hours a week, five-shift work generally comprises 33 to 34 hours a week, whereas three-shift work comprises 38 to 40 hours a week. Employees working irregular shifts are involved in frequently deviating work hours, which can vary substantially every week. In the present study, for irregular shifts we only included those employees reporting frequent night work within their shift.

\section{Infections}

The four-month prevalence of infections was also determined using self-administered questionnaires. Three common infections: common cold, flu-like illness, and gastroenteritis were inventoried as separate items in the questionnaires asking employees about the occurrence of common infections in the past four months. For clarification, a brief description of the infection was included in the question. This 
description mainly contained the typical symptoms of the infection. For common cold these symptoms were: clogged or running nose, a sore throat, coughing, and slight or no fever (temperature less than $38^{\circ} \mathrm{C}$ ), for llu-like illness: fever (temperature $38^{\circ} \mathrm{C}$ or more), with at least four of the following six complaints, muscular pain, fatigue, sore throat, clogged or running nose, coughing, headache. For gastroenteritis these symptoms included: slight or no fever, gastritis, nausea vomiting and/or diarrhea.

\section{Work environment}

In this study we included measures regarding the experience of several demands at work. Decision latitude was assessed with the Dutch version of the Job Content Questionnaire using the scale Decision Latitude. ${ }^{43.44}$ The level of psychological job demands was measured with the Dutch version of the Psychological Job Demands scale of the Job Content Questionnaire. ${ }^{43.44}$ The level of emotional demanding work was measured using a five item scale consisting of two items of the Questionnaire Experience and Assessment of Work (VBBA), ${ }^{45}$ two items of the Questionnaire on Work and Health $(V A G)^{46}$ and one self-formulated item. Physicall demands were measured using a dichotomous item of the Dutch questionnaire on Work and Health (VAG). ${ }^{46}$

\section{Demographics and health variables}

Information on age, gender, the presence of a long-term disease, smoking and drinking habits, was obtained through self-report in the baseline questionnaire. Information on the quality of sleep was obtained through one item asking employees "Did you sleep well in the past four months?". This item was scored on a four point scalle (never, sometimes, usually, always). The Checklist Individual Strength (CIS) was used to measure prolonged fatigue. ${ }^{47}$ The $\mathrm{CIS}$ is a 20 -item questionnaire developed to measure several aspects of prolonged fatigue. The CIS is a self-report instrument consisting of four factors: subjective experience of fatigue, concentration, motivation, and physical activity level. Higher scores indicate a higher degree of fatigue, more concentration problems, reduced motivation or less activity. A composite CIS-total score, ranging from 20 to 140 , can be constructed by adding the individual's scores on the four factors. The Cronbach's alpha of the total scale is 0.93 . The cut-off point for case classification used in the present study was CIS total $>76$. This cut-off point was established in a separate pilot study by means of defined samples with differences in fatigue levels. ${ }^{48}$ All those employees scoring $>76$ were considered to be probable fatigue cases. ${ }^{4 !}$

\section{Statistical method's}

We calculated crude and adjusted odds ratios (ORs) and $95 \%$ confidence intervals (Cl) for associations between each of the three common infections (common cold, flumlike illness and gastroenteritis) and each work schedule. The ORs were adjusted in several steps for demographics, longstanding disease, health behavior, psychological job demands (continuous variable), decision latitude (comtinuous variable), emotional demands (continuous variable), physical demands, and fatigue (continuous variable), and sleep quality. Each shift work type (three-shift, five-shift and irregular shift work) was compared with a reference group of day workers with respect to the prevalence of common infections. We used a multilevel analysis of a two-level structure, in which the 
individual employees (level 1) were nested within job tifles (level 2). Additionally T-tests and Chi-square tests were used to test univariate differences between employees in the different shift work lypes versus day workers. All procedures were performed using SPSS for Windows release 9.0.0. SAS release 8.02, and GLIMMIX, a SAS Macro for the multilevel analyses.

\section{Results}

Table 1 shows descriptive characteristics of the study population before matching on job title. The percentage of women involved in three- and five-shift work was significantly lower compaled to day work, whereas the percentage of women was significantly higher

Table 1 Descriptive characteristics study population

\begin{tabular}{|c|c|c|c|c|c|}
\hline & & Day work & ree-shift work & Five-shift work & Irregular shift work \\
\hline & N(number of organizations) & $5899(45)$ & $878(19)$ & $1058(11)$ & $420(25)$ \\
\hline \multirow[t]{2}{*}{ Demographics } & Gender & 32.6 & $11.6^{k i k b}$ & $6.1^{i * x}$ & $39.5^{\text {n+t }}$ \\
\hline & Age mean & 42.38 & $35.72^{* \pm *}$ & $37.96^{* 1 * k}$ & $37.87^{\text {t*xix }}$ \\
\hline \multirow[t]{10}{*}{ Haalth belluavior } & Smaking $\%$ & 22.5 & $46.7^{7 \times t}$ & $35.3^{\text {mixi }}$ & $37.1^{* *}$ \\
\hline & Alcohol use \% (glasses / wh) & & ${ }^{*} \mathbf{x} \mathbf{x}$ & * & $* *$ \\
\hline & - none & 24.4 & 37.1 & 28.8 & 34.3 \\
\hline & $=1-14$ & 64.2 & 52.5 & 59.9 & 57.6 \\
\hline & $-\quad 15.21$ & 8.6 & 7.1 & 8.0 & 5.5 \\
\hline & $=\quad \geq 22$ & 2.8 & 3.3 & 3.3 & 2.6 \\
\hline & Exercise \% & & $* * *$ & $* *$ & \\
\hline & - $0-1$ times I wk & 30.5 & 44.1 & 36.3 & 326 \\
\hline & $-2-7$ thmes / wk & 62.4 & 50.3 & 57.6 & 58.1 \\
\hline &.$>7$ times / wk & 7.1 & 5.5 & 6.1 & 9.3 \\
\hline \multirow{4}{*}{$\begin{array}{l}\text { Work-related } \\
\text { lactors }\end{array}$} & Plysically demanding work \% & 11.8 & $51.6 \%$ & $348^{2 \cdot n}$ & $71.9^{* * *}$ \\
\hline & $\begin{array}{l}\text { Psychological job demends } \\
(12-48) \text { t }\end{array}$ & 32.73 & $34.69^{* 2 * x}$ & $32.17^{* *}$ & $34.34 * *$ \\
\hline & $\begin{array}{l}\text { Decision latiude } \\
(24.96):\end{array}$ & 73.19 & $64.15^{* * * 4}$ & $67.73^{\text {tim }}$ & $68.79^{4+8 d}$ \\
\hline & $\begin{array}{l}\text { Emotional demands } \\
(0.5)+\end{array}$ & 0.90 & $1.61^{* *}$ & $1.18^{* i x}$ & $1.93^{1 / 4}$ \\
\hline \multirow[t]{7}{*}{ Healln: } & Longhterm disease \% & 24.7 & 26.2 & $21.7^{*}$ & 25.7 \\
\hline & Good sleep in past four months & & $* * *$ & 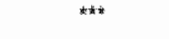 & 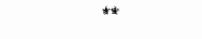 \\
\hline & - never & 2.5 & 5.4 & 2.7 & 3.4 \\
\hline & - sometimes. & 12.9 & 28.5 & 21.0 & 19.2 \\
\hline & - usually & 56.7 & 46.8 & 53.0 & 52.9 \\
\hline & - always & 27.9 & 19.2 & 23.3 & 24.5 \\
\hline & Fatigua $(\mathrm{C} / \mathrm{S}>76)$ & 20.7 & $32.2^{\text {k* }}$ & $25.9^{ \pm * x}$ & 21.2 \\
\hline
\end{tabular}

Significant difference with day work: * $P<0.05,{ }^{* *} P<0.01,{ }^{* * *} P<0.001$

+ Reference group for all three types of shift work

\$ Scale range 
in irregular shift work compared to day work. Shift workers were on average younger of age compared to day workers. Smoking was significantly more prevalent in shift workers as compared to day workers, with the highest percentage of smokers (46.7\%) observed in three-shift workers. Differences in alcohol use were also found between day and shift workers. The highest percentage of employees who reported to exercise never or only once a week was found in three-shift workers. With regard to job characteristics substantial differences emerged between day and shift workers. For example, the percentage of employees reporting their work to be physically demanding was substantially and significantly higher in all types of shift work compared to day work. Overall, the prevalence of employees reporting a long-term disease did not substantially differ between the work schedules, although the prevalence of a long-term disease was somewhat lower in five-shift work $(P<0.05)$ compared to day work. We found significant differences in sleep quality between employees in shift work and day work. Three-shift workers reported the highest percentage of poor sleep quality in the past four months. Compared to day work, the prevalence of fatigue was substantially higher in most shift work groups, with three-shift workers reporting the highest prevalence $(32.2 \%)$.

Table 2 shows the prevalence at baseline of common infections among employees working in different work schedules. The occurrence of common cold is highest among three-shift workers (57.5\%) and irregular shift workers (55.5\%). Flu-like illness is also most frequently reported by three-shift workers $(31.2 \%)$ and irregular shift workers $(30.5 \%)$. Finally, the highest prevalence for gastroenteritis was found among three-shift workers $(18.2 \%)$

Table 2 Prevalence of common infections among different work schedules

\begin{tabular}{|c|c|c|c|c|}
\hline & Day work & Three-shift work & Five-shift work & Urregular shifft work \\
\hline$N$ (number of organizations) & $5899(45)$ & $878(19)$ & $1058(11)$ & $420(25)$ \\
\hline Common cold $\%$ & 53.0 & $57.5^{*}$ & 51.0 & 55.5 \\
\hline Flu-like illness $\%$ & 22.4 & $312^{\text {ktk }}$ & 22.1 & $30.5^{* * k}$ \\
\hline Gastroenteritis \% & 11.8 & $18.2^{* * *}$ & $154^{* *}$ & $15.1^{*}$ \\
\hline
\end{tabular}

Significant difference with day work: ${ }^{*} P<0.05$, *** $P<0.01$, $^{* * *} P<0.001$

Because of the large differences observed between day and shift workers with regard to the perceived work-related demands, job title was used as a matching variable in multilevel analysis. Table 3 shows the ORs for the three distinguished common infections by shift type, using multilevel GLIMMIX models in which the individual employees were nested within job titles. Three-shift work was significantly associated with all three common infections (OR $1.42 ; \mathrm{Cl} 1.14-1.76$ for common cold, OR $1.72 ; \mathrm{Cl}$ 1.34-2.20 for flu-like illness, OR 1.83; Cl 1.40-2.38 for gastroenteritis). In general, for irregular shift workers similar but lower associations were observed. Five-shift work was only significantly associated with gastroenteritis (OR 1.64; Cl 1.29-2.08). No significant differences were found for the prevalence of common coll and flu-like illness, when comparing five-shift workers with day workers. Adjusting for demographics and health factors (age, gender and long-term disease) and for health behavior (smoking, drinking habits and exercise) resulted in weaker associations for all work schedules, except for 
the association between five-shift work and common cold. Compared to day work, fiveshift work was then associated with a lower risk for common cold (OR $0.79 ; \mathrm{Cll} 0.66$ 0.95). Subsequently, the ORs for common infections were additionally adjusted for several work-related demands, which resulted in changes of the ORs for the association between work schedules and common infections as well. Most ORs decreased, whereas the OR regarding the association between irregular shift work and flu-like illness increased (OR $1.52 ; \mathrm{Cl} 1.06-2.18$ ). Also, the OR for the association between five-shift work and gastroenteritis increased (OR 1.38; $\mathrm{Cl} 1.03-1.85$ ). In the final analyses, the ORs were additionally adjusted for sleep quality and fatigue levels, which resulted in only slight changes of the ORs for all three common infections. Statistically significant ORs remained for the associations between five-shift work and common cold (OR $0.79 \mathrm{Cl}$; 0.64-0.98); five-shift work and gastroenteritis (OR 1.42 Cl 1.05-1.91), and irregular shift work and flu-like illness (OR 1.63; $\mathrm{Cl} 1.13-2.36$ ).

Table 3. Odd Ratios and 95\% Confidence Intervals for common infections by shift type Multilevel GLIMMIX Models

\begin{tabular}{|c|c|c|c|c|c|c|c|c|c|c|}
\hline & & & & & & & & & & \\
\hline & $\mathrm{OR}$ & $95 \% \mathrm{Cl}$ & OR & $95 \% \mathrm{Cl}$ & Ork" & $95 \% \mathrm{Cl}$ & $O R^{3}$ & $95 \% \mathrm{Cl}$ & ORg & $95 \% \mathrm{C}$ \\
\hline 3-shilt work & 1.42 & $1.14 \times 1.76$ & 1.16 & $0.91 \times 1.48$ & 1.14 & 0.8814 .46 & 1.03 & $0.78-1.35$ & 1.03 & $0.78-1.36$ \\
\hline 5-shift work & 1.00 & $0.85 \times 1.19$ & 0.83 & $0.69-0.99$ & 0.79 & $0.66 m 0.95$ & 0.77 & $0.63-0.95$ & 0.79 & $0.64-0.98$ \\
\hline Irregular shift & 1.09 & $0.83-1.44$ & 1.02 & $0.76 \cdot 1.37$ & 1.01 & $0.75 \mathrm{~m} 1.36$ & 0.92 & $0.66-1.27$ & 0.95 & $0.68-1.32$ \\
\hline
\end{tabular}

Flu-like illiness

\begin{tabular}{lcccccccccc} 
& OR & $95 \% \mathrm{Cl}$ & OR & $95 \% \mathrm{Cl}$ & ORI & $95 \% \mathrm{Cl}$ & OR & $95 \% \mathrm{Cl}$ & OR & $95 \% \mathrm{Cl}$ \\
\hline 3-shift work & 1.72 & $1.34-2.20$ & 1.52 & $1.16-2.00$ & 1.41 & $1.07-1.87$ & 1.23 & $0.90-1.68$ & 1.23 & $0.90-1.70$ \\
5-shift work & 1.06 & $0.84-1.34$ & 0.92 & $0.72-1.17$ & 0.88 & $0.69-4.12$ & 0.82 & $0.64-1.06$ & 0.82 & $0.63-1.07$ \\
Irregular shift & 1.51 & $1.11-2.05$ & 1.40 & $1.01-1.95$ & 1.39 & $0.96-1.94$ & 1.52 & $1.06-2.18$ & 1.63 & $1.13-2.36$ \\
\hline
\end{tabular}

Gastroenteritis

\begin{tabular}{lcccccccccc} 
& OR & $95 \% \mathrm{Cl}$ & OR & $95 \% \mathrm{Cl}$ & ORI & $95 \% \mathrm{Cl}$ & OR & $95 \% \mathrm{Cl}$ & ORS & $95 \% \mathrm{Cl}$ \\
\hline 3-shift work & 1.83 & $1.40-2.38$ & 1.25 & $0.92-1.70$ & 1.15 & $0.84-1.59$ & 1.05 & $0.73-1.51$ & 1.06 & $0.73-1.54$ \\
5-shift work & 1.64 & $1.29-2.08$ & 1.39 & $1.08-1.80$ & 1.34 & $1.03-1.74$ & 1.38 & $1.03-1.85$ & 1.42 & $1.05-1.91$ \\
Irregular shift & 1.40 & $0.95-2.06$ & 1.28 & $0.85-1.93$ & 1.22 & $0.80-1.86$ & 1.15 & $0.73-1.81$ & 1.17 & $0.73-1.88$ \\
\hline
\end{tabular}

For every shift type, the reference group consisted of employees in day work with comparable occupations

"Corrected for age, gender, longstanding disease

I Additionally corrected for smoking, drinking habits and exercise

I Additionally corrected for psychobgical job demands, decision latitude, physical demands, and emotional demands

\$ Additionally corrected for sleep quality and fatigue

Finally, to study the role of fatigue and sleep quality in the relationship between work schedules and common infections separately, we conducted additional analyses, in which we adjusted the ORs only for demographics, the presence of a longstanding disease, fatigue and sleep quality. These analyses (specific data not shown) revealed that sleep quality and fatigue influenced the strength of the associations as well, although in general to a lesser extent as compared to the effect of perceived job demands. 


\section{Discussion}

In this study we found that the prevalence of three common infections (common cold, flulike illness, and gastroenteritis) differed significantly between employees involved in different work schedules. Three-shift workers reported the highest prevalence for all three infections. Taking into account the high prevalence of common infections and the fact that work schedules are not the primary 'etiological agent', the observed associations are quite large, moreover when considering the loss of productive work hours when infections result in employee absenteeism.

Because differences in work-related factors are often large between day and shift workers, in this study job title was used as a matching variable. Employees with similar job titles in different work schedules were matched in order to account for differences in the work environment. The crude ORs in the multilevel analyses revealed that shift work was clearly associated with a higher odds of common infections compared to day work. Three-shift work was strongly associated with all three infections. Compared to five-shift workers, three-shift workers have a working week comprising more hours. In addition, three-shift workers generally only have two (weekend) days available to recuperate before they switch to a new shift cycle. Others have observed that recovery from a shift did not occur by the end of the first rest day but might have occurred only by the end of the second rest day. ${ }^{49}$ The traditional weekly change of shifts, as for example seen in three-shift work, is often reported to be the worst solution. ${ }^{50,51}$

To elucidate possible underlying mechanisms relating work schedules to common infections, we adjusted in several steps consecutively for demographics, health, health behavior, job characteristics, sleep quality and fatigue. Adjustments for demagraphics, health status and health behavior resulted in lower odds for the association between work schedules and infections. This emphasizes the importance of correction for the above mentioned factors, since they are related both to infections and work schedules.

Subsequently, we corrected for several work-related demands. Although job title was used as a matching variable in order to take into account possible differences in demands, we still observed a change in the association between work schedules and infections after adjustment for work-related demands. Though the day and shift workers were in comparable job titles, there were still differences with regard to the perceived demands of the individual worker. Compared to day workers, shift workers may perceive these job characteristics as more demanding possibly since they are fighting their sleep. Another possibility is that job demands in similar jobs actually are more demanding, when performed in shift work. We are aware that adjustment for job characteristics may constitute over control and thus could lead to underestimation of risks, because these job characteristics may be part of the causal pathway linking work schedules to common infections. Therefore, we assume that the relatively crude results, only adjusted for age. gender and long-term disease, are more likely to represent the actual effect of shift work on the prevalence of common infections. The analyses with adjustments for job characteristics, however, provided important additional information to disentangle possible mechanisms linking work schedules to common infections. This is in line with 
other studies showing an association between work-related stressors and immune function.

Further evidence supports the view that lack of sleep lowers resistance to infection and that during periods of sleep deprivation, respiratory tract infections occur more frequently. ${ }^{28}$ Shift work has been clearly related to disturbed sleep. ${ }^{15,54}$ First, their unusual work hours prevent shift workers from sleeping at the normal time. Second, when shift workers do have an opportunity to sleep, they have to do so in an environment that is geared towards the awakened state. Third, night work and day sleep affect the circadian rhythm. ${ }^{55}$ In a study by Härma et al. ${ }^{15}$ for example, sleep complaints were more common in two- and three-shift workers as well as in irregular shift workers compared to day workers. In our study, shift work was also associated with poorer quality of sleep. In addition, shift workers had a significantly higher prevalence of fatigue. Higher fatigue levels are related to common infections as well. ${ }^{31}$ When contralling for sleep quality and fatigue levels, only minor changes appeared in the association between work schedules and common infections. A possible explanation for these small effects could be that perceived work demands next to sleep quality and fatigue, play a dominant role in the mechanism to explain the association befween work schedules and common infections. Thus, because we corrected for perceived demands in our analysis before we corrected in the last step for sleep quality and fatigue, a large part of the association may already have been explained by the level of perceived work demands. Additional analyses in which we corrected for fatigue and sleep quality, but not for work demands, resulted in changes of the associations. These changes were smaller as compared to the effect of adjusting for work-related demands. Because perceived work demands are related to fatigue in other studies, ${ }^{56}$ we feel that sleep disturbances and fatigue could constitute another pathway linking work schedules to common infections. Because sleep deprivation may result in increased susceptibility, shift workers may experience more infections compared to day workers. Altered light-dark cycles, which occur during shift work are associated with disruptions of normal sleep patterns. ${ }^{57}$ Common perceptions that lack of sleep lowers resistance to infections and that infections develop during or after periods of sleep loss suggest that sleep deprivation is likely to impair immune function. ${ }^{53}$ Disorganization or disturbance of the sleep-wake system interferes with the immunological neuroendocrime and thermal systems and contributes to pathological processes. Disruption of these systems is evident in diseases, such as infections. 50

The data presented in the study have been collected in a large-scale cohort study among employees from 45 different companies. Despite the almost inevitable shortcoming of large cohort studies using questionnaires, ${ }^{11}$ this study gave us the opportunity to study the relationship between common infections and different types of work schedules in a nonexperimental setting with participants observed in a natural environment with all the normal every day hassles. The items in the questionnaire concerning the common infections cover representative symptoms for common cold, flu-like illness and gastroenteritis. However, self-reports of gastroenteritis may also include reports of gastrointestinal disturbances in addition to actual infections, which are common complaints among shift workers. We are aware of the fact that self-reported illnesses 
may lead to under or over reporting. A study on the comparison between self-assessed and observer-assessed presence of colds, however, has demonstrated strong convergence between self-assessments of colds and physician ratings. With regard to work schedules, selection into shift work and outflow of less healthy shift workers moving from shift to daytime work might lead to an underestimation of the effects of shift work. ${ }^{19.23}$

Future studies could aim at the incidence of common infections among employees in different work schedules. Furthermore, it might be relevant to study effects of the direction of shift rotation in relation to the occurrence of infections, because it is argued that systems with a forward rotation may result in fewer problems for the shift worker than systems with a backward rotation. ${ }^{61} \mathrm{~A}$ forward rotating system is considered to be healthier because in the absence of external cues the sleep-wake and other circadian rhythms run with a period of approximately 25 hours so sleep occurs later and later. ${ }^{61-62}$

In summary, the present study showed that shift work is associated with a higher prevalence of common cold, flu-like illness and gastroenteritis compared to day work. Shift work was further associated with differences in health, health behavior, sleep, fatigue and perceived job characteristics, which constitute factors that should be taken into account in future studies examining the relationship between work schedules and health outcomes. More insight in these factors can be a starting point for interventions, when it is not feasible to change work schedules.

\section{Acknowledgements}

The Maastricht Cohort Study is part of the Netherlands concerted research action on "Fatigue at Work" granted by the Netherlands Organization for Scientific Research. This study was supported by grants from the Netherlands Organization for Scientific Research (NWO grants no. 580-02.254 and no. 580-02.201). The authors would like to thark LGPM van Amelsvoort, PhD, for his valuable advice concerning the statistical analyses.

\section{References}

1. Feeney $A$, North F, Head J, Canner $R$. Marmot M. Socioeconomic and sex differentials in reason for sickness absence from the Whitehall II study, Occup Environ Med 1998:55:91-98

2. Graham NM, Douglas RM, Ryan P. Stress and acute respiratory infection. Am J Epidemiol $1986 ; 124(3): 389-401$

3. Cobb JM. Steptoe A. Psychosocial stress and susceptibility to upper respiratory tract illness in an aduit population sample. Psychosom Med 1996,58(5):404-12.

4. Cohen S, Tyrrell DA, Smith A.P. Psychological stress and susceptibility to the common cold. N Engl J Med 1991,325(9):606-12.

5. Cohen S, Frank E, Doyle WJ, Skoner DP, Rabin BS, Gwaltney JM, Jr. Types of stressors that increase susceptibility to the common cold in healthy adults. Health Psychol 1998;:7(3):214. 23. 
6. Takkouche B, Regueira C, Gestal Otero JJ. A cohort study of stress and the common cold. Epidemiology 2001; $12(3): 345-9$

7. Clover RD, Abell T, Becker LA, Crawford S, Ramsey CN, Jir. Family functioning and stress as predictors of influenza Binfection. J Fam Pract $1989,28(5)-535-9$.

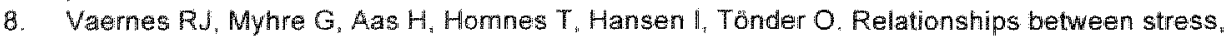
psychological factors, healh, and immune levels among military aviators. Work Stress 199: $:$ ol $5(1): 5-16$

9. Endresen I W. Elertsen B, Endresen C, Hjeimen AM, Matre R, Ursin H. Stress at work and psychological and immunological parameters in a group of Norwegian fiemale bank employees. Work Stress $1991,5(3): 217-27$.

10. Ursin H. Mykletun $R$, Tönder $O$, et al. Psychological stress-factors and concentrations of immunoglobulins and complement components in humans. Scand J Psychol 1984:25(4):340-7.

11. Mohren DCL, Swaen GMH, Borm PJA, Bast A, Galama JMD. Psychological job demands as a risk factor for common cold in a Dulch working population. J Psychosom Res 2001;50:21-7.

12. Costa $G$. The impact of shift and night work on health. Appl Ergon 1996,27/1),9-16.

13. Smith L. Macdonald I. Folkard $S$, Tucker $P$. Industrial shift systems. Appl Ergon $1998 ; 29(4): 273: 80$

14. Akerstedt T. Psychological and psychophysiological effects of shift work. Scand J Work Environ Health 1990:16 Suppl 1:67-73.

15. Harm M, Tenkanen L, Sjöblom T, Alikoski T, Heinsalmi P. Combined effects of shift work and life-style on the prevalence of insommia, sleep deprivation and daytime sleepiness. Scand $\downarrow$ Work Envirom Health 1998;24(4):300-7.

16. Bohlle P, Tilley Av. The impact of night work on psychological well-being. Ergonomics $1989,32(9): 1089,99$

17. Monk TH, Folkard S. Making shift work tolerable. London/Washington: Taylor \& Francis: 1992

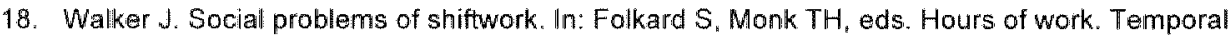
factors in work scheduling. Mew York: John Wiley \& Sons; 1985. p. 211-25.

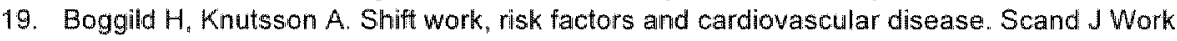
Environ Health 1999:25(2):85-99

20. Knutsson A, Akersitedt T, Jonsson BG, Orth-Gomer K. Increased risk of ischaemic heart disease in shift workers. Lancet 1986;8498(2):89-92.

21. Tenkamen L, Sjoblom T, Kalimo R, Alikosk T, Härmä M. Shift work, occupation and coronary

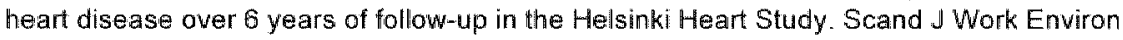
Health $1997 ; 23(4): 257-65$

22. Kristensen TS. Cardiovascular diseases and the work environment. A critical review of the epidemiologic literature on nonchemical factors. Scand J Work Environ Health $1989 ; 15(3): 165$ 79.

23. Van Amelsvoort LPGM. Cardiovascular risk profile in shift workers. Cardiac control, biological and lifestyle risk factors. Wageningen: Wageningen University; 2000.

24. Gordon NP, Cleary PD, Parker CE, Czeisler C.A. The prevalence and health impact of shiftwork. Am J Pulblic Health 1986;76(10):1225-8.

25. Harrington JM. Shift work and health. A critical review of the literature on working hours Ann Acad Med Singap 1994:23(5):699-705.

26. Curti R, Radice L, Cesana GC, Zanettui R, Grieco A. Work stress and immune system: lymphocyte reactions during rotating shift work. Preliminary results. Med Lav 1982;73,6;:564-9.

27. Kabayashi F, Furul H, Akamatsu $Y$, Watanabe $T$, Horibe $H$. Changes in psychophysiological punctions during night shift in nurses. Influence of changing from a full-dlay to a half-day work shift before might duty, Int Arch Occup Environ Health 1997;69(2):83-90.

28. Brown $\mathbb{R}$. Pang G. Husband AJ, King MG. Suppression of immumity to influenza virus infection in the respiratory tfact following sleep disturbance. Reg Immunol 1989;2(5):321-5.

29. Regestein QR. Monk TH. Is the poor sleep of shift workers a disorder? Am al Psychiatry $1991 ; 148(11): 1487-93$

30. Cohen S, Doyle WJ, Skoner DP, Rabin BS, Gwaltney JM, Jr. Social ties and susceptibility to the common cold. JAMA 1997:277(24):1940-4 
31. Mohren DCL, Swaen GMH, Kant IJ, Borm PJA, Galama JMD Associations between common infections and fatigue in a Dutch working populatiom: Results of the Maastricht Cohort Study on Fatigue at Work. Eur $\mathbb{E}$ Epidemiol 2002 (in press).

32. Kiecolt Glaser JK, Glaser R. Methodological issues in behavioral immunology research with humans. Brain Behav Immun 1988;2(1):67-78.

33. Nieman DC. Exercise, upper respitatory tract infection, and the immune system. Med Sci Sports Exerc 1994:26(2):128-39.

34. Cohen S, Tyrrell DA, Russell MA, Jarvis MJ, Smith AP. Smoking, alcohol consumption, and susceptibility to the common cold. Am J Public Health 1993;83(9):1277-83.

35. Boggild H, Burr H, Tuchsen F, Jeppesen HJ. Work environment of Danish shift and day workers. Scand J Work Environ Health 2001;27(2):97-105.

36. Jansen NWH Kant IJ, Nijhuis FJN, Wan den Brand PA. Work schedules as risk factors for need for recovery and fatigue: Results from the Maastricht Cohort Study after one year followup. Shiftwork International Newsletter 2001;18(1):52.

37. Jansen $N W_{\text {, Kant }} \| \mathrm{J}$. Need for recovery related to working time arrangements: results from the Maastricht Cohort Study on fatigue at work. Int J Behav Med 2000;7 Suppl. 3:S9.

38. Parkes KR. Shiftwork, job type, and the work environment as joint predictors of health-related outcomes. J Occup Health Psychol 1999;4(3):256-68.

39. Beurskens AJ, Bültmann U, Kant IJ, Vercoulen JH, Bleijenberg G, Swaen GM. Fatigue among working people: validity of a questionnaire measure. Occup Environ Med 2000,57(5):353-7.

40. Kant IJ, Beurskens AJHM, Schröer CAP, et all. De Maastrichtse Cohort Studie naar langdurige psychische vermoeidheid in de arbeidssituatie [The Maastricht Cohort Study on fatigue at work]. TBV 2000;8(8):226-32.

41. Bültmann U, Kant $\|$, Kasl $S$, Beurskens A, Van den Brandt P. Fatigue and psychological distress in the working population: Psychometrics, prevalence, and correlates. J Psychosom Res 2002;52(6):445-52.

42. CBS. Standaard Beroepenclassificatie 4992 [The Netherlands Standard Classification of Occupations 1992]. "s-Graventhage: SDU/uitgewerij; 1993.

43. Houtman I. Reliability and validity of the Dutch version of the Karasek Job Content Questionnaire. In: NIOSH/APA conference on Stress, Work, and Health. Washington DC: APA: 1995.

44. Karasek RA. The Jab Content Questionnaire and User's Guide (version 1.1). Los Angeles: Department of Industrial and Systems Engineering. University of Southern California; 1985

45. Van Veldhoven $M$. Meijman TF. Het meten van psychosociale arbeidsbelasting met een vragenlijst: de vragenlijst beleving en beoordeling van de arbeid (VBBA) The measurement of psychosocial job demands with a questionnaire (VBBA)]. Arnsterdam: NIA; 1994.

46. Gründemann RWW, Smulders PWG. De Winter CR. Handleiding Vragenlijst Arbeid en Gezondheid [Manual, Questionnaire on work and health]. Lisse: Swets \& Zeillinger; 1993

47. Vercoulen $J H$, Swanink CM, Fennis JF, Galama UM, Van der Meer JW, Bleilenberg $\mathrm{G}$. Dimensional assessment of chronic fatigue syndrome. J Psychosom Res $1994 ; 38$ (5);383-92

48. Bülmann U, De Vries M, Beurskens AJHM, Blejenberg G, Vercoulen JHMM, Kant IJ. Measurement of prolonged fatigue at work in the Mastricht Cohort Study: Determination of a cutoff point. I Occup Health Pisychol 2000;5(4):411-6.

49. Totterdell P. Speiten E, Smith L. Barton J, Fokard S. Recovery from work shifts" How long does it take? J Appl Psychol $1995 ; 80(1) 43-57$.

50. Knauth $P$. The design of shift systems. Ergonomics $1993 ; 36(1-3): 15-28$.

51. Knauth P. Designing better shift systems. Appl Ergon 1996; Voll 27(1):39-44.

52. Endresen $1 M$, Vaernes R, Ursim $H$. Tönder $O$. Psychological stress-factors and concentration of immunoglobulins and complement componemts in Norwegian nurses. Work Stress 1987,1:365 76

53. Kawakami N, Tanigawa T, Araki $S_{\text {" }}$ et al. Effects of job strain on helper-inducer (CD4+CD29+) and suppressor-inducer (CD4+CD45RA+) T cells in Japanese blue-collar workers. Psychother Psychosom 1997:66(4):192-8.

54. Akerstedt T. Is there an optimal sleep-wake pattern in shift work? Scand W Work Erwiron Health 1998;24 Supp. 3:18-27. 
55. Ruterifranz J, Colquhoun WP. Knauth $P$. Ghata JN. Biomedical and psychosocial aspects of shift work. A review. Scand J Work Environ Heath $1977,3(4): 165-82$.

56. Buhmam U, Kant J. Schrör CAP. Kasl SV. The relationship between psychosocial work characteristics and fatigue and psychological distress. Int Arch Occup Environ Heath 2002 ; $75.259-66$.

57. Toth LA, Regh JE. Eftects of sleep deprivation and other stressors on the immune and inflammatory responses of influtenza-infected mice. Life Sci 1998;63(8);01-9.

58. Toth LA. Sleep. sleep deprivation and infectious disease Studies in amimals. Adw Neuroimmunol 1995,5:79-92.

59. Moldofsky H. Sleep and the immune system. Int Immunopharmac 1995;17(8):649-54.

60. Macintyre $S$, Pritchard $C$. Comparisons between the selfmassessed and obsierver-assessed presence and sewerity of colds. Soc Sci Med 1989;29(11):1243-8.

61. Barton J, Folkard S. Advancing versuls delaying shift systems. Ergonomics 1993;36(1-3):59-64.

62. Van Amelswoor LPGM, Schouten EG, Maan AC, Swenne KA, Kok FJ. 24uHour heart rate variabilty in shift workers: Impact of shift schedule. J Occup Health $2001,43: 32-8$. 


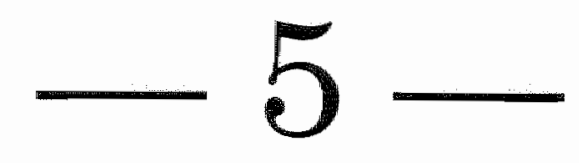

\title{
Associations between infections and fatigue in a Dutch working population: Results of the Maastricht Cohort Study on Fatigue at Work
}

\author{
Danielle CL Mohren" \\ Gerard MH Swaen' \\ IJmert Kant \\ Paul JA Borm² \\ Jochem MD Galama
}

\section{Abstract}

The relationship between fatigue and common infections was further explored, as part of a three year prospective cohort study on fatigue at work. The current study is based on seven successive questionnaires, covering the first two years of follow-up. The overall response at baseline was $45 \%(n=12,140)$. On T1 $10,592(87.2 \%$ compared to baseline response) employees returned the questionnaire. For T2, T3, T4, T5 and T6, 10,270 $(84.6 \%), 9655(79.5 \%), 8956(73.8 \%), 8692(71.6 \%)$ and $8070(66.5 \%)$ employees respectively returned the questionnaire. Self-administered questionnaires were used to determine the level of fatigue (Checklist Individual Strength) and the occurrence of common cold, flu-like illness and gastroenteritis. Regression analysis using Generalized Estimated Equations (GEE) were used for data analysis. We found a cross-sectional relationship between fatigue and the infections flu-like-illness and gastroenteritis, and a longitudinal relationship between an infection as a predictor of fatigue. For fatigue as a predictor of an infection, we found odds ratios (ORs) of 1.35 (Confidence interval (CI) 1.28-1.42) for flu-like illness and 1.33 (Cl 1.25-1.42) for gastroenteritis. The highest incidence of infections was found among employees who reported high fatigue levels on two successive occasions. The increased incidence of infections, is regarded as a substantial effect of fatigue because it is associated with significant absenteeism from work and leads to discomfort.

\footnotetext{
"Department of Epidemiology, Maastricht University, Maastricht, The Netherlanis

${ }^{2}$ Department of Fibre \& Particle Toxicology, Medical Institute for Environmental Hygiene,

Düsseldorf, Germany

${ }^{3}$ Department Medical Microbiology. University Medical Center St. Radboud. Nijmegen.

The Netherlands
} 


\section{Introduction}

Fatigue has been described as a common complaint but, non-specific symptom, ${ }^{1-3}$ associated with several medical and psychiatric illnesses. ${ }^{4}$ Acute fatigue is regarded as a normal phenomenon that will disappear after a period of rest, when tasks are switched, or when particular compensation strategies are used (working at a lower pace). ${ }^{5}$ In contrast, prolonged fatigue, which is described by Fukuda ${ }^{5}$ as self-reported persistent fatigue lasting one month of longer, may be more sustained, less reversible, and not task-specific. Fatigue does not only affect the individual performance and functioning at work and at home, ${ }^{7}$ it is also a major burden for society, in terms of financial, economic, and sociological losses. ${ }^{3}$ Among working populations, fatigue results in decreased productivity and an increase in the consumption of healthcare services. ${ }^{3}$ Research has indicated that psychological factors are extremelly important risk factors for the development of fatigue: adults who suffer from depression, emotional stress, or anxiety are much more likely to feel fatigued than those who are free of any of these psychological problems. ${ }^{8}$ Other possible causes of fatigue may be work-related factors, domestic factors, individual characteristics, or health conditions such as anemia or an infection.

Special attention has been paid to the possibility that fatigue has an infective origin leading to the term postviral fatigue syndrome. ${ }^{9}$ Prospective studies have suggested that certain viral infections are risk factors for fatigue, ${ }^{10,11}$ for instance glandular fever, whether or not caused by the Epstein-Barr virus ${ }_{1}^{12}$ whereas upper respiratory tract infections (URTIs) and other common infections are not. ${ }^{9}$ it is also widely agreed that fatigue, physical weakness and depression may follow viral infections such as influenza. ${ }^{13}$ In a study of Cope et al. ${ }^{10}$ predictors of postviral fatigue were studied, and $20.1 \%$ of the participants reported fatigue preceding the symptoms of a viral illness for which they attended the general practitioner. In this study preceding fatigue was reported to be a good predictor of becoming fatigued after an infection. On the other hand, infective symptoms did not predict fatigue 6 months later. Some people think they caught a virus because they felt tired or run down, ${ }^{14}$ a belief with some scientific basis. ${ }^{15}$

To elucidate the possible relationships between fatigue and infections, we focused on three different research questions:

1. Is there a cross-sectional relationship between an infection $T$ and fatigue $T$ ?

2. Is fatigue at $T-1$ a predictor for having an infection at $T$ ?

3 . Is an infection at T-1 a predictor for feeling fatigued at $T$ ?

We expanded the second research question including previous changes in fatigue and its effect on the occurrence of infections.

As mentioned above it is possible that the relationship between fatigue and infections varies with the type of infection. Therefore it is important to investigate the strength of the relationship for different infections and corrected for potential confounding factors. Another difficulty in investigating the relationship between fatigue and infectious diseases is the high incidence of infections. People experience four or five symptomatic viral infections per year. ${ }^{9}$ So, infections occur in rapid succession, which makes it difficult to 
find out if fatigue occurs before, during or after the infection. The infections included in this study are the common cold, flu-like illness and gastroenteritis. The incidence of these infections may be influenced by a seasonal pattern, which makes it important to control for seasonal variation.

The aim of the present study was to investigate the associations between fatigue and the occurrence of common infections (common cold, flu-like illness, and gastroenteritis), in a cohort of Dutch employees. The potential associations were investigated using the framework of the Maastricht Cohort Study on "Fatigue at Work". This is a study with a longitudinal setting using self-administered questionnaires. This cohort study surveys a large heterogeneous population of employees from different companies and organizations and follows them for three years.

\section{Methods}

\section{The questionnaire}

The participants of the Maastricht Cohort Study received nine questionnaires at fourmonthly intervals, and a total observation period of three years (1998-2001). During the three years of follow-up, respondents received annually one extensive and two short questionnaires, which were sent directly from Maastricht University to the employees home address. The results of the present study are based on the first seven questionnaires, covering the first two years of the study. In the baseline questionnaire (TO), the fourth (T3) and seventh (T6), exposures (work-related factors, individual characteristics, domestic and social factors) and outcomes (fatigue, need for recovery, burnout, etc.) were measured on an individual level using self-administered questionnaires. In the second (T1), third (T2) fifth (T4) and sixth (T5) (short) questionnaires, mostly outcomes were measured. Datta concerning fatigue and infections were measured in all seven questionnaires.

\section{The study population}

At baseline the Maastricht Cohort Study surveyed a large heterogeneous population of employees working in 45 different companies and organizations and followed this group for three years. ${ }^{716}$ A total of 12,161 employees completed the baseline questionnaire. Written consent was obtained from all participants. The overall response was $45 \%$. A non-response analysis was performed at baseline. The main reason for non-response was: "no time to fill out the questionnaire" (30\%), followed by "nothing will be done with the results of the study" (18\%), "not interested in the study object" $(10 \%)$, "sensitive information will be exposed to employer" (10\%), and "lost questionnaire of forgotten about it" $(10 \%)$. No significant differences were found in sociodemographic characteristics and general health between responders and non-responders. Nonresponders reported less fatigue complaints (42.0\% vs. $55.0 \%, x^{2}=11.10, P<0.05$ ) difficulties in work (16.5\% vs. $25.7 \%, x^{2}=7.75, P<0.05$ ), and sick leave $(21.3 \%$ vs. $39.1 \%$, $\left.x^{2}=21.50, p<0.05\right)$ compared to responders. Twenty-one questionnaires were discarded because of technical reasons, ${ }^{17}$ resulting in a study population of 12,140 employees. The average age was 40.97 years ( \pm SD 8.93 ); $26.9 \%$ of the participants were women and 
$73.1 \%$ were men. On T1 10,592 (87.2\% compared to baseline response) employees returned the questionnaire. For T2, T3, T4, T5 and T6, 10,270 (84.6\%), 9655 (79.5\%), $8956(73.8 \%), 8692(71.6 \%)$ and $8070(66.5 \%)$ employees respectively retumed the questionnaire.

\section{Fatigue and infections}

To determine the lewel of fatigue, we used the Checklist Individual Strength (CIS). ${ }^{16}$ The Cis was extensively tested in the clinical setting ${ }^{18,19}$ and validated in the working population. ${ }^{\text {it }}$ It is a 20 -item self-report questionnaire measuring four aspects of fatigue in separate scales, namely subjective experience of fatigue ( 8 items, e.g." "I feel tired"), concentration (5 items, e.g., "I have trouble concentrating"), motivation (4 items, e.g." "I feel no desire to do anything"), and physical activity (3 items, e.g." "I don't do much during the day $)^{20}$. The items are scored on 7-point Likert scales. Participants were instructed to indicate how they felt during the last two weeks. Higher scores on the separate scales indicate a higher degree of fatigue, more concentration problems, reduced motivation, or less activity. A composite total score (ranging from 20 to 140) was obtained by adding the individual's scores on the four factors. Based on receiver operating characteristics analysis, a CIS-total cut-off point of $>76$ was derived for use in the working population. ${ }^{5}$ This cul-off point was established in a separate pilot study by means of defined samples with differences in fatigue levels. All those employees were considered to report a levell of fatigue indicative of being "at risk" for sickness absence or work disability, and were designated as probable fatigue cases. ${ }^{5}$ To investigate the effect of previous changes in fatigue score on the occurrence of infections, we composed a new variable. Employees having a CIS score below or equal to the cut-off point at T-2 and $T-1$ (low-low) were considered as reference group. This reference group was compared to group 1 (high at both T-2 and T-1), group 2 (high at T-2 and low at T-1), and group 3 (low at $T-2$ and high at T-1).

The occurrence of infections was determined every four months using a single dichotomous item (yes/no) for each infection separately. Three common infections: common cold, flu-like illness and gastroenteritis were inventoried as individual items in the questionnaires. A brief description of the infection was included in the question. This description mainly contained the typical symptoms of the infection. For common cold these symptoms were: clogged or running nose, a sore throat, coughing, and slight or no fever (temperature less than $38^{\circ} \mathrm{C}$ ), for flu-like illness: fever (temperature $38^{\circ} \mathrm{C}$ or more), with at least four of the following six complaints, muscular pain, fatigue, sore throat, clogged or running mose, coughing, headache. For gastroenteritis these symptoms included: slight or no fever, gastritis, nausea, vomiting and/or diarrhea.

\section{Confounders}

Several potential confounders for the association between fatigue and infections were taken into consideration. These factors were age and gender, and seasonal variation since the questionnaires were administered in different seasons. 


\section{Statistical methods}

In the analysis presented in this study, fatigue scores, measured with the CIS score were dichotomized using the cut-off point of $>76$ to identify fatigued amployees. In the first analysis we investigated the association between fatigue (measured with the CIS as the dependent variable) and infections, measured cross-sectional, and corrected for age, gender, seasonal variation and the occurrence of ther infections (common cold, flu-like illness and gastroenteritis) in this period. The common infections: common cold, flu-like illness, were included in the model simultaneously. In the second analysis we investigated fatigue at $T-1$ as a predictor of an infection at $T$, corrected for the occurrence of infections at T-1, age, gender, and seasonal variation. This second research question was expanded, using changes in fatigue as a predictor of an infection at $T$. In the third analysis we investigated infections at $T-1$ as predictors of fatigue at $T$, and corrected for fatigue at T-1. Longitudinal regression analyses were conducted using Generalized Estimating Equations (GEE). ${ }^{21,22}$ GEE enables the investigator to model the simultaneous impact of covariates on the dependent variable at different time points. This dependent variable can be either dichotomous or continuous. All procedures were performed using Intercooled Stata 7.0 for Windows $98 / 95 /$ NT and SPSS 9.0 for Windows release 9.0 .0 . software.

\section{Results}

In Table 1, the results of the GEE-analysis regarding the cross-sectional relationship between fatigue and an infection (common cold, flu-like illness, and gastroenteritis), adjusted for age, gender and seasonal variation, are presented. The results show a statistically significant cross-sectional relationship between fatigue and flu-like illness and gastroenteritis. The strongest relationship was found between gastroenteritis and fatigue (OR 1.27; Cl 1.21-1.33)

Table 1 Adjusted ORs and $95 \%$ Cl regarding the cross-sectional relationship between fatigue at $T$ and infection T

\begin{tabular}{lll}
\hline & OR & \multicolumn{1}{c}{$95 \% \mathrm{Cl}$} \\
\cline { 2 - 3 } & \multicolumn{2}{c}{ ClS Total T } \\
\hline Common cold T & 1.02 & $0.99-1.06$ \\
Flu-like illness T & $1.18^{*}$ & $1.14 \% 1.23$ \\
Gastroenteritis T & $1.27^{*}$ & $1.21-11.33$ \\
\hline
\end{tabular}

Results are corrected for age, gender and seasonal variation.

CIS total T is dichotomized according to the described cult-off point ( $\mathrm{ClS}>76$ )

* $P<0.05$

Table 2 shows the results of the second research question, whether pre-existing fatigue is a predictor of an infection. The data showed that fatigue was a predictor of all three infections. Being fatigued at $T-1$ (CIS total $T-1>76$ ) preceding the infection ( $T$ ) increased the risk for flu-like illness or gastroenteritis with more than $30 \%$ at $T$, compared 
to non-fatigued employees. Having reported an infection at $T-1$ is a good predictor for reporting the same complaint at $T$. For gastroenteritis an OR of 5.05 (data not shown) was found.

Table 2 Adjusted ORs and $95 \%$ Cl regarding the longitudinal relationship between fatigue at $T-1$ and an infection at T

\begin{tabular}{|c|c|c|}
\hline & $\mathrm{OR}$ & $95 \% \mathrm{Cl}$ \\
\hline \multicolumn{3}{|l|}{ Common cold $T$} \\
\hline CIS total $T-y^{\dagger}$ & $1.13^{*}$ & $1.08-1.18$ \\
\hline \multicolumn{3}{|l|}{ Fu-like illness T } \\
\hline Cis total T-1t & $1.35^{*}$ & $1.28-1.42$ \\
\hline \multicolumn{3}{|l|}{ Gastroenteritis $T$} \\
\hline Cls total T-1 & $1.33^{*}$ & $1.25-1.42$ \\
\hline
\end{tabular}

Results corrected for seasonal variation, age, gender and the occurrence of infections at T-1.

$1 \mathrm{CIS}$ total T-1 is clichotomized according to the described cut-off point (CIS > 76)

$* 0<0.05$

We expanded the second research question by taking changes in the score of the preceding fatigue into consideration. These results are shown in Table 3 . A change in the level of fatigue between two successive time points showed to be a predictor for an infection at the next time point. Compared to the reference group (having two successive fatigue scores below or equal to the cut-off point), having prollonged fatigue $(T-2+T-1)$ increased the risk for either flu-like illness (OR 1.27; Cl 1.21-1.34) or gastroenteritis (OR $1.34 ; \mathrm{Cl} 1.25-1.43$ ) on $\mathrm{T}$ significantly. A change in fatigue score from low at $T-2$ to high at T-1 was related with an increased chance on the occurrence of a flu-like illness (OR $1.17 ; \mathrm{Cl} 1.08-1.26$ ) or gastroenteritis (OR $1.11 ; \mathrm{Cl} 1.02-1.22$ ) at $\mathrm{T}$. The effect was less pronounced than observed in the group of participants having two successive high $\mathrm{CIS}$ scores. In contrast, a switch from a high to a low CIS score was related with a clear reduction of the occurrence of infections at T. For common colld (OR 0.87; $\mathrm{Cl}$ 0.83-0.91) and flu-like illness (OR $0.79 ; \mathrm{Cl} 0.74-0.85$ ) this effect was significant. 
Table 3 Adjusted ORs and 95\% Cl regarding the longludinal relationship between changes in fatigue $(T-2, T-1)$ and an infection at $T$

\begin{tabular}{lll}
\hline & OR & $95 \% \mathrm{Cl}$ \\
\hline Common cold & & \\
CIS high T-2high T-1 & 1.04 & $1.00-1.09$ \\
CIS high T-2/low T-1 & $0.87^{*}$ & $0.83-0.91$ \\
CIS low T-2/high T-1 & 1.05 & $0.99-1.11$ \\
Flu-iike illness & & \\
CIS high T-2high T-1 & $1.27^{*}$ & $1.21-1.34$ \\
CIS high T-2/low T-1 & $0.79^{*}$ & $0.74-0.85$ \\
CIS low T-2high T-1 & $1.17^{*}$ & $1.08-1.26$ \\
Gastroenterits & & \\
CIS high T-2/high T-1 & $1.34^{*}$ & $1.25-1.43$ \\
CIS high T-2/low T-1 & 0.96 & $0.89-1.04$ \\
CIS low T-2high T-1 & $1.11^{*}$ & $1.02-1.22$ \\
\hline
\end{tabular}

Changes in CIS compared to reference group CIS low T-2llow T-1. Results corrected for seasonal wariation, age, gender and the occurrence of infections at $T$ $* P<0.05$

Table 4 shows the results of the relationship of infections at T-1 and fatigue at T. Flu-like illmess and gastroenteritis at $T-1$ caused an increase in fatigue at $T$ measured four months later. The largest effect was found for gastroenteritis (OR 1.14; $\mathrm{Cl} 1.07-1.21$ ). The found effects were less pronounced compared to the strength of the cross-sectional relationship between fatigue and infections and the relationship between fatigue as a predictor of infections.

Table 4 Adjusted ORs and $95 \% \mathrm{Cl}$ regarding the relationship between an infection at $\mathrm{T}-1$ and fatigue al $\mathrm{T}$

\begin{tabular}{|c|c|c|}
\hline & OR & $95 \% \mathrm{Cl}$ \\
\hline $\begin{array}{l}\text { CIS Tolal TI } \\
\text { common cold } T-1\end{array}$ & 1.02 & $0.98-1.06$ \\
\hline $\begin{array}{l}\text { CIS Total Tt } \\
\text { flu-fike illness T-1 }\end{array}$ & $1.13^{*}$ & $1.07-1.18$ \\
\hline $\begin{array}{l}\text { CIS Total Tt } \\
\quad \text { gastroenteritis T-1 }\end{array}$ & $1.14^{*}$ & $1.07-1.21$ \\
\hline
\end{tabular}

Results corrected for seasonal variation, age, gender and CIS total at T-11 (continuous). T CIS total T is dichotomized according to the described cut-off point (CIS $>76$ )

* $P<0.05$ 


\section{Discussion}

In this study we focused on three research questions conceming the relationship between fatigue and common infections. First, we found as others did before, that fatigue is a frequent symptom during infections. For flu-like illness and gastroenteritis we found a significant association with fatigue, which primarily results from the host immune response to the pathogen.

A second question we wanted to address was the role of fatigue preceding a viral illness. We found that preceding fatigue was significantly related with the occurrence of common infections. The largest effects were found for flu-like illness (OR 1.35; Cl 1.28-1.42) and gastroenteritis (OR 1.33; $\mathrm{Cl} 1.25-1.42$ ). In a cross-sectional study reported elsewhere, ${ }^{23}$ we reported a cross-sectional relationship between psychological job demands and common cold. Another prospective study, using the same cohort data, showed that psychosocial work characteristics were significant predictors for the onset of fatigue during one year follow-up in the working population. ${ }^{24}$ It may therefore be possible that fatigue acts as a intermediate factor between work-related factors and infections. So far, the relationship between preceding fatigue and infections has only been investigated in a few studies. In a study of Cope et al. ${ }^{10}$ on the effect of viral illness on the accurrence of fatigue, fatigue was reported as a cause for the viral illness by 54 of the 618 participating subjects. In another study by Cope et al., ${ }^{14}$ examining the beliefs of people about viruses, it was found that those presenting infective symptoms scored significantly higher on the following item: "I get viruses if I am run down or under stress" than other participants. In a study of Simith et al. ${ }^{25}$ it was found that chronic fatigue syndrome patients report more upper respiratory tact illnesses and greater symptom severity. Evidence has found that chronic fatigue syndrome patients have lower natural killer cell activity and low production of interferon gamma and interleukin-2. ${ }^{26}$ Although chronic fatigue syndrome patients, suffer from prolonged disabling fatigue, a comparable mechanism might be found in our fatigued employees causing increased susceptibility for common infections. When employees have sufficient time to recover from all the strains in their work and private situation before starting a new workday, the immune system remains less affected or unaffected. When demands exceed employees abilities, they may get run down which may increase their susceptibility to infections. The confrontation with a stressful event provokes a sympathoadrenal reaction in human beings. ${ }^{27}$ Sustained activation after work, known as spillover or incomplete unwinding. has been related to self-reported psychosomatic complaints. ${ }^{27}$

It is possible that people reporting a high level of fatigue, will experience more, or more severe symptoms during an infection or focus on bodily sensations, which make that they can recollect the infection in a past period when filling in questionnaires. The second research question in which the effect of fatigue preceding an infection was studied, was expanded by analysis of the effect of changes in preceding fatigue scores. It was found that employees reporting a high levell of fatigue during two successive periods of four months scored more infections in the following period compared to the reference group. In our study a thigh level of fatigue during two successive periods is comparable to a fatigue period of at least four and a half months, and according to 
Fukuda et al. ${ }^{6}$ is called prolonged fatigue. An increased infection rate is in accordance with the hypothesis that overachievement affects the immune system and makes people more susceptible to infections. When the level of fatigue decreased after a period of high fatigue, the incidence of infections decreased to below that in a control group with constant low fatigue scores (Table 3). We did not investigate the reason for this change in fatigue, perhaps changes in work-related factors or personal factors, or having a vacation in the specific period, changed the level of fatigue.

Studying the role of common infections as a risk factor for fatigue in our third research question, we found that fatigue can last for months, even after common respiratory or gastrointestinal infections. We measured a difference in fatigue level even after four months ( $T$ ) between employees reporting flu-like illness or gastroenteritis at $T-1$ and employees free of these infections. These effects were statistically significant though not very large, and also smaller than the cross-sectional effects. In an editorial of White ${ }^{28}$ it was mentioned that it was unlikely that common upper respiratory tract infections trigger chronic fatigue syndrome, and the significant but weak relationship between common viral infections and fatigue six months later may be unrelated to the virus itself. This fatigue may be caused by a patient's consequent adaptation, which may be mediated by changles in sleep pattern, physical deconditioning, and endocrine and immune systems, all of which may interact in a vicious circle. ${ }^{28}$ Also Cope et al ${ }^{10}$ attributed chronic severe fatigue not to features of the viral illness but to symptom-attributional style and dactor behavior. Other studies report of fatigue after an infection when it concerns more severe infections like hepatitis, ${ }^{29}$ infectious mononucleosis ${ }^{30}$ and aseptic meningitis. ${ }^{31,32}$ From our study however, we conclude that even common infections are followed by a prolonged but minor increase in fatigue levels. A problem when studying the causal relationship between common infections and fatigue is the fact that adults on average experience four symptomatic illnesses per year. It should therefore be easy to incorrectly attribute fatigue symptoms to a viral infection since they occur in temporal sequence even though no such link exists. ${ }^{33}$

Another point which applies to all three research questions is the use of questionnaires in determining the presence of an infection. The occurrence of common infections in our study population was determined by using self-reported illnesses. It is possible that selfreponted illnesses reflect influences of stress, cognitive processes, and self perceptions that are not associated with an infectious disease. ${ }^{34}$ lin this respect the potential underlying effects of negative affectivity on the self-report nature of our measures have to be recognized. ${ }^{35}$ Individuals high on negative affectivity may perceive their enwironment more neglatively, thereby creating spurious associations between fatigue and infections. In our longitudinal analysis, we corrected for baseline values of the outcome valuable, reducing the possible influence of negative affectivity. ${ }^{24}$ We are aware of the fact that using self-reported illiness may lead to over or under reporting. Selfreports can be used to assess infectious illnesses, but the validity of self-reported health data has been questioned because of their correlation with psychological distress. ${ }^{36}$ The argument against using self-reported health data assumes that psychological distress leads to a spurious over reporting of symptoms. However self-report methods that focus on very specific, well-operationalized symptoms show reliable associations with 
physicians' diagnosis. However it should be clear that it is practically impossible to clinically monitor a large cohort like this, during a two-year period. Undoubtedly some of those judged to have a viral illness would not have shown evidence of infection by serology or culture, but we can also assume that there would be participants with a symptom-less viral infection. ${ }^{10}$ Previous research has demonstrated strong convergence between self-assessments of colds and physician ratings. ${ }^{37}$ Congruence between interview data and physician diagnoses demonstrated excellent agreement regarding the presence or absence of an infection. ${ }^{38}$

An overall response rate of $45 \%$ at baseline was reasonable for a survey in the working population, though a potential biasing of the results relative to a selective participation of employees cannot be ruled out. The response rate at follow-up was not affected by selective non-response from different sectors, trades and companies participating in the Maastricht Cohort Study. ${ }^{24}$ This prospective cohort study starting with more than 12,000 employees gave us the opportunity to study the complex relationship between infections and fatigue. Although we did not find very large effects, for common infections like common cold, flu-like illness and gastroenteritis, we regard an increase in the incidence of infections of more than $30 \%$ as substantial, since these infections have a high prevalence. Risk factors in the work environment for fatigue, should be evaluated to find out if changes in these factors can reduce the incidence of infections.

\section{Acknowledgements}

The present study, (NWO grant no. 580-02.254), is part of the Maastricht Cohort Study on Fatigue at Work. The Maastricht Cohort Study participates in the Netherlands concerted research on "Fatigue at Work" granted by the Netherlands Organisation for Scientific Research (NWO).

\section{References}

1. David A, Pelosi A, McDonald E, Stephens D, Ledger D, Rathbone $R$, et al. Thred, weak, or in need of rest: fatigue among general practice attenders. BM $\Downarrow 1990 ; 301(6762): 11992202$

2. de Rijk AE, Sichreurs KM. Bensing JM. What is behind "l'm so tired"? Fatigue experiences and their relations to the quality and quantity of external stimulation. $\downarrow$ Psychosom Res $1999 \cdot 47(6) 509-23$

3. Tiesinga LJ, Dassen TW, Halfens Ru. Fatigue: a summary of the definitions, dimensions, and indicators. Nurs Diagn 1996;7(2):51-62.

4. Addington AM, Gallo JJ, Ford DE, Eaton WW. Epidemiology of unexplained fatigue and major depression in the community: The Baltimore ECA follow-up, 1984-1994. Psychol Med $2001: 3 \pi(6): 1037 \cdot 44$.

5. Bültmann U, De Vries M, Beurskens AJHM, Bleijenberg G, Vercoulten JHMM, Kant IJ. Measurement of prolonged fatigue at work in the Maastrich Cohor Study: Determination of a: cutoff pointt. 3 Occup Health Psychol 2000;5(4):411-6

6. Fukuda K, Straus. SE. Hickie I, Sharpe M, Dobbins J, Komarroff A, et al. The chronic fatigue syndrome: A comprehensive approach to its definition and study. Ann Intern Mled $1994 ; 121: 953-9$. 
7. Kant 1J, Beurskens AJHM, Schröer CAP, Nithuis FJN, Van Sehayck CP, Wan den Elzen HJ, et al. De Maastrichtse Cohort Studie naar langdurige psychische vermoeidheid in de: arbeidssituatie [The Maastricht Cohort Study on fatigue at work]. TBV 2000;8(8) 226-32.

8. Chen MK. The epidemiology of selfperceived fatigue among aduts Prev Med 1986;15(1):74 81 .

9. Wessely S, Chalder T, Hirsch S, Pawlikowska T. Wallace P. Wright DJ. Postinfectious fatiglue: prospective cohort study in primary care [see comments]. Lancet 1995;345(8961):1333-8.

10. Cope $H_{\text {}}$ David A, Pelosi A, Mann A. Predictors of chronic "postviral" fatigue. Lancet $1994 ; 344$ (8926):864-8.

11. Hotopf M, Noah N, Wessely S. Chronic fatigue and minor psychiatric morbidity after viral meningitis: a controlled study. J Neurol Neunosurg Psychiatry 1996;60(5):504-9.

12. White PD, Thomas JM, Amess J, Grower SA, Kangro HO, Clare AW. The existence of a fatigue syndrome after glandular fever. Psychol Med 1995;25(5);907-16.

13. Hall SR, Smith AP. Behavioural effects of infectious mononucleosis. Neuropsychobiology $1996: 33(4): 202-9$

14. Cope H, David A, Mann A. "Maybe it"s a virus?: beliefs about viruses, symptom attributional style and psychological health. J Psychosom Res 1994:38(2):89-98.

15. Cohen $S$, Tyrrell DA, Smith AP. Negative life events, perceived stress, negative affect, and susceptibility to the common cold. J Pers Sac Psychol 1993;64(1):131-40.

16. Beurskens Aw, Bultmann U, Kant IJ, Vercoulen JH, Bleijenberg G, Swaen GM. Fatigue among working people: validity of a questionnaire measure. Occup Environ Med 2000;57(5):353-7.

17. Bültmann U, Kant $\mid J_{\text {uKas }}$ SV, Beurskens AJHM, Van den Brandt PA. Fatigue and psychological distress in the working population: Psychometrics, prevalence, and correlates. Psychosom Res 2002,52(6):445-52.

18. Vercoulen $\mathrm{JH}_{3}$, Hommes $\mathrm{OR}$, Swanink $\mathrm{CM}$, Jongen PJ, Fennis JF, Galama JM, et al. The measurement of fatigue in patients with multiple sclerosis. A multidimensional comparison with patients with chronic fatigue syndrome and healthy subjects. Arch Neurol 1996,53(7),642-9

19. Vercoullen $\mathrm{JH}$, Swanink CM. Fenmis JF, Galama JM, van der Meer JW, Bleijenberg $G$. Prognosis in chronic fatigue syndrome: a prospective study on the natural course. I Neurot Neurosurg Psychiatry 1996;60(5):489-94.

20. Vercoulen $\mathrm{JH}$, Swanink CM, Fennis JF, Galama JM, van der Meer JW, Bleijenberg $\mathrm{G}_{\text {. }}$ Dimensional assessment of chronic fatigue syndrome. J Psychosom Res 1994,38(5):383-92.

21. Liang $K-Y, Z$ eger SL. Longitudinal analysis using generalized linear models. Biometrika 1986;73:13-22.

22. Zeger SL, Liang KY. Longitudinal data analysis for discrete and continuous outcames. Biometrics 1986,42(1):121-30.

23. Mohren DCL, Swaren GMH, Borm PJA, Bast A, Galama JMD. Psychologicall Job Demands a as a risk factor for common cold in a Dutch working population. J Psychosom Res 2001;50:21-7.

24. Bültmann U, Kant IJ, Van den Brandt PA, KasI SV. Psychosocial work characteristics as risk factors for the onset of fatigue and psychologicall distress: Prospective results from the Maastricht Cohort Study. Psychol Med 2002;32.333-45.

25. Smith $A$, Thomas M. Borysiewicz L, Llewelyn M. Chronic fatigue syndrome and susceptibility to upper respiratory tract illness. Br J Health Psychol 1999; 4(Pt 4):327-35.

26. Straus $S$. Chronic fatigue symdrame. In: Rosen $S$, editor. Medicime for the public. Bethesda: MD: National Institute of Health; 1996. p. 1-50.

27. Kuiper Jl, Van der Beek AJ, Meiman TF. Psychosomatic complaints and umwinding of sympathoadrenal activation after work. Stress Med 1998;14(1):7-12.

28. White PD. The relationship between infection and fatigue [editoriall. J Psychosom Res $1997,43(4): 345-50$

29. Benjamin JE, Hoyt RC. Disability following postvaccinal (yellow fever) heaptitis: a study of 200 patients manifesting delayed convalescence. JAMA 1945:128:319-24.

30. Lambore $S$, MoSherry $J$, Kraus AS. Acute and chronic symptoms of mononucleosis. $I F$ am Pract $1991 ; 33(1) ; 33-7$. 
31. Lepow M. Coyne $\mathbb{N}$, Thompson LB, Carver DH: Robbins FC. A elinical, epidemiological and laboratory inwestigation of aseptic meningitis during the four-year period, 1955-1958. II. The clinical discase and its sequelae. N Eng J Med 1962;266:1188.93.

32. Muller $R$, Nylander I, Larsson LE, Widen L, Frankenhaeuser M. Sequelae of primary aseptic meningomencepalitis. A clinical, socionedical, ellectroencephalogiraphic and psychological study. Acta Psychiatr Neurol Scand 1958;33 Suppl 126:1-115.

33. Holopf MH, Wessely S. Viruses, neurosis and fatigue [see comments] I Psychosom Res 1994:38(6):499-514.

34. Cohen S. Tyrrell DA, Smith AP. Psychological stress and susceptibility to the common cold N Engl J Med 1991:325(9):606 12 .

35. Watson D, Clark LA. Wegalive aftectivity: the disposition to experience aversive emotional states. Psychol Bull 1984:96:465-90.

36. Mechanic D. The experience and reporting of common physical complaints. $J$ Health Soc Behav $1980,21(2) \cdot 146-55$.

37. Macintyre S, Pritchard C. Comparisons beween the self-assessed and observer-assessed presence and severity of colds. Soc Sci Med 1989;29(11):1243-8.

38. Orts K, Sheridan JF, Robinson Whelen S, Glaser R, Malarkey WVB, Kiecolt Glaser JK. The reliability and validity of a structured interview for the assessment of infectious illness symptoms. J Behav Med 1995;18.6) 517-29. 


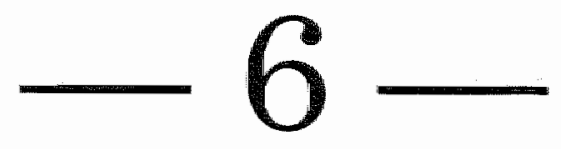

\title{
Common infections and the role of Burnout in a Dutch working population
}

\author{
Danielle CL Mohren" \\ Gerard MH Swaen ${ }^{1}$ \\ IJmert Kant ${ }^{1}$ \\ Ludovic GPM van Amelsvoort' \\ Paul JA Borm ${ }^{2}$ \\ Jochem MD Galama ${ }^{3}$
}

\begin{abstract}
Objective. To determine if burnout is a risk factor for common cold, flumlike illness, and gastroenteritis. Methods. We conducted a prospective cohort study among 12,140 employees at baseline, using three consecutive self-administered questionnaires. The Maslach Burnout Inventory General Survey (MBI-GS), was used to define employees with burnout complaints (level one) and clinical burnout (level two). The cross-sectional relationship between burnout and the occurrence of common infections was assessed at baseline, using logistic regression analysis. Survival analysis with Cox regression, was performed to study the longitudinal relationship between burnout and the subscales of the MBI-GS as risk factors for common infections. Results. For both levels of burnout an increased incidence of common infections was found at baseline. The largest effect was found for the relationship between burnout and gastroenteritis (OR 1.86; $\mathrm{Cl} 1.57-2.21$ for level one, and OR 3.59; $\mathrm{Cl} 2.09-6.17$ for level two). The longitudinal analyses showed comparable results, although less pronounced. The largest effect was again found for gastroenteritis (RR 1.55; $\mathrm{Cl} 1.28-1.86$ for level one, and RR 2.09; Cl 1.09-3.98 for level two. For flu-like illness and common cold we found smaller but significant effects at level one, but not at level two. The subscale 'Exhaustion' was found to be the strongest predictor for infections at both levels of burnout. Conclusions. This study provides evidence for bumout as a risk factor for common infections in a large heterogeneous population. Taking into account that burnout or its subscales are not primary etiological agents for these common infections, the observed effects are large.
\end{abstract}

\footnotetext{
'Department of Epidemiology, Maastricht University, Maastricht, The Netherlands

${ }^{2}$ Department of Fibre \& Particle Toxicology, Medical Institute for Environmental Hygiene,

Düsseldorf, Germany

${ }^{3}$ Department Medical Microbiology, University Medical Center St. Radboud, Nijmegen,

The Netherlands
}

Journall of Psychosomatic Resiearch; in press 


\section{Introduction}

Burnout is a work-related syndrome, which is characterized by emotional exhaustion, depersonalisation, and diminished personal accomplishment. ${ }^{1.2}$ Emotional exhaustion is the key aspect of the syndrome and refers to feelings of being over-extended and drained from one's emotional resources. Depersonalisation refers to negative, cynical, detached, and impersonal attitudes and feelings towards other people. Reduced personal accomplishment refers to a decline in one's feelings of competence and a tendency to evaluate oneself negatively, particularly regarding one's work with other people. ${ }^{3}$ Burnout has traditionally been associated with jobs in the human service sector involving intensive contact with people in need of aid. However more recently burnout is also considered a major issue in occupational health ${ }^{1}$ in other sectors. Bumout as encountered outside human services comprises three elements; Exhaustion (Ex), Cynicism (Cy) and Professional efficacy (Pe). The Maslach Burnout inventory-General Survey (MBI-GS) has been specifically developed to assess burnout outside human services. The Masiach Burnout Inventory (MBI), is universally accepted as the standard to assess Burnout. Schaufeli and Enzmann ${ }^{4}$ calculated that the MBI is used in over $90 \%$ of all published articles and dissertations. Several studies have confirmed the hypothesized three-factor study of the MBI-GS. ${ }^{3.5,6}$ Moreover, this factor structure appears to be invariant across occupational groups $s^{3,5,6}$ and cross-national.

Several job characteristics have been suggested as risk factors for bumout, as well in human services as outside this sector. There is evidence that factors like job demands, and a lack of social support, feedback and autonomy are risk factors for burnout. ${ }^{7}$ But also demographic characteristics like, age, gender, marital status, and education have been associated with the risk for burnout. Burnout has important dysfunctional ramifications, implying substantial costs for both organizations and individuals because of, for example, increases in turnover, absenteeism, reduced productivity, and consultation of human services. ${ }^{8-10}$ Freudenberger ${ }^{11}$ found that several mental complaints based on clinical observations, like exhaustion, headache, insomnia, irritability, suspicion, negativism, cynicism, frustration, and disappointment were more prevalent among burnout patients.

There have been very few studies dealing with bumout as a precursor of illness. Burnout may have a negative effect on the immune system and consequently increase the incidence of infections. In a previous study, ${ }^{12}$ using the same cohort data as the present one, we found that fatigue, measured with the Checklist Individual Strength, ${ }^{13}$ was a risk factor for common infections like common cold, flu-like illness, and gastroenteritis. ${ }^{12}$ Although the origin of fatigue can be work-related and nonwork-related, it can also have a mental, physical and biological origin. In contrast burnout, is a work-related syndrome. and caused by stressful work conditions. Until now there are only a few studies that reported associations between burnout and aspects of the immune system. Hendrix ${ }^{14}$ found a small but statistically significant correlation between emotional exhaustion and the prevalence of common cold cq. flu, in a stress-based health promotion model. Also Freudenberger ${ }^{11}$ found a relationship between burnout and increased susceptibility for common cold. In a study by Bargellini et al., ${ }^{15}$ seventy one physicians of all grades were 
recruited among different departments to a cross-sectional survey. It was found that physicians who reported high levels of personal accomplishment showed significantly higher numbers of total lymphocytes, $T$ cells (CD3), $T$ helper cells (CD4), and $T$ suppressor cells (CD8) than those who scored low levels. Nakamura et al ${ }^{16}$ studied the three components of the MBI in relation to natural killer cell activity (NKCA) and cell subsets in 42 male workers. It was found that workers with a high depersonalisation score showed a lower NKCA and a lower proportionality of CD5 $7^{+}$CD $16^{*}$ cells (natural killer cell subset, to total lymphocytes. Persistent low NK cell function has been shown to be associated with greater risk for health impairments, including infectious diseases and cancer. ${ }^{15}$ In a study of Kushnir and Melamed, ${ }^{17}$ wartime and pre-war (baseline levels) burnout and related symptomatology were compared among 162 Israeli civilians who carried on with the employment duties throughout the Gulf war. It was found that pre-war burnout was positively associated with wartime upper respiratory tract infections.

The prospective Maastricht Cohort Study was used as a framework to study the effect of two levels of burnout (clinical burnout and burnout complaints) on the susceptibility to common infections (common cold, flu-like illness, gastroenteritis) in a large heterogeneous working population. The study was performed in a longitudinal setting. Because other studies indicated that specific scales of the MBI were related to impairment of the immune system, we also studied the effects of the individual subscales of the MBI-GS (Exhaustion, Cynicism, and Professional efficacy).

\section{Methods}

\section{The questionnaire}

The participants of the Maastricht Cohort Study received nine questionnaires in total, at four-monthly intervals, and a total observation period of three years (1998-2001). Once a year the participants received a questionnaire with both exposures (work-related factors, individual characteristics, domestic and social factors) and outcomes (fatigue, need for recovery, burnout, etc.) measured on an individual level using self-administered questionnaires. The participants received a short questionnaire twice a year, measuring mainly outcomes. Burnout was only measured once a year in the extensive questionnaires. The current study is based on the data collected in the first year of study ( $T O, T 1$ and $T 2$ ).

\section{The study population}

At baseline the Maastricht Cohort Study surveyed a large heterogeneous population of employees in 687 different professions ${ }^{18}$ working in 45 different companies and organizations and followed this group for three years. ${ }^{19,20} \mathrm{~A}$ total of 12,161 employees completed the baselline questionnaire. Written consent was abtained from all participants. The overall response was $45 \%$. Twenty one questionnaires were discarded because of technical reasons, ${ }_{3}{ }^{21}$ resulting in a study population at baseline of 12,140 employees. The average age at baseline was 40.97 years $( \pm \operatorname{SD} 8.93) ; 26.9 \%$ of the participants were women and $73.1 \%$ were men. 


\section{Burnowt}

Burnout was measured with a Dutch translation of the MBI-GS. ${ }^{22}$ The Maslach Bumout inventory (MBI) was originally developed to determine burnout in human service providers. Recently, the MBI-GS was developed, a measure of bumout which can also be used in other occupations. ${ }^{23}$ This MBI-GS has three subscales that parallel the MBl: Exhaustion (Ex), Cyricism (Cy), and Professional efficacy (Pe). The exhaustion items are generic, without the MBI's emphasis on emotions and without direct reference to service recipients. The items include references to both emotional and physical fatigue. The items of the subscale cynicism reflect indifference or a distant attitude towards work itself. Professional and non-social aspects of occupational accomplishments are included, it assesses the employee's expectations of continued effectiveness at work ${ }^{3}$

All 15 items of the MBI-GS are scored on a seven-point likert scale ranging from ' 0 ' (never) to ' 6 ' (daily). According to the manual of the MBI-GS subjects scoring in the upper quartile of the Ex scale $(>2.40)$, and in the upper quartile of the Cy scale $(>2.25)$ or in the bottom quartile of the Pe scale $(<3.5)$ are labelled as subjects with burnout complaints. $^{22}$ Two levels of burnout were subject of study. Level one, at which subjects have burnout complaints and should be regarded as probable burnout cases, and level two, at which subjects should be labelled as clinical burnout, corresponding with a group of patients corresponding with the ICD-10 classification for neurasthenia. ${ }^{22}$ Subjects scoring in the 95 percentile of the Ex scale $(>4.20)$, and in the 95 percentile of the Cy scale $(>3.75)$ or in the 5 percentile of the Pe scale $(<2.33)$ are labelled as subjects with clinical burnout. Non-cases were described by using the complement of the rules to describe probable cases. Using this strict condition, we excluded several employees who already scored above the cut-off points of the subscales of the MBI-GS, but who did not yet meet other criteria for burnout, leaving a group of non-cases free of complaints.

\section{Infections}

The occurrence of infections was determined every four months. Three common infections: common cold, flu-like illness, and gastroenteritis were inventoried as individual items in the questionnaires. A brief description of the infection was included in the question. This description mainly contained the typical symptoms of the infection. For common cold these symptoms were: clogged or running nose, a sore throat, coughing, and slight or no fever (temperature less than $38^{\circ} \mathrm{C}$ ), for flu-like illness: fever (temperature $38^{\circ} \mathrm{C}$ or more), with at least four of the following six complaints, muscular pain, fatigue, sore throat, clogged or running nose, coughing, headache. For gastroenteritis these symptoms included: slight or no fever, gastritis, nausea, vomiting and/or diarrhea.

\section{Demographics and health variables}

At baseline, employees provided information on age, gender, and educational level. The presence of a longstanding disease was measured using a single dichotomous item: "Do you have a longstanding disease" (Yes/No). The participants were also asked which disease was present at baseline (using a list of 19 different diseases). This information was used to distinguish between the presence of a somatic disease and non-somatic disease. Information on depressive mood was measured using a single dichotomous item "Did you feel dejected almost every day in the past two weeks" (Yes/No). 
Information on sick leave was gathered by asking the participants if they were currently on sick leave.

\section{Statistical methods}

In the first analysis we investigated the association between burnout and either common cold "flu-like illness, or gastroenteritis cross-sectionally, and adjusted for age and gender, and additionally for the presence of a longstanding somatic illness, using logistic regression analysis. Odds ratios (ORs) and $95 \%$ confidence intervals $(95 \% \mathrm{Cl}$ ), were calculated. We used our baseline data at To, to study this relationship. Crossusectional relationships at baseline were studied for both levels of burnout.

This cross-sectional analysis was expanded by using the two levels of burnout as predictors of infections at later time-points. Separate multivariate survival analysis by the Cox regression mode ${ }^{24}$ were performed for all three infections. We excluded employees reporting an infection at baseline. We modeled the time to the first infection and calculated risk ratios (RRs) and $95 \% \mathrm{Cl}$, between burnout cases and employees free of burnout complaints at TO, and corrected for age, gender, and additionally for the presence of a longstanding somatic illness.

In the final analysis we studied the effect of the separate scales of burnout on the incidence of infections. Again multivariate survival analysis by the Cox regression model ${ }^{24}$ were performed for all three infections separately, yielding RRs and $95 \% \mathrm{Cl}$. The scores on the subscales were dichotomized for this analysis, using the same cut-off scores as for case finding. All procedures were done using SPSS for Windows, release 9.0.0. software.

\section{Results}

In Table 1, the baseline characteristics of the study population are shown. Comparing healthy employees with the groups of employees at the two levels of bumout. considerable differences in sick leave were observed. More than $20 \%$ of the clinical burnout cases was on sick leave at baseline, almost ten times more than in the group of healthy employees. Employees in the bumout groups reported to be lower educated. Employees in the clinical burnout group reported the highest prevalence of longstanding diseases. After differentiating between somatic and non-somatic disease, large differences were found for the presence of non-somatic disease between the three groups. Clinical burnout cases reported almost a 20 fold higher percentage and probable cases a nine times higher percentage, compared to the group of healthy employees. Large differences were also found for depressive mood, with a more than 16 times higher percentage reported in the clinical burnout group compared to the group of healthy employees. With respect to common infections, reported at baseline (TO), we found that the highest prevalence of infections was reported in the group of clinical 
Table 1 Baseline characteristics of study population

\begin{tabular}{|c|c|c|c|c|c|c|}
\hline \multirow[b]{2}{*}{ Age (mean, SD) } & \multicolumn{2}{|c|}{$\begin{array}{l}\text { "Healthy } \\
\text { employees" } \\
\mathrm{N}=8512\end{array}$} & \multicolumn{2}{|c|}{$\begin{array}{c}\text { Probable } \\
\text { burnout cases } \\
\text { (level one) } \\
N=1666\end{array}$} & \multicolumn{2}{|c|}{$\begin{array}{l}\text { Cunical } \\
\text { bumout cases } \\
\text { (lewel two) } \\
N=187\end{array}$} \\
\hline & 40.83 & 8.88 & 41.11 & 9.25 & 40.7 & 9.49 \\
\hline & N & $\%$ & N & $\%$ & $N$ & $\%$ \\
\hline \multicolumn{7}{|l|}{ Gender } \\
\hline Women & 2351 & 27.7 & 393 & 23.6 & 42 & 22.5 \\
\hline Men & 6147 & 723 & 1269 & 76.4 & 145 & 77.5 \\
\hline \multicolumn{7}{|l|}{ Education Level } \\
\hline Primary school & 312 & 3.8 & 114 & $7.1^{*}$ & 15 & $8.5^{*}$ \\
\hline Lower vocational education & 1180 & 14.3 & 344 & 21.4 & 43 & 24.4 \\
\hline Lower secondary school & 1018 & 123 & 231 & 14.4 & 31 & 17.6 \\
\hline Intermedialte vocational education & 2055 & 24.9 & 344 & 21.4 & 37 & 21.1 \\
\hline Upper secondary school & 719 & 8.7 & 131 & 8.2 & 15 & 8.5 \\
\hline Upper vocational education & 1988 & 24.1 & 293 & 18.2 & 24 & 13.6 \\
\hline University & 981 & 11.9 & 150 & 9.3 & 11 & 8.3 \\
\hline \multicolumn{7}{|l|}{ Presence of a longstanding disease } \\
\hline No & 6707 & 80.7 & 933 & $58.8^{*}$ & 81 & $46.3^{+}$ \\
\hline Yes & 1608 & 19.3 & 654 & 41.2 & 94 & 537 \\
\hline \multicolumn{7}{|l|}{ - Somatic disease } \\
\hline No & 6867 & 824 & 1201 & $74.5^{*}$ & 147 & 81.7 \\
\hline Yes & 1462 & 17.6 & 410 & 25.5 & 33 & 18.3 \\
\hline \multicolumn{7}{|l|}{ - Non-somatic disease } \\
\hline No & 8337 & 97.9 & 1379 & $82.8^{*}$ & 115 & $61.5^{*}$ \\
\hline Yes & 175 & 2.1 & 287 & 17.2 & 72 & 38.5 \\
\hline \multicolumn{7}{|l|}{ Currently on sick leave } \\
\hline No & 8265 & 97.1 & 1495 & $89.7^{*}$ & 147 & $78.6^{*}$ \\
\hline Yes & 247 & 2.9 & 171 & 10.3 & 40 & 21.4 \\
\hline \multicolumn{7}{|l|}{ Depressive moad } \\
\hline No & 8093 & 96.2 & 1093 & $671^{*}$ & 69 & $37.7^{\star}$ \\
\hline Yes & 320 & 3.8 & 536 & 32.9 & 114 & 62.3 \\
\hline \multicolumn{7}{|l|}{ Common cold } \\
\hline No & 4069 & 48.2 & 640 & $38.8^{*}$ & 63 & $34.1^{*}$ \\
\hline Yes & 4373 & 51.8 & 1009 & 61.2 & 122 & 65.9 \\
\hline \multicolumn{7}{|l|}{ Flu-like illness } \\
\hline No & 6616 & 78.6 & 1085 & $66.2^{*}$ & 113 & $61.4^{*}$ \\
\hline Yes & 1804 & 21.4 & 555 & 33.8 & 71 & 38.6 \\
\hline \multicolumn{7}{|l|}{ Gastroenteritis } \\
\hline No & 7530 & 89.5 & 1305 & $79.8^{*}$ & 131 & $71.2^{*}$ \\
\hline Yes & 887 & 10.5 & 331 & 20.2 & 53 & 28.8 \\
\hline
\end{tabular}

"P< 0.05 (t-test or chi-square tesl comparing "hea thy employees" with both burnout groups

A significant difference is displayed once in each categary laken together

t By "healthy employees" we mean non probable and non climical cases 
burnout cases. Comparing either probable and clinical burnout cases with healthy employees we found significant differences in occurrence of all three infections.

Table 2 shows the cross-sectionall relationship between two levels of burnout and common infections at baseline, corrected for age, gender, education level and the presence of a longstanding somatic inness. For both levels of burnout we found a significant correlation with common infections. The largest effects were found when comparing the occurrence of common infections in a group employees free of clinical burnout complaints with a group of clinical burnout cases. When comparing the different infections the largest effect was found for gastroenteritis with an adjusted $O R$ of $1.86(\mathrm{Cl}$ $1.57-2.21)$ at levell one, and an OR of $3.59(\mathrm{Cl} 2.09-6.17)$ ) at burnout level two, comparing burnout cases with employees free of burnout complaints. For gastroenteritis this difference in OR was also significant between level one and two. Additional adjustment for the presence of a longstanding somatic disease did not yield substantial differences. Since burnout cases could have already been sick prior to baseline, and since this could have jeopardized our analysis, we excluded prevalent cases at baseline and repeated the same analysis on data after one year follow-up (T3). This analysis yielded comparable results (data not shown), in the same direction and order of magnitude as the previous analysis at baseline.

Table 2 Adjusted ORs and $95 \% \mathrm{Cl}$ regarding the cross-sectional relationship between burnout and common infections at baseline for two levels of burnout

\begin{tabular}{|c|c|c|c|c|c|c|c|c|}
\hline & \multicolumn{4}{|c|}{$\begin{array}{c}\text { Probable burnout cases } \\
\text { (level one) }\end{array}$} & \multicolumn{4}{|c|}{$\begin{array}{c}\text { Clinical burnowt cases } \\
\text { (level two) }\end{array}$} \\
\hline & ORt & $95 \% \mathrm{Cl}$ & $\mathrm{OR}^{ \pm}$ & $95 \% \mathrm{Cl}$ & $\mathrm{OR}^{\dagger}$ & $95 \% \mathrm{Cl}$ & OR: & $95 \% \mathrm{Cl}$ \\
\hline Common cold & $1.45^{*}$ & $1.28-1.65$ & $1.42^{*}$ & $1.25-1.62$ & $1.91^{7}$ & $1.19-3.05$ & $1.9 t^{*}$ & $1.19 \cdot 3,05$ \\
\hline Flu-like illness & $1.75^{*}$ & $1.52-2.00$ & $1.70^{*}$ & $1.48-1.96$ & $2.18^{*}$ & $1.35-3.51$ & $2.19^{*}$ & $1.45-3.52$ \\
\hline Gastroenteritis & $1.90^{*}$ & $1.61-2.25$ & $1.86^{*}$ & $1.57-2.21$ & $3.588^{*}$ & $2.09-6.15$ & $3.598^{*}$ & $2.09 \cdot 6.17$ \\
\hline
\end{tabular}

*P<0.05

$\uparrow$ Adjusted OR, corrected for age, gender and education level

*Adjusted $\mathrm{OR}$, adiditionally corrected for longstanding somatic illness

S Significant difference between probable and clinical burnout cases

To determine if there is a causal relationship between burnout and infections it is necessary to use longitudinal data. We used a multivariate survival analysis by the Cox regression model to describe the relationship between bumout at two levels and common infections, correcting for several factors. The results of these analysis are shown in Table 3 . The effect of burnout complaints (level one) yielded results in the same directions and onder of magnitude as the cross-sectional results. Again the largest effect was found for gastroenteritis (adjusted RR $1.55 ; \mathrm{Cl} 1.28-1.86$ ). The longitudinal effect of clinical burnout on the occurrence of infections was found to be more pronounced, although the observed effects for common cold and flu-like illness were non-significant. We did not find significant differences between probable and clinical burnout cases, with respect to the incidence of infections. 
Table 3 Mutivariate surviual analysis for common iniections

\begin{tabular}{|c|c|c|c|c|c|c|c|c|}
\hline & \multicolumn{4}{|c|}{$\begin{array}{l}\text { Probable burnout cases } \\
\text { (level one) }\end{array}$} & \multicolumn{4}{|c|}{$\begin{array}{l}\text { Clinical bumout cases } \\
\text { (lewel two) }\end{array}$} \\
\hline & $\mathrm{RR}^{+}$ & $95 \% \mathrm{Cl}$ & $\mathrm{RR}^{\mathrm{i}}$ & $95 \% \mathrm{Cl}$ & $\mathrm{RR}^{\mathrm{t}}$ & $95 \% \mathrm{Cl}$ & $R R^{\ddagger}$ & $95 \% \overline{\mathrm{Cl}}$ \\
\hline Common cold & $1.17^{\mathrm{m}}$ & $1.02-1.34$ & $1.16^{x}$ & $1.01-1.33$ & 1.29 & 0.77 .2 .16 & 1.30 & 0.78 .2 .17 \\
\hline Flu-lake illness & $1.36^{*}$ & $1.16-1.57$ & $1.31^{*}$ & $1.13-4.52$ & 1.26 & $0.72 \cdot 1.68$ & 1.28 & $0.73-2.25$ \\
\hline Gastroenteritis & $1.57^{*}$ & 1.301 .89 & $1.55^{*}$ & $1.28-4.86$ & $2,08^{\text {it }}$ & $1.09-3.96$ & $2.09^{*}$ & $1.09-3.98$ \\
\hline
\end{tabular}

${ }^{*} P<0.05$

Adjusted RR, corrected for age, gender and education level

*Adjusted RR, additionally corrected for longstanding somatic illness

As described earlier, burnout is characterized by three subscales: exhaustion "cynicism and professional efficacy. The individual longitudinal effect of these subscales on the occurrence of infections is shown in Table 4. The subscales are dichotomized, according to the cut-off points used for burnout case finding of probable and clinical burnout cases.

Table 4 Adjusted OR's and 95\% Cl regarding the longitudinal relationship between subscales of burnout and common infections

\begin{tabular}{|c|c|c|c|c|c|c|c|c|c|c|c|c|}
\hline \multirow[b]{2}{*}{ Leval one } & \multicolumn{4}{|c|}{ Exhaustion } & \multicolumn{4}{|c|}{ Cynicism } & \multicolumn{4}{|c|}{ Professional efficiacy } \\
\hline & RRI & $95 \% \mathrm{Cl}$ & RRE & $95 \% \mathrm{Cl}$ & RRI & $95 \% \mathrm{Cl}$ & $\mathrm{RR}$ & $95 \%$ & RRi & $95 \% \mathrm{Cl}$ & $R R^{n}$ & $95 \% \mathrm{Cl}$ \\
\hline Common colet & $1.12^{*}$ & $1.01-1.24$ & $1.11^{*}$ & $1.00 m-1.23$ & 1.06 & $0.96-4.18$ & $\$ .06$ & $0.95 \cdot 1.18$ & $1.11^{1^{k}}$ & $1.01 \cdot 1.23$ & $4.11^{\circ}$ & $1.01-1.23$ \\
\hline Flu-Hhe illness & $1.30^{\circ}$ & $1.16 \times 1.45$ & $1.27^{*}$ & $1.14-1.42$ & $1.21^{*}$ & $1.08 \times 1.37$ & $1.19^{*}$ & $1.065-1,34$ & $1.17^{n}$ & $1.05-1.31$ & $1.16^{*}$ & $1.04-1.30$ \\
\hline Gestroenteritis & $1.50^{\circ}$ & $4.30 \times 1.73$ & $1.49^{*}$ & $1.29-1.72$ & 1.2. & $1.04-1.42$ & $124^{*}$ & 1.0341 .41 & $1.21^{*}$ & $1.04-1.40$ & $1.20^{*}$ & $1.04-1.39$ \\
\hline Level two & $\mathrm{RR} !$ & $95 \% \mathrm{Ci}$ & $\mathbb{R R}^{1}$ & $95 \% \mathrm{Cl}$ & $R R^{t}$ & $95 \% \mathrm{Cl}$ & $\mathrm{RR}$ & $95 \%$ & $\mathrm{RR}$ & $95 \% \mathrm{Cl}$ & $\mathrm{RR}^{\dagger}$ & $95 \% \mathrm{Cl}$ \\
\hline Common cold & 1.12 & $0.81 \cdot 1.55$ & 1.12 & $0.84-1.55$ & 1.22 & $0.88-1.69$ & 1.22 & $0.88-1.69$ & 1.00 & $0.72-1.38$ & 1.00 & $0.72-1.38$ \\
\hline Flu-like illness & 128 & $0.90-1.82$ & 1.25 & $0.88-1.79$ & 1.24 & $0.86-1.80$ & 125 & 0.861 .84 & 1.22 & 0.851 .84 & 4.21 & $0,85-1.74$ \\
\hline Gestroanteritis & $170^{*}$ & $1.10-2.64$ & $169^{*}$ & 1.09262 & 1.44 & 0.89 .2 .34 & 144 & 0.89234 & 1.18 & 0.72 .1 .92 & 11.18 & $0.72-1.92$ \\
\hline
\end{tabular}

Exhaustion was found to be the most important predictor for infections at level one, with significant adjusted RR of $1.11(\mathrm{Cl} 1.00-1.23)$ and $1.27(\mathrm{Cl} 1,14-1.42)$ and 1.49 (Cl 1.291.72) for common colld, flu-like illness, and gastroenteritis respectively. Slightiy lower (but still significant) RRs (except for common cold) were found for Cynicism on infections. Also Professional efficacy had significant effects on the occurrence of all three infections. For level two, the RRs were slightly higher compared to level one, for the effect of exhaustion on flu-like illness and gastroenteritis. The effect of cynicism was higher compared to level one, but non-significant for all three infections. The effect of Professional efficacy was equal or even slightly lower at level two, and for all three infections non-significant. There were no significant differences found between probable and clinical burnout cases for any of the infections. 


\section{Discussion}

In this study we investigated the effect of two levels of burnout on the occurrence of infections. Comparing the baseline characteristics of the study population (Table 1), we found differences in the level of education. Employees with bumout complaints both at level one and level two had a lower education, which is in contrast to findings by others who have found that those with a higher education report higher levels of burnout compared to less educated employees. ${ }^{7}$ It is possible that the use of a heterogeneous sample of employees did influence these characteristics. Research on burnout has been mainly conducted in four sectors: teaching, social services, healthcare and law enforcement. ${ }^{25}$ These sectors usually comprise highly educated employees. Our sample however comprises employees from 45 different companies and organizations, with a wide range of educational background among employees. All sectors and trades are represented, with an overrepresentation of the industry comprising groups of lower educated employees.

We did not find large differences in the presence of a longstanding somatic disease between the three groups. The largest differences were found for the presence of nonsomatic diseases between the groups. We corrected our results only for the presence of somatic diseases, because of possible overcorrection when studying the effect of burnout. Depressive mood is a common complaint for people with burnout (complaints). As expected the highest level was found in the group of clinical burnout cases.

Our results show a fairly strong cross-sectional relationship, between burnout and the prevalence of common infections. The relationship between psychosocial factors and infections (mainly common cold) has already been established in other studies. ${ }^{26}$ Earlier research supports the general notion that burnout is a response to overload, experienced workload and time pressure are consistently related to burnout. ${ }^{7}$ In another sludy using the same baseline data, ${ }^{27}$ we found a relationship between Psychological Job Demands (which comprises aspects of job demands, time pressure and conflicting demands) and common cold.

In order to establish causal relationships between bumout and the occurrence of infections, it is necessary to use a longitudinal approach. We limited the current sludy to one year of follow-up, as hazard curves (graphs not shown) showed that after one year follow-up the effect of burnout at baseline on future common cold ebbed away. For flulike iliness and gastroenteritis the effect continued over time. Burnout was measured once a year, and we regarded the burnout levell to be stable in this period. Our longitudinal results (Table 3) show support for a causal relationship between burnout and subsequent infections, indicating that in burnout patients the immune system may be less effective. For gastroenteritis this effect increased when the burnout level was higher. In another longitudinal study we found that fatigue is a risk factor for subsequent infections, and changes in the fatigue level can influence these effects. ${ }^{12}$ It is possible that burnout can act as a co-factor in the pathogenesis of infections. Burnout is associated with occupational stress and can be seen as the chronic depletion of an individual's coping resources. In a study of Melamed ${ }^{28}$ it was shown that chronic burnout 
was associated with elevated somatic arousal and increased salivary cortisol levels. An exaggerated HPA-axis response resulting in elevated levels of cortisol may result in increasing susceptibility to infections ${ }^{17,29,30}$ suggesting an immunosuppressive effects of cortisol. It is not very likely that burnout influences virus exposure. Most of the employees having burnout complaints are still at work, and to some extent also the group of clinical burnout cases was at work at baseline (shown in Table 1). It is therefore probable that a relationship between burnout and common infections was mediated by impairment of the immune system. We could not determine why the strongest relationghip was found between burnout and gastroenteritis in comparison with the other infections. We hypothesize that self-reports of gastroenteritis include also reports of gastrointestinal disturbances in addition to actual infections, which are common complaints when experiencing stress in general. Psychosocial factors have a complex relationship with gastrointestinal illnesses. ${ }^{31}$ For instance, dyspeptic subjects showed a significantly higher prevalence of psycho-emotional disorders in a study of Lond et al. ${ }^{32}$

Examination of the causal effect of the separate subscales, showed that Exhaustion was the strongest predictor of these common infections. Which is in accordance with the notion that exhaustion is the key aspect of burnout and the most obvious manifestation of this complex syndrome. The results also show that Cynicism and lack of Professional efficacy at level one, play a role in acquiring common infections. At the level two the effects were only significant for the effect of Exhaustion on gastroenteritis. The strong identification of Exhaustion with burnout has led to some to argue that the other two aspects of the syndrome are incidental or unnecessary. ${ }^{10}$ Comparing the results of Table 3 with Table 4 , where the concept of burnout as a whole is integrated, we found larger effects studying the complete burnout concept. This may suggest that although exhaustion reflects the stress dimension of burnout, it fails to capture the critical aspects of the relationship people have with their work. ${ }^{7}$

By excluding employees reporting an infection at baseline, we lost a group of participants having burnout complaints or employees which could be considered as clinical burnout cases at baseline. It might be possible that this group of burnout cases comprises another group compared to burnout cases without an infection at baseline. Because our goal was to study the effect of burnout as a predictor of infections we think it is necessary to exclude employees reporting an infection at baseline. This way it is more clear that burnout is the predictor of infections, and not the result of infections. Another reason to exclude employees reporting an infection at baseline is to take the "complainers syndrome" partly into account. Because the determination of infections was based on self-reports of employees, it may have resulted in possible over or under reporting. However, several studies showed a high degree of validity of the wolunteers' self assessment compared to other ways of assessment. ${ }^{33.34}$

In conclusion, taking the high incidence of these infections into account and the fact burnout or the subscales of burnout are not the primary cause in infectious diseases, ${ }^{10}$ the observed effects are quite large in regard to the loss of productive work hours when infections result in employee absenteeism. Using data from the Maastricht Cohort Study is was possible to study the effect of burmout in a longitudinal setting. There have been 
only a few studies that connect the immune system or the occurrence of infections to (some aspects of) burnout. This study provides further evidence supporting a causal relationship between burnout and disease outcome in a large heterogeneous working population.

\section{Acknowledgements}

The present study is part of the Maastricht Cohort Study an "Fatigue at Work", which is granted by the Netherlands Organization for Scientific Research (NWO grant no. 580-02254). The Maastricht Cohort Study participates in the Netherlands concerted research on "Fatigue at Work".

\section{References}

1. Cordes CL, Dougherty TW. A review and an integration of research on job burnout. Acad Manage Rev 1993;18(4):621-56.

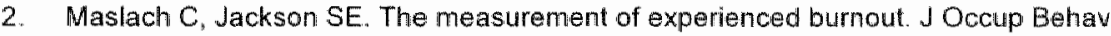
$1981: 2: 99-113$.

3. Schutte N, Toppinen S, Kalimo $R$, Schaufeli $W$. The factorial walidity of the Maslach Burnout Inventory-General Survey (MBI-GS) across occupational groups and nations. J Occup Organ Psych 2000;73(1):53-66.

4. Schaufeli WB. Enzmann D. The burnout companion to study and practice: A critical analysis. London: Taylor \& Francis; 1998.

5. Leiter MP, Schaufeli WB. Consistency of the burnout construct across occupations. Anxiety Stress Coping 1996:9(3):229-43.

6. Taris TW, Schreurs PJG, Schaufeli WB. Construct validity of the Maslach Burnout InventoryGeneral Survey: A two-sample examination of its factor structure and correlates. Work Stress 1999:13(3):223-37

7. Maslach C, Sichaufeli WB, Leiter MP. Job burnout. Annu Rev Psychol 2001;52:397-422.

8. Jackson SE, Maslach C. After-effects of job-related stress: Families as victims. J Occup Behav $1982 ; 3: 63-77$.

9. Leiter MP. Maslach C. The impact of interpersonal environment on burnout and organizational commitment. J Organ Behav 1988:9(4):297-308.

10. Shirom A. Burnout in work organizations. In: Cooper $\mathrm{CL}$, Robertson I, editors. International review of industrial and organizational psychology. New York: Wiley; 1989. p. 25-4B

11. Freudenberger $\mathrm{H} J$. Burnout "contemporary issues, trends, and concerns. In: Farber BA, editor. Stress and bumout in the human services. New York: Pergamon; 1983.

12. Mohren DCL, Swaen GMH, Kant IJ, Borm PJA, Galama, IMD. Associations between common infections and fatigue in a Dutch working population: Results of the Maastricht Cohort Study on Fatigue at Work. Eur J Epidemiol 2002 (in press).

13. Vercoulen JH. Swanink CM, Fennis. JF, Galama JM, van der Meer JW, Bleijenberg G Dimensional assessment of chronic fatigue syndrome. I Psychosom Res 1994;38(5);383-92.

14. Hendrix WH, Steel RP, Leap TL, Surnmers. TP. Development of a stress-related health promotion model: Antecedents and arganizational effectiveness outcomes. ISoc Behav Pers 1991;6(7):141-62.

15. Bargellini A, Barbieri A, Rovesti S, Vivoli R, Roncaglia R, Borella P. Relation between immune variables and bumout in a sample of physicians. Occup Environ Med 2000;57(7):453-7.

16. Nakamura H, Nagase $H$, Yoshida M, Ogino K. Natural killer (NK) cell activity and NK cell subsets in workers with a tendency of burnout,. J Psychosom Res 1999;46(6):569-78. 
17. Kushnir T, Melamed S. The Gulf War and its impact on bumout and well-being of working civilians. Psychol Med 1992,22(4),987-95.

18. Butmann U, Kant $\downarrow$, Van Amelswoon LGPM, Van den Brand PA, KasI SV. Diferences in fatigue and psychological distress across occupations: Resulis from the Maastricht cohort study on fatigue at work. J Occup Environ Med 2001,43(11):976-83.

19. Beurkkens AJ, Butmenn U, Kant I, Vercoulen JH, Bleijenberg G, Swaen GM. Fatigue among working people: wallity of a questionnaire measure. Occup Emiron Med 2000;57(5):353-7.

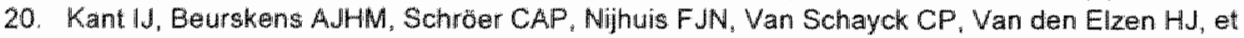
al. De Maastrichtse Cohort Studie naar langdurige psychische vermoeidheid in de arbeidssituatie [The Maastricht Cohort Study on fatigue at work]. TBV 2000;8(8):226-32.

21. Butmann U, Kant 1, Kas: SV, Beurskens A.JHM, Van den Brandt PA. Fatigue and psychological distress in the working population: Psychometrics, prevallence, and correlates. J Psychosom Res $2002: 52(6): 445-52$

22. Schaufeli WB, van Dierendonk, D. UBOS, Utrechtse Burnout Schaal, Handleiding. Lisse: Swets Test Publishers: 2000.

23. Schaufeli WB, Leiter MP, Maslach C, Jackson SE. MBL General Survey. 3rded. Palo Alto, CA: Consulting Psychologists Press; 1996.

24. Cox D. Regression models and life tables. JR Stat Soc B 1972,34:187-220

25. Schaufeli W. Burnout: Een owerzicht wan empirisch onderzoek. Gedrag Organisatie $1990,3(1): 3-31$

26. Cohen $S$, Williamson GM. Stress and infectious disease in humans. Psychol Bull $1991,109(1): 5-24$

27. Mohren DCL, Swaen GMH, Borm PJA, Bast A, Galama JMD. Psychological Job Demands as a risk factor for common cold in a Dutch working population. J Psychosom Res 2001:50:21-7.

28. Melamed S, Ugarten U, Shirom A, Kahana L, Lerman $Y$, Froom P. Chronic bumout, somatic arousal and elevated salivary cortisol levels. J Psychosom Res 1999;46(6):591-8.

29. O'Connor TM, O'Halloran DJ, Shanahan F. The sitress response and the hypothalamicpituitary-adrenal axis: from molecule to melancholla. Q J Med 2000;93(6):323-33.

30. Kahill S. Symptoms of professional burnout: a review of the empirical evidence. Can Psychol $1988 ; 29: 284-97$.

31. Drossman DA. The role of psychosocial factors in gastrointestinal ullness. Scand J Gastroenterol Suppl 1996:221:1-4.

32. Lond $E$, Varmann P. Elshtein $N$, Josia U, Litwinenko $T$, Mumma M, et al. Dyspepsia in rural residents of Estonia. Life-style factors, psychoemotional disorders, anid familial history of gastrointestinal diseases. Scand J Gastroenterol 1995;30(9):826-8.

33. Macintyre $S$, Pritchard $C$. Comparisons between the self-assessed and observer assessed presence and severity of colds. Soc Scil Med $1989.29(11): 1243-8$.

34. Orts K, Sheridan JF, Robinson Whelen S, Glaser R, Malarkey WB, Kiecolt Glaser JK. The reliability and validity of a structured interview for the assessment of infectious itlness symptoms. I Behaw Med 1995;18(6):517-29 


\title{
$-7$
}

\section{Fatigue and job stress as predictors for sickness absence during common infections}

\author{
Danielle CL Mohren" \\ Gerard MH Swaen" \\ IJmert Kant ${ }^{\mathrm{t}}$ \\ Constant $P$ van Schayck ${ }^{2}$ \\ Jochem MD Galama ${ }^{3}$
}

\begin{abstract}
The objective of this study was to investigate the effect of health and work-related factors as predictors of subsequent sickness absence when experiencing common infections (common cold, flu-like illness, and gastroenteritis). We used self-reported data from the Maastricht Cohort Study to study these relationships. Multivariate survival analysis revealed no significant effects of job demands, decision latitude or job strain on absence in workers experiencing common infections. Low levels of commitment (RR $1.22 ; \mathrm{Cl}$ $1.03-1.44$ ), and low job satisfaction (RR 1.36; Cl 1.13-1.164) increased the chance of being absent during a common cold. Also having a longstanding disease increased the chance of being absent during a common infection. Having an executive function decreased the chance of being absent. We conclude that absence during a common cold is partly influenced by motivational factors in work, in contrast to more severe common infections which are more health related. Insight in factors related to absenteeism, are important as a start for preventive measures to reduce sickness absence.
\end{abstract}

\footnotetext{
'Department of Epidemiology, Maastricht University, Maastricht. The Netherlands ${ }^{2}$ Department of General Practice, Maasticht University. Maastricht, The Netherlands ${ }^{3}$ Department of Medical Microbiology, University Medical Center St. Radboud, Niimegen. The Netherlands.
} 


\section{Introduction}

Infections like common cold, flu-like illness, and gastroenteritis cause considerable discomfort and absence from work. In a study among 5620 civil servants on reasons for sickness absence, it was found that respiratory infections and gastroenteritis accounted for between 50 and $60 \%$ of all spells of absence. "These infections account also for a substantial fraction of the sickness absence rates in the Netherlands. Differences in severity in these common infections, can play a role in deciding whether or not to go to work.

In general, because sickness absence has an important economic impact in costs of health insurance and loss of productivity, ${ }^{2}$ identification of its predictors is essential to come up with preventive measures. There are large variations in sickness absence rates among working populations. In the Netherlands sickness absence rates are known to vary in certain occupational groups from $3 \%$ or even lower to rates in excess of $20 \%$. It is very unlikely, however, that a different incidence of somatic illnesses can completely account for these large differences in sickness absence rates. Therefore, most probably other than somatic factors will contribute to the decision to stay at home. Studies aimed at investigating factors that play a role in the workers' decision to stay at home or go to work, have identified a number of factors (social, psychological, and physical factors). The grade of employment, job satisfaction, baseline health, ${ }^{3}$ work demands, ${ }^{4.5}$ control and support, ${ }^{24.5}$ are all factors found to be associated with the duration of sickness absence. in contrast, factors like difficulties in replacement during sickness absence, working in human service organizations, and financial loss as a consequence of being absent ${ }^{B}$ may contribute to the decision not to take sick leave.

We hypothesize that sickness absence during common infections can also be influenced by psychosocial factors. Depending on the severity of the infection, we suggest that the role of these factors in the decision to be absent from work, differ.

The first and probably most important factor that determines sickness absence is disease status. Evidently, the chance to be absent from work, is much higher when a person is ill, than when he or she is healthy. For this reason we included common infections as reported by the employees (common cold "flu-like illness or gastroenteritis) as illness status in our research. We therefore tried to exclude the effect of the illness itself on sickness absence by means of selecting groups of study subjects who all reported similar complaints, to see who turned in sick and who did not. Studies on associations between independent variables and sickness absence that do not include illiness status in their analysis, essentially cannot distinguish between risk factors for the illness and factors that are related to sickness absence after having acquired an illness. We regarded sickness absence behavior within a group of workers who reported to suffer from infections as an outstanding opportunity to study the role of psychosocial factors, apart from the physical disease "on the worker's decision to stay at home or go to work. 
The aim of the present study was to investigate which factors in the psychosocial work environment as well as work organization are predictors of subsequent sickness absence when experiencing common infections (common cold flu-like illness, gastroenteritis). Furthermore we studied the effect of health related variables (presence of longstanding disease, fatigue) on sickness absence. Employees may well be using short spells of absence as a coping strategy to enable them to deal with stressful roles both at work and at home.?

In this large scale prospective cohort study, work-related and nonwork-related factors are measured prospectively on an individual level by means of self-administered questionnaires. To determine the occurrence of common cold, flu-like illness and gastroenteritis we used self-reported experiences of symptomatic infections that occurred in the previous four months. We used also self-reports of sickness absence to determine the days of absence due to an infection in the previous four months.

\section{Methods}

\section{The questionnaire}

The participants of the Maastricht Cohort Study received in total nine questionnaires, at four-monthly intervals, and a total observation period of three years (1998-2001). Once a year the participants received a questionnaire with both exposures (work-related factors, individual characteristics, domestic and social factors) and outcomes, measured on an individual levell using self-administered questionnaires. The participants received a short questionnaire twice a year, measuring mainly outcomes. The time frame of the questionnaires sent out to the employees in the Maastricht Cohort Study is shown in Table 1.

Table 1 Time frame of questionnaires within the Maastricht Cohort Study

\begin{tabular}{llcc}
\hline Questionnaire & Time & Extensive questionnaire & Short questionnaire \\
\hline Baseline T0 & May 1998 & $X$ & \\
T1 & September 1998 & & $\times$ \\
T2 & January 1999 & $X$ & $\times$ \\
T3 & May 1999 & & $\times$ \\
T4 & September 1999 & & $\times$ \\
T5 & January 2000 & $X$ & $\times$ \\
T6 & May 2000 & & $\times$ \\
T7 & September 2000 & & \\
T8 & January 2001 & & \\
\hline
\end{tabular}


The results of this present study are based on the last extensive questionnaire (T6, May 2000) measured after two years of follow-up and the last short questionnaire (T8, January 2001 ).

\section{The study population}

At baseline the Maastricht Cohort Study surveyed a large heterogeneous population of employees in 687 different professions ${ }^{3}$ working in 45 different companies and organizations and followed this group for three years. ${ }^{9.10}$ A total of 12,161 employees completed the baseline questionnaire. Written informed consent was obtained from all participants. The overall response percentage at baselline was $45 \%$. Twenty one questionnaires were discarded because of technical reasons, ${ }^{11}$ resulting in a study population at baseline (TO) of 12,140 employees. The average age was 40.97 years ( \pm $\mathrm{SD} 8.93) ; 26.9 \%$ of the participants were women and $73.1 \%$ were men. After two years of follow-up 8070 employees completed the extensive questionnaire (T6) $92.7 \%$ of these employees $(n=7482)$ completed also the last questionnaire (T8).

\section{Infections and sickness absence}

The occurrence of infections was determined every four months. Three types of infections: common cold, flu-like illness, and gastroenteritis were inventoried as individual items in the questionnaires. A brief description of the infection was included in the quiestion. This description mainly contained the typical symptoms of the infection. For common cold these symptoms were: clogged or running nose, a sore throat, coughing, and slight or no fever (temperature less than $38^{\circ} \mathrm{C}$ ), for flu-like illness: fever (temperature $38^{\circ} \mathrm{C}$ or more), with at least four of the following six complaints, muscular pain, fatigue, sore throat, clogged or running nose, coughing, headache. For gastroenteritis these symptoms included: slight or no fever, gastritis, nausea, vomiting and/or diarrhea. For this study we used the data from the last questionnaire (T8) to determine the occurrence of infections.

The outcome for this study was sickness absence as a result of common cold, flu-like illness, or gastroenteritis. Sickness absence, due to these common infections, was determined in the final questionnaire (T8) using self-reports. Employees were asked if they had been absent from work in the previous four months due to common cold, flu-like illness, or gastroenteritis.

\section{Demographic, health and health behavior variables}

At baseline, employees provided information on age, gender, and educational level. Smoking habits were determined with a single dichotomous item. The presence of a longstanding disease was measured using a single dichotomous item.

\section{Work characteristics}

We measured psychological job demands (PJD), decision latitude (OL), job insecurity, management tasks, commitment and job satisfaction. We used data from the extensive questionnaire measured after two years follow-up to determine these factors (T6). The Psychological Job Demands scale from the Job Content Questionnaire of Karasek ${ }^{12}$ was 
used to determine the levell of P.JD. This scale is a five-item indicator measuring job demands, time pressure, and conflicting demands. ${ }^{13}$ DL is defined as the sum of two sub-scales, which are also measured with the Job Content Questionnaire: Skill Discretion (six items) and Decision Authority (three items). It is an indicator measuring the subject's influence on or control over his or her work, job variety, and the possibility for learning new skills. ${ }^{13}$ The response options for each item varied on a four-point scale from "strongly disagree" to "strongly agree". The total scores of the scales were then grouped into tertiles. Additionally, the Job Demand-Control model (DC model) ${ }^{14,155}$ states that the different interactions of PJD and DL result in four possible work situations: high strain jobs (high PJD, low DL); active jobs (high PJD, high DL); low strain jobs (low PJD, high DL), and passive jobs (low PJD, low DL). By dichotomizing PJD and DL at their mediam ( $P J D=32$ and $D L=72$ ) we grouped the employees acconding to their work situation. Both job insecurity (single item derived from the Questionnaire on psychosocial job demands and job stress (VBBA) ${ }^{18}$ and managernent tasks (self-formulated item) were measured with a single dichotomous item ("Do you fear losing your job on short notice?" and "Do you fulfill and executive function?"). Commitment was determined by the sum of a three-item scale derived from the VBBA. ${ }^{16}$ Job satisfaction was measured with a single item on a four-points scale (good, fair, moderate, not good) derived from the Questionnaire on Work and Health (VAG). ${ }^{17}$ We grouped the answer categories 'moderate' and 'not good" into one category, because of the skewed distribution of the item. This resulted in an item on a three-points scale (good, fair, moderate/not good). Regarding work schedules, employees were asked whether they worked irregular shifts, two-, three-, four-, or five-shift work, exclusively evening or night work, or whether they worked day-time only. In the present study only day-shift, three-shift, five-shift or irregular shift workers were included for investigating differences between the schedules. ${ }^{113}$

\section{Fatigue}

To determine the level of fatigue, we used the Checklist Individual Strength (CIS). ${ }^{9}$ The CIS is a 20-item self-report questionnaire measuring four aspects of fatigue in separate scales, namely subjective experience of fatigue (eight items, e.g. "I feel tired"), concentration (five items, e.g." "I have trouble concentrating"), motivation (four items, e.g. "I feel no desire to do anything"), and physical activity (three items, e.g." "I don't do much during the day $\left.)^{\mathrm{r}}\right){ }^{19}$ The items are scored on seven-point Likert scales. Participants were instructed to indicate how they felt during the last two weeks. Higher scores on the separate scales indicate a higher degree of fatigue, more concentration problems, reduced motivation, or less activity. A composite thatal score (ranging from 20 to 140 ) was obtained by adding the individual's scores on the four factors. Based on receiver operating characteristics analysis, a Cis-total cut-off point of $>76$ was derived for use in the working population. ${ }^{20}$ This cut-off point was established in a separate pilot study by means of defined samples with differences in fatigue levels. All those employees were considered to report a level of fatigue indicative of being "at risk" for sickness absence or work disability, and were designated as probable fatigue cases. ${ }^{20}$

\section{Statistical methods}

Risk ratios (RRs) and $95 \%$ confidence intervals $(95 \% \mathrm{Cl}$ ) for sickness absence for all three infections separately were calculated using multivariate survival analysis by means 
of the Cox regression model. ${ }^{21}$ For this analysis we selected employees who reported an infection (either common cold, fu-like illiness, or gastroenteritis) as reported in the final questionnaire (T8). For common cold this resulted in a study population of $n=3685$ for flu-like illness and gastroenteritis, $n=1101$ and $n=745$ respectively. All procedures were done using SPSS for Windows 9.0 sotware.

\section{Results}

As sthown in Table 2, the highest period prevalence was found for common cold $(50.0 \%)$. The highest percentage of absence was found for flu-like iliness. Within the group of employees reporting flu-like illness, almost $70 \%$ of the employees were absent from work for at least one day. Only $29.7 \%$ of employees reporting a common cold, were absent from work because of this common cold.

Table 2 Prevalence of common infections and absence from work

\begin{tabular}{|c|c|c|c|c|c|c|}
\hline & \multicolumn{2}{|c|}{ Common cold } & \multicolumn{2}{|c|}{ Flu-like illness. } & \multicolumn{2}{|c|}{ Gastroenteritis } \\
\hline & N & $\%$ & $N$ & $\%$ & $\mathrm{~N}$ & $\%$ \\
\hline Prevalence & 3685 & 50.0 & 1101 & 14.8 & 745 & 10.1 \\
\hline Absence from work during infection & 1027 & 29.7 & 741 & 69.3 & 308 & 45.3 \\
\hline
\end{tabular}

In Table 3, the effect of several demographic, health behavior, and health variables on sickness absence due to infections is shown. With regard to all three infections, women were relatively more on sick leave compared to men. Comparing women with men in relation to absence during common cold we found a RR of $1.23(\mathrm{Cl} \mathrm{1.08-1.40)}$ ). For the other infections, there was no statistically significant difference between men and women.

Table 4 shows the effect of fatigue, work-related factors and the presence of a longstanding disease on sickness absence, corrected for age, gender, educational level and smoking, in employees all reporting infections. Being fatigued (CIS score > 76) at T6. (May 2000) was a risk factor for being absent from work during a common cold at T8 (January 2001), with an adjusted RR of 1.20 (Cl 1.05-1.37). Such an effect was not found for absence due to flu-like illness or gastroenteritis. High job demands or low levels of decision latitude did not have a significant effect on absence during infections. Comparing different work situations as specified by the DC model, we did not find significant effects on sickness absence. With regard to work schedules, we found that three-shift workers (RR $0.58 ; \mathrm{Cl} \quad 0.39-0.87$ ) and five-shift workers (RR 0.73; $\mathrm{Cl}$ 0.55-0.98) were less absent from work during a common cold, compared to day time workers. The effect of work schedules on absence during flu-like illness or gastroenteritis was in the same direction but weaker and not significant. Comparing irregular shift workers to 
Table 3 Crude risk ratios for the effect of demographic and health behavior variables on sickness absence due to infections

\begin{tabular}{|c|c|c|c|}
\hline & \multicolumn{3}{|c|}{ Absence from wark during: } \\
\hline & Common cold & Flu-like illiness & Gastroenteritis \\
\hline & $\operatorname{RR}(95 \% \mathrm{Cl})$ & $\operatorname{RR}(95 \% \mathrm{Cl})$ & $\operatorname{RR}(95 \% \mathrm{Cl})$ \\
\hline \multicolumn{4}{|l|}{ Age } \\
\hline$-\leq 25$ & $0.76(0.48-1.21)$ & $1.07(0.72-1.61)$ & $1.28(0.72-2.28)$ \\
\hline$-26-35$ & $0.98(0.83-1.15)$ & $1.03(0.86-1.23)$ & $1.10(0.83-1.47)$ \\
\hline$-36-45^{m}$ & 1 & 1 & 1 \\
\hline$-46-55$ & $1.15(1.00-1.33)$ & $0.99(0.83-1.19)$ & $1.39(1.05-1.84)$ \\
\hline$-\geq 56$ & $0.95(0.66-1.37)$ & $1.21(0.84-1.74)$ & $1.51(0.79-2.88)$ \\
\hline \multicolumn{4}{|l|}{ Gender } \\
\hline - Ment & 1 & 1 & 1 \\
\hline - Women & $1.23(1.08 \cdots 1.40)$ & $1.14(0.98-1.33)$ & $1.05(0.83-1.34)$ \\
\hline \multicolumn{4}{|l|}{ Educational level } \\
\hline - Primary school & $0.84(0.56-1.25)$ & $0.71(0.44-1.14)$ & $0.86(0.34 \cdot 2.19)$ \\
\hline - Lower vocational education & $0.96(0.76-1.22)$ & $0.81(0.60-1.08)$ & $1.05(0.66-1.69)$ \\
\hline - Lower secondary school & $0.90(0.72-1.12)$ & $0.95(0.73-1.23)$ & $1.25(0.84-1.86)$ \\
\hline - Inter vocational education & $1.02(0.82-1.27)$ & $0.92(0.70-1.19)$ & $1.14(0.76-1.71)$ \\
\hline - Upper secondary school & $1.15(0.90 \times 1.47)$ & $0.94(0.68-1.31)$ & $1.13(0.66-1.91)$ \\
\hline - Upper vocational education & $0.86(0.69 \times 1.06)$ & $0.93(0.72-1.19)$ & $1.00(0.67-1.49)$ \\
\hline - University" & 1 & 1 & 1 \\
\hline \multicolumn{4}{|l|}{ Smoking } \\
\hline - No & 1 & 1 & 1 \\
\hline - Yes & $1.02(0.89-1.18)$ & $0.89(0.75-1.05)$ & $0.99(0.76-1.30)$ \\
\hline
\end{tabular}

Reference group

day-workers, no effect was found with respecl to absence during common infections. A low level of commitment increased the chance of being on sick leave during a common cold (RR 1.22; Cl 1.03-1.44). However, commitment appeared to have no effect on absence during a flu-like illness or gastroenteritis. A low level of job satisfaction had an increasing effect on absence due to common cold, in a dose dependent manner (fair: RR 1.12; $\mathrm{Cl} 0.98-1.28 ;$ moderate/not good: $R \mathrm{R}$ 1.36; $\mathrm{Cl} 1.13-1.64$ ). Having an executive function decreased the chance of being absent due to an infection. For absence during common cold this effect was significant (RR $0.82 ; \mathrm{Cl} 0.70 .0 .96$ ). Comparable, bull nonsignificant effects were found for absence during flu-like illness or gastroenteritis. Employees reporting a longstanding disease were more on sick leave during a common cold, compared to employees free of such a disease (RR $1.21 ; \mathrm{Cl} 1.05-1.40$ ). 
Table 4 Survival analysis, adjusted risk ratios for sickness absence due to infections

\begin{tabular}{|c|c|c|c|}
\hline & \multicolumn{3}{|c|}{ Absence from work during: } \\
\hline & Common cold & Flumike illness & Gastroenteritis \\
\hline & $\mathrm{RR}^{\prime}(95 \% \mathrm{CH})$ & $\mathrm{RR}^{*}(95 \% \mathrm{Cl}$ & $\operatorname{RR}(95 \% \mathrm{Cl})$ \\
\hline Fatigue $(C 1 S>76)$ & $1.20(1.05-1.37)$ & $1.02(0.87-1.20)$ & $0.90(0.70-1.16)$ \\
\hline \multicolumn{4}{|c|}{ Psychological لób Demands } \\
\hline Low & 1 & 1 & 1 \\
\hline Medium & $1.01(0.87-1.18)$ & $1.03(0.85-1.24)$ & $1.05(0.80-1.39)$ \\
\hline High & $1.08(0.92-1.26)$ & $0.94(0.78-1.12)$ & $0.75(0.57-1.00)$ \\
\hline \multicolumn{4}{|l|}{ Decision latitude } \\
\hline Low & $1.08(0.91-1.28)$ & $1.08(0.88-1.32)$ & $0.97(0.71-1.33)$ \\
\hline Medium & $1.04(0.89-1.22)$ & $1.03(0.86-1.25)$ & $1.06(0.79-1.42)$ \\
\hline High & 1 & 1 & 1 \\
\hline \multicolumn{4}{|l|}{ Nork situation } \\
\hline Low strain & 1 & 1 & 1 \\
\hline Aclive & $1.20(0.99-1.46)$ & $1.01(0.80-1.27)$ & $0.73(0.51-1.04)$ \\
\hline Passive & $1.09(0.90-1.33)$ & $1.07(0.85-1.36)$ & $0.89(0.63-1.26)$ \\
\hline High strain' & $1.12(0.92-1.37)$ & $0.99(0.78-1.25)$ & $0.81(0.56-1.17)$ \\
\hline \multicolumn{4}{|l|}{ Work schedules } \\
\hline Day work" & 1 & 1 & 1 \\
\hline Three-shift work & $0.58(0.39-0.87)$ & $0.72(0.46-1.11)$ & $0.95(0.47-1.92)$ \\
\hline Five-shitit work & $0.73(0.55-0.98)$ & $0.82(0.59-1.14)$ & $0.75(0.44-1.28)$ \\
\hline Irregular shift & $1.00(0.77 \cdot 1.28)$ & $1.03(0.77-1.39)$ & $0.85(0.55-1.32)$ \\
\hline \multicolumn{4}{|l|}{ Cammitment } \\
\hline Low & $1.22(1.03-1.44)$ & $1.05(087-1.28)$ & $0.90(0.66-1.21)$ \\
\hline Medium & $1.04(0.88-1.23)$ & $1.03(0.85-1.26)$ & $0.84(0.62-1.13)$ \\
\hline High" $^{*}$ & 1 & 1 & 1 \\
\hline \multicolumn{4}{|l|}{ Job satisfaction } \\
\hline Good & 1 & 1 & 1 \\
\hline Fair & $1.12(0.98-1.28)$ & $1.12(0.95-1.32)$ & $0.89(0.69 \cdot 1.14)$ \\
\hline Moderatelnot good & $1.36(1.13-1.64)$ & $1.03(0.82-1.29)$ & $1.00(0.71-1.40)$ \\
\hline Executive function & $0.82(0.70-0.96)$ & $0.93(0.78-1.12)$ & $0.80(0.60-1.07)$ \\
\hline Job insecurity & $1.14(0.95-1.37)$ & $1.14(0.93-1.40)$ & $1.06(0.76-1.48)$ \\
\hline Longstanding disease & $1.21(1.05-1.40)$ & $1.14(0.95-1.35)$ & $1.08(0.83-1.42)$ \\
\hline
\end{tabular}

Reference group

"Corrected for age, gender, educational level, and smoking

\section{Discussion}

Sickness absence is the outcome of factors, including physical impairments, subjective ill health, as well as the sick role a person takes, which may not essentially be related to the illness itself. ${ }^{22}$ In this study we selected employees who reported to have suffered from common infections, and studied the effect of other variables on their decision to go 
to work or stay at home. We found in particular for mild infections, that a number of factors from the psychosocial work environment contribute to the decision to go on sick leave. Thus, sickness absence is not simply an indicator of ill health, but reflects partly a deliberate choice of the employee, based on factors that encourage or discourage absence from work, e.g. a form of coping behavior. ${ }^{3.723}$

For common cold, which is a mild condition, we found that several work-related (shift work, commitment, job satisfaction, having an executive function) and health factors (fatigue, presence of a longstanding disease) play a role in the decision to stay at home during the illness. For flu-like illness or gastroenteritis, which are associated with more physical complaints, no significant effect of work-related and health factors were found on the decision to stay at home. Only $30 \%$ of the employees reporting a common cold was on sick leave during this infection, compared to almost $70 \%$ of the employees who reported a flu-like illness (Table 2). Colds and flu-like illnesses are different in that colds produce local symptoms (nasal secretion) whereas flu-like ilness is defined by systemic effects. ${ }^{24}$ We assume that the difference in severity of symptoms between these two infections explains the differences in outcome for the contribution of other factors on sickness absence. To a lesser extend, this holds also for the difference between common cold and gastroenteritis. Thus, it is assumed that the mild course of common colds is responsible for the ability to detect a contribution of work-related factors to the decision to take sick leave.

Consistent with a large number of studies ${ }^{22,25}$ our data showed that women are more frequently absent from work compared to men. For absence during a common cold the gender effect was significant (RR $1.23 ; \mathrm{Cl} 1.08-1.40$ ). We found no significant differences between age groups or groups with different educational levels, which is in contrast to the outcome of a study of Marmot et al. ${ }^{3}$ Among a group of civil servants studied by Marmot et al., it was found that the lower the emplayment grade, the higher the grade of sickness absence. It is possible that by selecting only those employees who reported an infection, we already lost the effect of age and educational level. The decision to be absent from work may be only slightly or not influenced by these factors.

Being fatigued ( $\mathrm{CIS}>76$ ) at $T 6$ is a risk factor for absence from a common cold at $T 8$. Fatigued employees are probably less able to attend their jobs when having a cold, compared to others with no or less complaints of fatigue. Fatigued employees may "use" an infection as a reason to be absent from work and recover from their fatigue. We previously reported that infections and fatigue are related to each other. ${ }^{26}$ Besides the fact that fatigue is a common symptom of an infection, and that it can also persists for months, we also found that fatigue can be a predictor of an infection at later stage.

Significant effects were not found for a contribution of job demands and decision latitude or job strain to absenteeism. In the literature, reviewed by Bourbonnais and Mondor, ${ }^{27}$ also no clear evidence is found for an association between psychological job demands, decision latitude, job strain, and the occurrence or duration of any type of sick leave. In a cross-sectional study we found an association between high levels of job demands, low levels of decision latitude and the occurrence of common cold. No evidence was 
found for the relationship between job strain and the occurrence of common cold. ${ }^{26}$ Employees in three- and five-shifts reported lower absenteeism due to common infections, compared to day workers. The effect was significant for absence during common cold and may be explained by a high level of commitment towards colleagues working in the same team. Correction for commitment (data not shown), did not change the outcome. The latter may be caused by the fact that commitment, measured in this cohort study, reflected commitment towards the company. Low levels of commitment towards the company, increased the chance of being absent during a comman cold. For flu-like illness and gastroenteritis such an effect was not observed. Absence during a common cold was higher for employees reporting a low level of job satisfaction (RR 1.36; Cl 1.13-1.64). In the study of Marmot, in which the relationship between self reported health status and sickness absence was studied among civil servants, ${ }^{3}$ it was found that job satisfaction was more strongly associated with spells of 1-2 days than with longer spells of absence. Having a leadership position was related with a low absence rate during a common cold. It is possible that low replaceability in the job plays a role, which is often the case for employees in leadership positions, in high sickness presenteeism. ${ }^{6}$ In a previous study, we found that job insecurity increased the risk of common infections and health problems. ${ }^{29}$ In the present study however, only a tendency towards increased rates was found, but the effect was not significant. Other studies have shown that job insecurity can also be related to a decrease in absence rates, because companies may want to keep their "healthy employees" in case of downsizing or reorganization. ${ }^{22,30}$

Having a longstanding disease increased the chance of being absent during a common cold. For flumlike illness and gastroenteritis we found comparable although non-significant effects. Employees having a longstanding disease may have more severe symptoms or complications, when having a mild infection like a comman cold. For this present study we did not discriminate between different longstanding diseases. But the presence of certain longstanding diseases can result in complications during infections. For instance common colds often predispose patients with COPD to develop lower airway infections ${ }^{31}$ which are one of the most common causes of exacerbations in COPD patients ${ }^{32}$

When interpreting the results of this study one should keep in mind that the data are based on self-reports. Rees and Cooper ${ }^{33}$ reported that self-reports of total sickness absence in a previous six months period was an acceptable measure of sickness absence for use in studies in which for whatever reason, access to actual sickness data is difficult. It is possible that illness behavior and reporting bias contribute to sickness absence. We selected employees based on their self-reports of an infection. Self-reports of illnesses may lead to over or under reporting. However, comparisons of self-assessed and observer-assessed observations of colds showed a high degree of validity. ${ }^{34}$ in most of the participating companies, employees report to be sick by a telephone call to the company, with a reason for the absence. Most of the time when it is only a short spell of absence, there is no external control by the company or company doctor. For this reason, if an employee does not want to attend work it is possible that he calls in sick and gives a minor illness as a reason. In our questionnaire there are several possibilities to report sickness absence, also without reporting a reason. We think that asking 
specifically about absence when having an infection, there is less reason for overreporting.

Absence during a common cold can be partly influenced by motivational factors in work. like commitment and job satisfaction and not work content. Insight in factors that play a role in the decision to stay a home during a minor illness are important to come up with preventive measures to reduce sickness absence.

\section{Acknowledgements}

The present study is part of the Maastricht Cohort Study on "Fatigue at Work". The Maastricht Cohort Study participates in the Netherlands concerted research on "Fatigue at Work" granted by the Netherlands Organisation for Scientific Research (NWO grant no. 580-02.254).

\section{References}

1. Feeney $A$, North $F$, Head J, Canner $R$, Marmot M. Socioeconomic and sex differentials in reason for sickness absence from the Whitehall II study. Occup Environ Med 1998:55:91-8.

2. Niedhammer I, Bugell I, Goldberg $M$, Leclerc $A$, Gueguen A. Psychosocial factors at work and sickness absence in the Gazel cohort: a prospective study. Occup Environ Med 1998;55:73541.

3. Marmot M, Feeney A, Shipley M, North F, Syme SL. Sickness absence as a measure of heallth status and functioning: from the UK Whitehall II study. J Epidemiol Community Health 1995:49(2): 124-30.

4. North FM, Syme SL, Feeney A, Shipley M, Marmot M. Psychosocial work environment and sickness absence among British civil servants: the Whitehall II study. A Journal Public Health 1996:86(3):332-40.

5. Vahtera $\mathrm{J}$, Kivimäki $M$, Pentti $J$, Theorell T. Effect of change in the psychosocial work environment on sickness absence: a seven year follow up of initially healthy employees. J Epidemiol Community Health 2000;54:484-93.

6. Aronsson G, Gustafsson K, Dallner M. Sick but yet at work. An empirical study of sickness presenteeism. J Epidemial Community Health 2000;54:502-9.

7. Kristensen TS. Sickness absence and work strain among Danish slaughterhouse workers: An analysis of absence from work regarded as coping behaviour. Soc Sci Med 1991, Vol 32(1):1527.

8. Bültmann U, Kant IJ, Van Amelsvoort LGPM, Van den Brandt PA, Kasi SV. Differences in fatigue and psychological distress across occupations: Results from the Maastricht cohort study on fatigue at work. J Occup Environ Med 2001,43(11):976-83.

9. Beurskens $A_{a}$, Bultmann $U$, Kant $U$, , Vercoulen $J H_{*}$ Bleijenberg $G$, Swaen GM. Fatigue among working people: validity of a questionnaire measure. Occup Environ Med 2000;57(5):353-7

10. Kant 1 J, Beurskens AJHM, Schröer CAP, Nijhuis FJN, Van Schayck CP, Van den Elzen HJ, et al. De Maastrichtse Cohort Studie naar langdurige psychische vermoeidheid in de arbeidssituatie [The Maastricht Cohort Study on fatigue at work]. Tijdschrift voor Bedrijfs- en Verzekeringlsgeneeskunde $2000 ; 8(8): 226-32$.

11. Bulltmann U, Kant IJ, KasI SV, Beurskens AJHM, Van den Brandt PA. Fatigue and psycholagical distress in the working population: Psychometrics, prevalence, and correlates. $J$ Psychosom Res 2002:52(6):445-52. 
12. Karasek RA. The Job Conient Questioninaire and User's Guide (version 1.11). Los Angeles: Depariment of Industrial and Systems Engineering. University of Southern California; 1985 Marchi.

13. Niedhammer 1, Goldberg M, Leclerc A, Bugel I, David S. Psychosocial factors at work and subsequent depressive symptoms in the Gazel cohort. Scand J Work Environ Health $1998 ; 24(3): 197-205$

14. Karasek RL. Theorell T. Healthy work: Stress, productivity and the construction of working life. New Yark: Basic Books; 1990

15. Karasek RA. Job Demands, Jab Decision Latitude; and mental strain: Implications for job redesign. Adm Sici Q 1979;24:285-311.

16. Van Veldhoven $M_{4}$ Meijman TF. Het meten van psychosociale arbeidisbelasting met een vragenlijst: de vragenllist beleving en beoordeling van de arbeid (VBBA) (The measurement of psychesocial job demands with a questionnaire (VBBA)]. Amsterdam: NIA; 1994

17. Gründemann RWM, Smulders PWG, De Winter CR. Handleiding Vragenlijst Arbeid en Gezondheid [Manual, Questionnaire on work and health]. Lisse: Swets \& Zeitlinger; 1993

18. Jansen NWH, Kant IJ, Van Amelsvoort LPGM, Nijhuis F.JN, Van den Brandt PA. Need for recowery after work: Evaluating short-term effects of working hours, patterns and schedules (submilted for publication).

19. Vercollen JH, Swanink CM, Fennis JF, Galama JM, van der Meer JW, Bleijenberg $G$. Dimensional assessment of chronic fatigue syndrome. J Psychosom Res 1994:38(5):383-92.

20. Bültmann U, De Vries M, Beurskens AvHM, Bleijenberg $G$, Vercoulen JHMM, Kant $Y$. Measurement of prolonged fatigue at work in the Maastricht Cohort Study: Determination of a cutoff point. J Occup Heaith Psychol 2000;5(4):411-16.

21. Cox D. Regression models and life tables. JR Stat Soc B 1972;34:187-220.

22. Voss M, Floderus $B$, Diderichsen $\mathbb{F}$. Physical, psychosocial, and organisational factors relative to sickness absence: a study based on Sweden Post. Occup Environ Med 2001;58(3):178-84.

23. Rael EG, Stansfeld SA, Shipley M, Head J, Feeney A, Marmot M. Sickness absence in the Whitehall II study, London: the role of social support and material problems. J Epidemiol Community Health 1995:49(5):474-81.

24. Smith AP. Respiratory virus infections and performance. Philos Trans R Soc Lond B Biol Sci $1990 ; 327(1241) 519-28$.

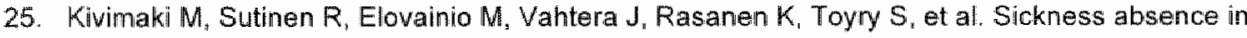
hospital physicians: 2 year follow up study on determinants. Occup Environ Med 2001;58(6):361-6.

26. Mohren DCL, Swaen GMH, Kant IJ, Borm PJA, Galama JMD. Associations between common infections and fatigue in a Dutch working population: Results of the Maastricht Cohort Study on Fatigue at Work. Eur J Epidemiol 2002 (in press).

27. Bourbonnais $R$. Mondor $M$. Job strain and sickness absence among nurses in the province of Quebec. Am J Ind Med 2001;39(2):194-202.

28. Mohren DCL, Swaen GMH, Borm PJA. Bast A, Galama JMD. Psychological Job Demands as a risk factor for common cold in a Dutch working population. J Psychosom Res 2001,50:21-7.

29. Mohren DCL. Swaen GMH, van Amelswoort LGPM, Borm PJA, Galama JMD. Job insecurity as a risk factor for common infections, and health complaints (submitted for publication).

30. Vahtera J, Kivimaki M, Pentti J. Effect of orglanisational downsizing on health of employees. Lancet 1997;350(9085):1124-8.

31. Smith CB, Golden CA, Kanner RE, Renzetti AD, Jr. Association of viral and Mycoplasma pneumoniae infections with acute respiratory illness in patients with chronic obstructive pulmonary diseases. Am Rev Respir Dis 1980;121(2):225-32

32. Suzuki T, Yanai M Yamaya M, Satoh Nakagawa T, Sekizawa K, Ishida S, et al. Erythromycin and common cold in COPD. Chest 2001:120(3):730-3

33. Rees $D, C o o p e r ~ C L$. Research note: reliability of self-report sickness absence data in the health service. Health Serv Manage Res 1993;6(2):140-1.

34. Macintyre S, Pritchard $C$. Comparisons between the self-assessed and observer-assessed presence and severity of colds. Soc Sci Med 1989;29(11):1243-8 


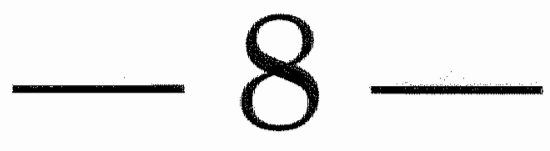

\section{Epilogue}

The goal of this epilogue is to discuss the resuits presented in the previous chapters in a broader perspective. In this chapter, the effect of work-related factors and fatigue on the occurrence of common infections will be discussed. Furthermore, the use of questionmaires to determine the presence of acute common infections will be evaluated. Although the strength and limitations of the different studies in this thesis have already been discussed in detail, we will dilate upon the overall methodological issues. Finally, the implications of the results for health research will be discussed.

In the Introduction, a conceptual model was introduced that constitutes the basis for this thesis. In the Introduction, it was hypothesized that work-related factors causing stress, can result in an increased susceptibility to common infections, as measured by an increase in the prevalence of such infections. Infections can lead to the activation of the immune system, resulting in fatigue. Since fatigue is also influenced by work-related factors, there may be a complex interaction between work-related factors, common infections and fatigue. The goal of the thesis was three-fold. First, the relationship between work-related factors and common infections was investigated and second the relationship between fatigue and common infections was studied. Finally, the role of factors in the work environment (job demands, job insecurity, working in shifts, etc), and health related factors (fatigue and the presence of a longstanding disease), on the decision to be absent from work when experiencing a common infection, was studied.

\section{Acute common infections}

\section{Determination of acute common infections}

The central theme of this thesis was the effect of work-related factors and fatigue on the occurrence of common infections (common cold, influenza-like illinesses and gastroenteritis) among Dutch employees. Most studies on acute illness development in humans, thend to be done under restricted laboratory conditions, involving experimentally induced infections, ${ }^{1-4}$ and/or various narrowly defined manipulations of stress or psychosocial stimuli. The results presented in this thesis, however, are based on observational data from the prospective Maastricht Cohort Study on "Fatigue at Work". As described in detail in the Introduction, the occurrence of common infections was determined using self-administered questionnaires. The validity of this method will now be discussed, with special emphasis on the abillity of the employees to distinguish between the different infections. 
An important issue that should be kept in mind, is that self-reports may be influenced by personal traits. In this respect the potential effect of negative affectivity has to be recognized. ${ }^{6}$ Individuals which score high on negative affectivity may perceive their environment more negatively, thereby creating spurious associations between workrelated factors or fatigue and the reports of acute common infections, which may be also influenced by negative affectivity. To partly overcome this problem we corrected in our longitudinal studies for the values of the outcome variable at the same time-point as the exposure was measured, or we excluded prevalent cases in our analyses, thereby controlling for the influence of negative affectivity, strengthening the findings which are based on the self-reports.

With regard to the measurement of common infections, the ability of the employees to make a proper distinction between the different infectious illnesses, is also an important issue. In the Introduction we already compared the prevalence of the common infections in the cohort, with the data based on the virological weekly reports ${ }^{7}$ from the virology laboratories, and found a striking similarity in the trend of the infections. As shown in chapter 7 , large differences were found in the prevallence of the three infections. The employees reported a four-monthly prevalence of $50.0 \%$ for common cold, $14.9 \%$ for influenza-like illnesses, and 10.1\% for gastroenteritis respectively. Also differences in absenteeism during these common infections were found, with the highest percentage $(69.3 \%)$ of absenteeism during an episode of influenza(-like) illness. Thus, the results clearly indicate that the employees seem to be well able to distinguish between the three infectious illnesses which were investigated.

Evidence from epidemiological studies ${ }^{8-12}$ and from experimental viral-challenge studies $^{2,4,13-15}$ supports that persons reporting psychological stress have a higher incidence as weil as a greater severity of illness. In this thesis no information was collected on the number of episodes of a certain infection in the four-month period and on the duration of symptoms. We only asked the employees about the presence of common infections in the previous four months. Although there is only a small chance that employees experience more than one episode of the same acute infection in this period, it should be taken into account that not having this information, may have led to an underestimation of the effect. It may also be possible that differences existed in the duration of illiness among employees reporting a common infection. The duration of illness may also be influenced by work-related factors and fatigue. It should be kept in mind, that a difference in the severity or duration of illness, could have had an effect on our study outcome, because employees having more severe symptoms or experiencing a longer period of discomfort, may have been more able to recollect the presence of an infection in the previous period, compared to those with a short and mild disease. A potential difference in duration or severity of common infections would give valuable additional information with respect to the impact of work-related factors and fatigue, and should therefore be studied in future research. 


\section{Role of work-related factors}

We hypothesized that work-related factors causing stress, can result in an increased susceptibility to common infections, as measured by an increase in the prevalence of these infections. In respect to the effect of work-related factors on the occurnence of common infections, the use of objective versus subjective work-related factors will be discussed. Furthermore, the use of a cross-sectional and of a longitudinal design to study the relationship between work-related factors and common infections, will be discussed.

To determine the effect of the work enwironment on the occurrence of common infections, we used both factors from the well known Demand-Control model from Karasek. $^{16,17}$ as well as other work-related factors (job insecurity and work schedules). The work-related factors that were subject of study can be divided in subjective and objective factors. Any kind of a "subjective" response to a questionnaire report can be placed somewhere on a dimension from "low in dependency on cognitive and emotional processing" to "high in dependency on cognitive and emotional processing", 18 Psychological job demands and decision latitude as described in chapter 2, can be seen as subjective work-related factors, expressing the perceived demands or perceived control of the employees in their work. Job insecurity. as described in chapter 3 , can be considered as an objective and subjective work-related factor. It can be caused by an objective threat if an organization is in the process of downsizing or reorganization, but it can also be caused by uncertainties about one"s own capabilities without an actual objective threat. Job insecurity is viewed as a classical work stressor with the expectation that continued exposure to job insecurity will result in impaired psychological and physical health. ${ }^{12}$ The response to the item in the questionnaire may be influenced by interpersonal differences in the way workers perceive their individual job insecurity. ${ }^{20}$ Work schedules (chapter 4), or in other words, working in shifts, can be seen as an objective work-related factor, which can act as a potential stressor affecting the individual employee. Both objective and subjective work-related factors showed to influence the occurrence of common infections. This means that although subjective factors are possibly influenced by negative affectivity, they can induce comparable results as objective factors, indicating that the perception of an individual employee about the work environment, is an important issue to take into account when developing preventive measures.

In the second and fourth chapter, the results of cross-sectional analyses were discussed. Because of this cross-sectional design, the observed associations can not (immediately) be interpreted as cause-effect relationships. Moreover, the cause effect relationships may be influenced by reverse causation. Suffering from an infection, may influence the perception of one's work. This potential problem is possibly larger in the study of chapter 2 , in which the effect of psychological job demands and decision latitude on common cold is discussed than in that of chapter 4 , in which the effect of shift work is studied. Although working in shifts is measured in a self-reported questionnaire, it is unlikely that the response to the item is influenced by personal trait. With respect to job insecurity (chapter 3), we found in both the cross-sectional and longitudinal analyses, comparable results for the effect of this work-related factor on common infections. 


\section{Role of fatigue}

As described in the conceptual model in the Introduction, fatigue may be associated with common infections, or play an internediate role in the relationship between work-related factors and common infections. To study this complex relationship between common infections and fatigue a longitudinal approach is a prerequisite, in order to disentangle the role of fatigue in the etiology of common infections. Two different expressions of fatigue were subject of study.

First, we studied the relationship between fatigue, measured with the Checklist Individual Strength ${ }^{21,22}$ and the occurrence of common infections. An attempt was made to disentangle the complex relationships by studying the different directions of the relationship. As described in chapter 5, common infections were accompanied by fatigue. Fatigue could also persists for months even after infections like, common cold, flu-like illness, and glastraenteritis. The effect of fatigue as a risk factor for common infections was also subject of study, showing that fatigued employees report significantly more infections compared to their non-fatigued colleagues. Second, the effect of burnout measured with the MBI-GS, ${ }^{23.24}$ on the occurrence of common infections, was discussed in chapter 6 . Employees with burnout complaints reported significantly mone infections in comparison to employees free of these complaints. Clinical burnout (at this point a large part of the employees were already absent from work) showed to have an even larger impact on the occurrence of infections. The strongest effect was found for the relationship between burnout and gastroenteritis. This effect should not only be attributed to an impaired immune system, resulting in an increase in glastroenteritis, but can also be due to a classical stress response resulting in gastrointestinal complaints, which closely resembles the symptoms of gastroenteritis. Thus, the reports of gastroenteritis in the Maastricht Cohort Study contain probably several cases of Irritable Bowel Syndrome, ${ }^{25,20}$ resulting in comparable symptoms. This can also be seen as an additional explanation for the poor similarity between the trend in the prevalence of gastroenteritis and the results from the surveillance data based on the virological weekly reports ${ }^{7}$ and tests on bacteria commonly responsible for gastroenteritis, as shown in the Introduction (Figure 5).

In chapter 5 we found support for the hypothesis that common infections can result in fatigue as well. This result is in agreement with the findings that certain viral infections are risk factors for fatigue, ${ }^{27.28}$ for instance glandular fever. However, upper respiratory tract infections, and other common infections are not known to cause fatigue. ${ }^{27-29}$ in both chapters it was shown that fatigue can result in an increase in the occurrence of common infections. Because demands in the work situation can also increase fatigue, ${ }^{30}$ we assume that complex relationships exist between work-related factors, common infections, and fatigue.

Fatigue, as measured with the Checklist Individual Strength was introduced as a more general complaint. Fatigue can be work-related, but it can also have a mental or physical origin. In contrast, burnout is a work-related syndrome, and considered to be caused by stressful work conditions. After studying the effect of the subscales of burnout, we found that the exhaustion scale was the strongest predictor of infections, in comparison to the 
other subscales. We found a relatively low correlation of 0.575 between the Maslach Burnout Inventory-General Survey (used to measure burnout) and the Checklist Individual Strength (used to measure the level of fatigue). Although a large percentage $(67.1 \%)$ of our probable burnout cases and clinical cases $(90.1 \%)$ can also be considered as fatigued, not all of the fatigue cases have bumout complaints. Of the employees who should be considered as fatigue cases, $58.6 \%$ is also a probable bumout case but only $7.1 \%$ a clinical burnout case. We also found differences in the prevalence and incidence of fatigue and burnout in our cohort. We found a prevalence of $21.9 \%$ for fatigue and $16.4 \%$ for probable burnout, and $1.6 \%$ for clinical burnout. Larger differences were found for the incidence of fatigue and burnout. For fatigue we found an incidence of $12.0 \%$ after one year "for probable and clinical burnout the incidences were $6.1 \%$ and $0.8 \%$ respectively. Because of the relatively low correlation between the two concepts and the small overlap between fatigue and bumout cases we conclude that fatigue and burnout represent two different concepts, which are both associated with an increased risk for common infections.

\section{Sickness absence due to common infections}

A large percentage of absenteeism from work is caused by infections. In a study among 5620 civil servants on reasons for sickness absence, it was found that respiratory infections and gastroenteritis accounted for between $50 \%$ and $60 \%$ of all spells of absence. ${ }^{31}$ In the final part of the thesis sickness absence as a result of common infections was subject of study. If employees report an infection, who will be on sick leave and who will go on and attend work? High levels of psychological job demands and low decision latitude, did not have an effect on the decision to be absent from work when reporting an infection. However, low levels of commitment and job satisfaction, and the presence of a longstanding disease did increase the chance to be absent during a common cold. Having an executive function, and working in three or five shifts decreased the chance to be absent from work during all three common infections. We conclude that, absence during a common cold, is more influenced by motivational factors than by demands in work. Absence during flu-like illness and gastroenteritis is more health related. Because of the severity of the latter infections in comparison with the common cold work-related factors can only play a minor role in the decision to be absent.

\section{Conclusions and implications for health research}

In this thesis we found support for the relationship between several work-related factors (high psychological job demands, low decision latitude, job insecurity, shift work) and acute common infections and for the relationship between fatigue and infections. Furthermore, work-related factors (shift work, having an executive function, commitment. job satisfaction, etc) and health related variables (fatigue and the presence of a longstanding disease), have their effect on the decision to be absent from work during an infection. So, it can be concluded that a poor work environment has its effect on the prevalence of common infections, and thus on the employees well-being, and possibly on the productivity and the level of sickness absence. Consequently, common infections 
should be added to the list of adverse health effects as a result of a poor work environment. Because of the high prevalence of these common infections, this negative health effect should be considered as a major one in regard to the work environment. As an example, $50 \%$ of the total cohort of the employees reported a common cold in the questionnaire of January 2001 (chapter 7 ), almost $30 \%$ reported to be absent from work due to this cold, resulting in approximately 4450 sick days in this period of four months, and an average of 0.6 sick days per person in our cohort. Taken into account that an adult typically gets two to five colds a year, ${ }^{3}$ this results in at least 1.2 sick days a year per persion due to a cold. In 2001, the Dutch population, consisted of over 7 million employees. This means that per year 8.4 million days of work are lost due to a common cold. In chapter 2 , an OR of 1.20 was found for the relationship between psychological job demands and common cold, resulting in an population attributable risk of almost $5 \%$. Reducing high job demands can result roughly in a decrease of over 420,000 sick days due to common cold. Although this calculation, should be interpreted with some caution because several assumptions had to be made, it can be concluded that negative aspects from the work environment can have an important impact on work absenteeism, which indicates the necessity to develop preventive measures.

\section{Preventive measures}

Although it is not the goal of this thesis to come up with ready-made interventions, possible starting-points for interventions could be discussed. With regard to the accurrence of common infections, preventive measures could be introduced at different points, influencing the source of infections and susceptibility to the viruses responsible for these infections.

It is unthinkable to reduce exposure to the pathogens, responsible for acute common infections, because of their universal nature, which makes that any social activity may result in contact with the pathogen and subsequently lead to an infection. Therefore, preventive measures should concentrate on the factors that increase susceptibility to infections. Reducing those factors responsible for a poor work environment, might result in a decrease of the incidence of common infections. In order to come up with interventions in the work environment, it should be determined if factors like high psychological job demands, low decision latitude, job insecurily, and work schedules can be changed, in order to create a healthier work environment. As discussed earlier factors like psychological job demands and decision latitude are subjective experiences of an individual employees about the demands in his or her work. In order to change perceived demands, one should change among other things the perception of the emplayee. But objective demands in the work environment are probably the basis for the perceptions. Thus reducing these factors at a higher level (for instance department or company levell) may also influence the perception of the individual employee. Feelings of job insecurity, as a result of an upcoming reorganization or downsizing, are difficult to prevent from happening. Reorganizations and downsizing usually do not affect the complete organization. But as long as there is no security about the faith of the employees, (almost) everyone will experience job insecurity. A shorter period of insecurity would be beneficial for the health, because it will than only affect a small part of the employees within a company. Another work-related factor that was investigated in relation to the 
occurrence of common infections, was working in different shift systems. Especially, employees in three-shift work reported more infections in comparison with day workers, or employees in other shifts. For several companies in the Maastricht Cohort Study. working in shifts is necessary in order to keep the production process going. Therefore influencing this factor is difficult. But, it should be kept in mind, that not every employee is capable of working in shifts. In a study of Jansen et al.." it was found, that shift workers changing from shift work to day work reported substantially higher levels of fatigue levels prior to change, compared to those remaining in shift work. Fatigue, which was also associated with common infections, is frequently cited as a major cause of shift work intolerance. ${ }^{33}$ If employees, who are unable to cope with the demands or fatigue accompanying their shift work, have the possibility to change to day work, it may result in less infections and absenteeism. Both fatigue and burnout showed to increase the occurrence of infections. Common infections could also result in fatigue afterwards. Early detection of fatigue or burnout is valuable in order to possibly decrease the occurrence of common infections, and possibly reducing absenteeism, assuming that high levels of fatigue or burnout complaints can be decreased. As described in chapter 5 , changes in the level of fatigue have an effect on the occurrence of common infections.

Another issue regarding the susceptibility is that psychosocial factors may have their greatest effect among those whose immune systems are already affected, such as the elderly, individuals whose health is already impaired, and patients with immunosuppressive diseases. ${ }^{34}$ These situations can hardly be influenced. Voluntary influenza vaccinations programs among thealthy employees, as a preventive measure, are currently hot topics within companies. An influenza vaccination is effective against an influenza virus. However, true influenza infections account only for a small part of the acute common infections.

\section{Final conclusion}

Common infections can be considered as multiple determined events. Although the work situation is only one, and not the primary etiological agent, of the many areas, which have an influence on the devellopment and progression of common infections, it should be considered as an important risk factor.

\section{References}

1. Cohen $S$. Psychological stress and susceptibity to upper respiratory infections. Am d Respir Crit Care Med 1985;152(4 Pt 2):553-8.

2. Cohen $S$, Tyrrell DA, Smith AP. Psychological stress and susceptibility to the common cold. N Engl J Med 1991;325(9):606-12.

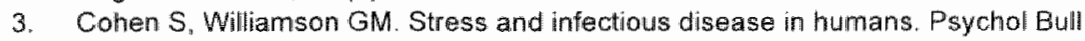
$1991 ; 109(1): 5-24$.

4. Stone AA, Bowbjerg DH, Neale JM, Napoli A, Valdimarsdottir H, Cox D, et al. Development of common cold symptoms following experimentall rhinovirus infection is related to prior stressful life events. Behaw Med 1992;18(3):115-20. 
5. Amick $\mathrm{B}$. Kagl S. Work Stress, In: McDonald $\mathrm{C}$ editor. Epidemiology of work-related diseases. London: BMu Publishing Group: 2000. p. 283-308.

6. Watson D. Clark LA. Negative affectivity: the disposition to experience aversive emotional states, Psychol Bull 1984;96:465-90.

7. van den Brandhof WE, Kroes ACM Bosman A. Peeters MF. Hejnen MLA. Rapportage van virologische diagnostiek in Nederland. Representativiteit van de gegevens uit de virologische weekstaten. [Reporting virusi diagnostics in the Netherlands: representativeness of the virological weekly reports. Infectieziekten Bulletin 2002;13(4):110-13.

8. Clover RD, Abell T, Becker LA, Crawford S, Ramsey $C N$, Jt. Family functioning and stress as predictors of influenza B infection. J Fam Pract 1989;28(5):535-9.

9. Boyce WT, Jensen EW, Cassel JC, Collier AM, Smith AH, Ramey CT. Influence of life events and family routines on childhood respiratory tract illness. Pediatrics 1977;60(4 Pt 2):609-15.

10. Graham NM, Diouglas $\mathrm{RM}_{\varepsilon}$ Ryan $P$. Stress and acute respiratory infection. Am J Epidemiol 1986;124(3):389-401.

11. Meyer RJ, Haggerty RJ. Streptococcal infections in families. Pediatrics 1962;29:539-549.

12. Turner Cobb JM, Steptoe A. Psychosocial stress and susceptibility to upper respiratory tract illness in an adult population sample. Psychosom Med 1996:58(5):404-12.

13. Cohen S, Frank E, Doyle WJ, Skoner DP, Rabin BS, Gwaltney JM, Jr. Types of stressors that iricrease susceptibility to the common cold in healthy adults. Health Psychol 1998;17(3):21423.

14. Cohen S, Tyrrall DA, Simith AP. Negative life events, perceived stress, negative affect, and susceptibility to the common cold. I Pers Soc Psychol 1993;64(1):131-40.

15. Glaser R, Rice J, Sheridan J, Fertell R, Stout J, Speicher $C$, et al. Stress-related immune suppression: health implications. Brain Behav Immuin 1987;1(1):7-20.

16. Karasek RA. Job Demands, Job Decision Latitude, and mental strain: Implications for jab pedesign. Adm Sci Q 1979;24:285-311.

17. Karasek RL, Theorell T. Healthy wark: Stress, productivity and the construction of working life. New York: Basic Books; 1990.

18. Frese M, Zapf D. Methodological issues in the study of work stress: Objective vs subjective measurement of work stress and the question of longitudinal studies. in: Cooper CL, Payne $R$. editors. Causes, Coping and Consequences of Stress at Work. Chichester. Wiley; 1988. p. $375-411$

19. Barling J, Kelloway EK. Job insecurity and health: The moderating role of workplace control. Stress Med 1996;12(4):253-59.

20. Van Vuuren CV. Met ontslag bedreigd: Werknemers in onzekerheid over hun arbeidsplaats bij veranderingen in de organisatie [Threatened with redundancy: Workers in job insecurity during organizational change]. Amsterdam: VU uitgeverij; 1990.

21. Vercoulen JH, Swanink CM, Fennis JF, Galama JM, van der Meer JW, Bleijenberg G. Dimensional assessment of chronic fatigue syndrome. J Psychosom Res 1994;38(5):383-92.

22. Beurskens AJ, Bultmann U, Kant IJ, Vercoulen JIH, Bleijenberg G. Swaen GM. Fatigue among working people: validity of a questionnaire measure. Occup Environ Med 2000;57(5):353-7.

23. Schaufeli WB, van Dierendonk. D. UBOS, Utrechtse Burnout Schaal, Handleiding. Lisse: Swets Test Publishers; 2000.

24. Schaufeli WB, Leiter MP, Maslach C, Jackson SE. MBI-General Survey. 3rd ed. Palo Alto, CA: Consulting Psychologists Press; 1996.

25. Drossman DA. The Rome criteria process: diagnosis and legitimization of irritable bowel syndrome. Am J Gastroenterol 1999;94(10):2803-7.

26. Vanner S.J, Depew WT, Paterson WG, DaCosta LR, Groll AG, Simon JB, et al. Predictive value of the Rome criteria for diagnosing the irritable bowel syndrome. Am J Gastroenterol $1999 ; 94(10): 2912-7$.

27. Cope H, David A. Pelosi A, Mann A. Predictors of chronic "postviral" fatigue. Lancet $1994 ; 344(8926): 864-8$.

28. Hotopf $M$, Noah $N$, Wessely $S$. Chronic fatigue and minor psychiatric morbidity after viral meningitis: a controlled study. J Neurol Neurosurg Psychiatry 1996;60(5):504-9. 
29. Wessely S, Chalder T, Hirsch S, Pawlikowrska T. Wallace P. Wright DJ. Postinfectious fatigue: prospective cohort study in primary care. Lancet 1995;345(8961):1333-8.

30. Bültmann U, Kant IJ, Van den Brandt PA, Kasi SV. Psychosocial work characteristics as risk factors for the onset of fatigue and psychological distress: Prospective results from the Maastricht Cohort Study. Psycholl Med 2002;32:333-45.

31. Feeney $A$, North F, Head J, Canner R, Marmot M. Socioeconomic and sex differentials in reason for sickness absence from the Whitehall II Study. Occup Environ Med 1998:55(2):91-8.

32. Jansen NWH, van Amelswoort LGPM, Kristensen TS, van den Bramdt PA, Kant I. Work schedules and fatigue. A prospective cohort study. (submitted for publication).

33. Harrington JM. Shift work and health. A critical review of the literature on working hours. Ann Acad Med Singap 1994:23(5):699-705.

34. Kiecolt Glaser JK "Glaser R. Methodological issues in behavioral immunology research with humans. Brain Behav Immun 1988;2(1):67-78. 


\section{Summary}

Acute common infections, such as the common cold, influenza-like illnesses, and gastroenteritis are very prevalent in the general population, and cause considerable discomfort and absenteeism. These infections are subject of the studies described in this thesis.

Over the years, evidence has accumulated that stress, caused by psychosocial factors, influences the immune system and subsequently the susceptibility to infections and the duration of symptoms. The work environment can be a source of stress caused by several work-related factors. Although there are a number of studies which demonstrate a link between work stress and changes in the immune system, in only a few studies the relationship between work stress and the risk for infections has been investiglated. Workrellated factors are also risk factors for fatigue, and fatigue may act as an intermediate between work-related stressors and common infections. Fatigue may also play a role in the susceptibility to acute viral infections. Virall infections are usulally accompanied by fatigue, and can trigger long-term fatigue and chronic fatigue syndrome. The effect of work-related factors on the occurrence of common infections is still unclear. Evidence is mainly based on cross-sectional studies, under experimental conditions.

The aim of this thesis was to study the relationship between several work-related factors. and the occurrence of acute common infections, and the potential role of fatigue in this relationship. In the introduction (chapter 1) the rationale of the study, a description of causes and symptoms of acute common infections, the impact of acute common infections, and a description of the design of the Maastricht Cohort Study is given. The Maastricht Cohort Study on "Fatigue at Work", was used as a sampling frame to further elucidate the relationships. At baseline, the Maastricht Cohort Study surveyed a large heterogeneous population of employees $(n=12,140)$. The participants received nine questionnaires in total, at four-monthly intervals and a total observation period of three years. The main health outcome in this thesis was the occurrence of common infections. The occurrence of common cold, flu-like illness, and gastroenteritis was inventoried in each questionnaire, using self-reported information on common infections symptoms. In large scale cohort studies the use of questionnaires is almost inevitable, but it may lead to under or over reporting of the effect. A small pilot study among a group of generail practitioners (GPS), in which good correspondence was found between GPs diagnosis and the subjective experience of their patients, was performed in order to test the validity of the infection items in the questionnaire. Furthermore, the prevalence of the acute common infections was compared with virology weekly reports. It was concluded that the use of self-reports of common infections was a valuable method to determine common infections. Other methods, such as serology "were not practical due to large samples.

In the first part of the thesis the effect of several work-related factors on the occurrence of common infections was investigated. In chapter 2 , primarily the effect of psychological job demands on the occurrence of clinical symptoms of common cold was investigated. The effect of decision latitude, another dimension of the "Job Strain model", and the effect of the interaction between psychological job demands and decision latitude, on the 
occurrence of common cold was also investigated. In addition, factors such as age, gender, having asthma, smoking and alcohol use, having young children, and having a leadership position were considered as potential confounding factors. In this study, wo separate cross-sectional analyses were performed using the baseline data from the Maastricht Cohort Study. In the first logistic regression analysis, the adjusted odd ratio (OR) for having a cold in the past four months in subjects reporting high psychological job demands (upper quartile) versus those reporting low psychological job demands (bottom quartile) was 1.20 ( $\mathrm{Cl} 1.08$-1.33). A higher risk emerged among those with young children (OR $1.70 ; \mathrm{Cl} 1.47-1.96$ ), those having a history of asthma (OR $1.69 ; \mathrm{Cl}$ 1.28-2.22) or being under the age of 40 (OR 1.28; $\mathrm{Cl} 1.14-1.43$ ) and among smokers (OR 1.23; $\mathrm{Cl} 1.09-1.38$ ). In a second analysis, the psychological job demands score was used as a continuous score, and the decision latitude scale was added as a continuous variable to the model as well. For this analysis the complete population was taken into consideration. Employees reporting high psychological job demands reported significantly more common colds (OR $1.13 ; \mathrm{Cl} 1.06-1.21)$. An inverse relationship between decision latitude and the risk for common cold was found. The results supported an association between psychological job demands and common cold. In spite of the almost inevitable shortcomings of a large cohort study using questionnaires, the relationship between common cold and work-related factors was investigated in a nonexperimental setting with participants, observed in a natural environment with all the normal everyday hassles.

In chapter 3 , the role of job insecurity, on the occurrence of acute common infections and health complaints is described. Job insecurity due to downsizing and the closure of facilities has been connected to negative changes in self-rated health, increases in longstanding illness, adverse sleep patterns, minor psychiatric morbidity, increase in sickness absence and somatic symptoms. Job insecurity may also lower the employee's resistance to infections and consequently increase the incidence of infections. Both cross-sectional and longitudinal analyses were performed in order to study the effect of job insecurity on the occurrence of common cold, flu-like illness, gastroenteritis, and health complaints. To gain insight in possible underlying mechanisms, linking job insecurity to common infections or health complaints, adjustments were made for several potential confounding factors (demographics, health behavior, health, and job characteristics) in consecutive steps in the analyses. A cross-sectional relationship between job insecurity and common infections or health complaints was found. For the longitudinal analyses, the largest effect was found for flu-like illness (OR 1.39; $\mathrm{Cl} 1.22$ 1.57) and health complaints (OR 1.51; Cl 1.39-1.64). Additional correction for health behavior (smoking and drinking habits), the presence of a longstanding disease, and work-related demands, resulting in lower ORs. An increase in common infections or health complaints has a substantial impact on the employees well-being and may result in economic consequences for the company.

Work schedules, or in other words working in shifts, can be seen as a more objective work related factor in comparison with psychological job demands or job insecurity. The role of working in different shifts systems on the occurrence of common infections was investigated in chapter 4. Employees in the different work schedule groups were 
matched on job title. For example, employees working three-shift systems, were matched with a reference group of day-workers with similar job titles. We used a multilevel analysis, in which employees (level 1) were nested within job titles (level 2), adjusted for demographics, longstanding disease, health behavior, work-related factors, fatigue and sleep quality. Results from the multilevel analyses showed that, compared to day work, shift work was associated with a higher risk for common infections, with the highest risk in three-shift workers. Compared to day work, shift work was further associated with differences in health, health behavior, sleep, fatigue and perceived job characteristics, factors which may influence the occurrence of infections and should be taken into account in future studies as well.

As described in the introduction (chapter 1), fatigue may be associated with common infections, or play an intermediate role in the relationship between work-related factors and common infections. To study the complex relationship between work-related factors, common infections and fatigue a longitudinal approach is a prerequisite, in order to disentangle the role of fatigue in the etiology of common infections. Two different expressions of fatigue were subject of study. In chapter 5 , the relationship between fatigue, measured with the Checklist Individual Strength, and the occurrence of common infections was investigated. The results of this study are based on the first seven successive questionnaires. Regression analyses using Generalized Estimated Equations were used for data analyses. It was found, that fatigue is a frequent symptom during infections. Furthermore, a longitudinal relationship between an infection as a predictor of fatigue was found. For fatigue as a predictor of an infection, we found ORs of 1.35 ( $\mathrm{Cl}$ 1.28-1.42) for flu-like illness and 1.33 (Cl 1.25-1.42) for gastroenteritis. The highest incidence of infections was found among employees who reported high fatigue levels on two successive accasions. The increased incidence of infections is regarded as a substantial effect of fatigue because it is associated with significant absenteeism from work and leads to discomfort.

In chapter 6, the role of bumout as a risk factor for common cold, flu-like illness, and gastroenteritis was investigated. Burnout has traditionally been associated with jobs in the human service sector involving intensive contact with people in need of aid. However, more recently burnout is also considered a major issue in occupational health in other sectors. Burnout as encountered outside human services comprises three elements: Exhaustion, Cynicism and Professional efficacy. The Maslach Burnout Inventory-General Survey (MBI-GS) has been specifically developed to assess burnout outside human services. There have been a very few studies dealing with burnout as a precursor of illiness. Burnout may have a negative effect on the immune system and consequently increase the incidence of infections. The MBI-GS was used to define employees with burnout complaints (level one) and clinical burnout (level two). The cross-sectional relationship between burnout and the occurrence of common infections was assessed at baseline, using logistic regression analysis. Survival analysis, was performed to study the longitudinal relationship between burnout and the subscales of the MBI-GS as risk factors for common infections. For both levels of burnout an increased incidence of common infections was found at baseline. The largest effect was found for the relationship between burnout and gastroenteritis (OR 1.86; Cl 1.57-2.21 for 
level one, and OR 3.59; $\mathrm{Cl} 2.09-6.17$ for level two). The longitudinal analyses showed comparable results, although less pronounced. The largest effect was again found for gastroenteritis (RR 1.55; Cl 1.28-1.86 for level one, and RR 2.09; Cl 1.09-3.98 for level two). For flu-ike illness and common cold we found smaller but significant effects at level one, but not at level two. The subscale 'Exhaustion' was found to be the strongest predictor for infections at both levels of burnout. This study provides evidence for burnout as a risk factor for common infections in a large heterogeneous population.

A large percentage of absenteeism is caused by infections. In the final part of this thesis, sickness absence as a result of common infections was subject of study. In chapter 7. the effect of health and work-related factors as predictors of subsequent sickness absence when experiencing common infections was studied. Employees reporting an infection in the final questionnaire (T8) were selected. The effect of work-related factors, fatigue and health on the decision to be absent from work was studied using multivariate survival analysis. This analysis revealed no significant effects of job demands, decision latitude or job strain on absence in workers experiencing common infections. Low levels of commitment (RR 1.22; Cl 1.03-1.44), and low job satisfaction (RR 1.36; Cl 1.13-1.164) increased the risk of being absent during a common cold. Also having a longstanding disease increased the chance of being absent during a common infection. Having an executive function decreased the chance of being absent. It was concluded that absence during a common cold is partly influenced by motivational factors in work, in contrast to more severe common infections, such as influenza(-like illnesses) which are more health related. Insight in factors related to absenteeism, are important as a starting point for preventive measures to reduce sickness absence.

In chapter 8 , the epilogue, the results of this thesis were presented in a broader perspective. The validity of the method to determine the presence of acute common infections was discussed. From the results from chapter 2,3 , and 4 , it can be concluded that both objective and subjective work-related factors influenced the occurrence of common infections. This means that aithough subjective tactors couid possibily be influenced by negative affectivity, they can induce comparable results as objective factors, indicating that the individual's perception of the work environment, is an important issue to take into account when developing preventive measures. The role of fatigue in relation to the occurrence of common infections was discussed on the basis of the results from chapter 5 and 6 , in which two different expressions of fatigue (fatigue determined with the Checklist Individual Strength and burnout as determined by the MBIGS) were used. Because the relatively low correlation between the two concepts and the small overlap between fatigue and burnout cases, it can be concluded that fatigue and burnout represent two different concepts, which are both associated with an increased risk for common infections. From chapter 7, it was concluded that absence during common cold, is mostly influenced by motiwational factors. Absence as a result of flu-like illness and gastroenteritis is only to a minor level influenced by these factors.

The epilogue ends with conclusions and implications for health research, in which also possible starting points for interventions were discussed. It is concluded that a poor psychosocial work environment has its effect on the prevalence of common infections, 
and thus on the employees well-being, and possibly on the productivity and the level of sickness absence. Therefore common infections, such as common cold flu-like illness, and gastroenteritis, should be added to the list of adverse health effects as a result of a poor psychosacial work environment. Based on the results it is not possible to come up with ready-made interventions, but possible staring points for interventions were discussed, influencing the source of infections and susceptibility to the viruses responsible for these infections.

Common infections can be considered as multiple determined events. Although the work situation is only one, and not the primary etiological agent, of the many factors, which have an influence on the development and progression of common infections, it should be considered as an important risk factor. 


\section{Samenvatting}

Acute infecties, zoals verkoudheid, griep of griepachtige infecties, en buikgriep, komen veel voor in de algemene bevolking en veroorzaken veel ongemak en verzuim op het werk. Deze infecties zijn onderwerp van studie in dit proefschrift.

In de afgelopen jaren is bewijs verzameld dat stress als gevolg van psychosiociale factoren, het immuunsysteem kan beïnvloeden en als gevolg daarvan de gevoeligheid voor infecties en de duur van de symptomen kan beinvlloeden. De werkomgeving kan een bron zijn van stress, veroorzaakt door werkgerelateerde factoren. Hoewel er studies beschikbaar zijg die een verband aantonen tussen werkstress en veranderingen in het immuunsysteem, zijn er maar weinig studies waarin de relatie tussen werkstress en het risico op infecties is anderzocht. Werkgerelateerde factoren kunnen ook worden gezien als risicofactoren voor vermoeidheid en vermoeidheid zou gezien kunnen worden als een intermediair tussen werkgerelateerde factoren en infecties. Vermoeidheid zou ook een rol kunnen spelen bij de gevoeligheid voor acute virale infecties. Virale infecties gaan vaak gepaard met vermoeidheid, en kunnen mogelijk langdurige vermoeidheid en het chronisch vermoeidheid syndroom veroorzaken.

Het doel van dit proefschrift is om de relaties tussen werkgerelateerde factoren en acute veelvoorkomende infecties, en de potentiële rol van vermoeidheid in deze relatie, te onderzoeken. In de introductie (hoofdstuk 1) wordt de basis van de studie, een beschrijving van de oorzaken en symptomen van acute infecties, de impact van acute infecties en het design van de Mlaastrichtse Cohort Studie beschreven. De Maastrichtse Cohort Studie naar "Vermoeidheid in de Arbeidssituatie", is gebruikt als sample frame om de relaties op te helderen. Bij baseline werd in de Maastrichtse Cohort Studie een grote heterogene populatie van werknemers $(n=12,140)$ gevolgd. De deelnemers ontwingen negen vragienlijsten mel een interval var vier maanden en een totale observatieperiode van drie jaar. De belangrijkste gezondheidsuitkomst in dit proefschrift is het voorkomen van acute infecties. Het optreden van verkoudheid, griep en buikgriep is geinventariseerd in elke vragenlijst, waarbij gebruik is gemaakt van zelifgerapporteerde informatie over de symptomen van deze infecties. In grootschalige cohort studies is het gebruik van vragenlijsten bijna onvermijdelijk, maar dit zou wel tot onder- of overrapportage van het effect kunnen leiden. Een kleine pilat studie onder een groep huisartsen, is uitgevoerd om de validiteit van de infectie-items in de vragenlijst te testen. Hierin werd een goede overeenkomst gevonden tussen de gestelde diagnose door de huisarts en de subjectieve beleving van de patiënten. Verder zijn de prevalenties wan de acute infecties wergeleken met de Virologische weekstaten. Op basis van deze resultaten is geconcludeerd dat het gebruik van zelfgerapporteerde gegevens om het optredlen van acute infecties te bepalen. gezien kan worden als een valide methode. Andere methoden, zoals bijvoorbeeld het gebruik van serologie, waren niet praktisch uitvoerbaar in verband met het groot aantal participanten in de studie.

In het eerste deel van het proefschrift werd het effect wan verschillende werkgerelateerdle factoren op het optreden van acute infecties onderzocht. In hoofdstuk 2, wordt primair het effect van psychologische taakeisen op het voorkomen van symptomen van 
verkoudheid onderzocht. Het effect van regelmogelijkheden, een andere dimensie van het "Job Strain model" en het effect van de interactie tussen psychologische taakeisen en regeimogelijkheden op verkoudheid, werd ook onderzocht. Verder werden factoren zoals, leeftijd, geslacht, het hebben van astmatische klachten, roken, alcoholgebruik, het hebben van jonge kinderen en het geven van leiding, gezien als potentiële confounders. In deze studie zijn twee verschillende cross-sectionele analyses uitgevoerd op de baseline data van de Maastrichtse Cohort Studie. In de eerste logistische regressieanalyse, is een gecorrigeerde odds ratio (OR) van 1,20 (betrouwbaarheidsinterval (BI) 1,08-1,33) gevonden woor verkoudheid in de afgelopen vier maanden bij werknemers die hoge psychologische taakeisen rapporteren (hoogste kwartiel) in vergelijking met een groep die lage psychologische taakeisen rapporteerde (laagste kwartiel). Een hoger risico kwam naar voren onder werknemers, met jonge kinderen (OR 1,70; $B \| 1,47-1,96$ ), met astma (OR 1,69; $\mathrm{C} \| 1,28-2,22$ ), die jonger waren dan 40 jaar (OR 1,$28 ; \mathrm{BI} 1,14$ 1,43 ), en onder rokers (OR $1.23 ; \mathrm{Cl} 1.09-1,38$ ). In een tweede analyse, is de score op de schaal psychologische taakeisen als een continue variabele meegenomen. Verder is de score op de schaal regelmogelijkheden ook als een continue variabele aan het model toegevoegd. Voor deze analyse is de gehele populatie meegenomen. Werknemers met hoge psychologische taakeisen rapporteerden significant meer verkoudheden (OR 1,13: BI 1,06-1,21). Een omgekeerde relatie werd gevonden tussen regelmogelijkheden en het risico op een verkoudheid. De resultaten ondersteunen een associatie tussen psychologische taakeisen en verkoudheid. Ondanks de bijna onvermijdelijke tekortkomingen van een grootschalige cohort studie waarbij gebruik gemaakt wordt van wragenlijsten, werd de relatie tussen werkgerelateerde factoren en verkoudheid wel onderzocht in een niet-experimentele setting, waarbij de deelnemers werden gevolgd in hun natuurlijke omgeving met alle normale dagelijkse beslommeringen.

In hoofdstuk 3 wordt de rol van toekomstonzekerheid op het optreden van acute infecties en gezondheidsklachten onderzocht. Toekomstonzekerheid als gevolg van inkrimping en sluiting van bedrijven is al in verband gebracht met negatieve veranderingen in zelfgerapporteerde gezondheid, toename in langdurige ziekten, ongunstige slaappatronen, psychische klachten, toename in ziekteverzuim en somatische symptomen. Toekomstonzekerheid zou ook de weerstand van werknemers tegen infecties kunnen beînvloeden en als gevolg daarvan kunnen resulteren in een toename van de incidentie van deze infecties. Er zijn zowel cross-sectionele als longittudinale analyses uitgevoerd om het effect van toekomstonzekerheid op het optreden van verkoudheid, griep, buikgriep en gezondheidsklachten te onderzoeken. Om inzicht te krijgen in mogelikke onderliggende mechanismen, waardoor toekomstonzekerheid in verband kan worden gebracht met infecties en gezondheidsklachten, is er achtereenvolgens gecorrigeerd voor verschillende potentiële confounders (demografische factoren, gezondheidsgedrag, gezondheid, werkkenmerken). Er is een cross-sectionele relatie gevonden tussen toekomstonzekerheid en infecties of gezondheidsklachten. In de longitudinale analyse werd het grootste effect gevonden woor griep (OR 1,39; BI 1,22-1,57) en gezondheidsklachten (OR 1,51; BI 1,39-1,64). Achtereenvolgens corrigeren voor gezondheidsgedrag (roken en drinken), de aanwezigheid van een langdurige ziekte, en werkkenmerken, resulteerde in lagere ORs. Een toename in infecties en gezondheidsklachten heeft een substantiële invloed op het 
welbevinden van de werknemers en zou kunnen resulteren in economische consequenties voor het bedrijt.

Werktijdregelingen, of in andere woorden het werk in verschillende ploegendiensten, kan gezien worden als een meer objectieve werkgerelateerde factor in vergelijking met psychologische taakeisen of toekomstonzekerheid. De rol van verschillende werktijdregelingen op infecties is onderzacht in hoofdstuk 4. Werknemers in verschillende werktijdregelingen zijn gematched op beroep. Bijwoorbeeld, werknemers in 3-ploegendienst zijn gekoppeld aan een referentiegroep van dagdienstmedewerkers in vergelijkbare beroepen. Er is een multillevel analyse uitgevoerd waarbij werknemers (niveau 1) zijn genest binnen beroepen (niveau 2), hierbil is gecorrigeerd voor demografische factoren, langdurige ziekte, gezondheidsgedrag, werkgerelateerde factoren, vermoeidheid en slaapkwaliteit. De resultaten van de multilevel analyse lieten zien dat in vergelijking met dagdienst, het werken in ploegendienst was geassocieerd met een hoger risico op infecties, het hoogste risico werd gevonden onder 3ploegendienstwerkers. In vergelijking met dagdienst, was het werken in ploegen verder geassocieerd met verschillen in gezondheid, gezondheidsgedrag, slaap, vermoeidheid en ervaren werkkarakteristieken, factoren die mogelijk ook het optreden van infecties kunnen beïnvloeden en daarom ook in vervolgstudies meegenomen dienen te worden.

Zoals beschreven in de introductie (hoofdstuk 1), is vermoeidheid mogelijk geassocieerd met infecties, of speelt het een rol in de relatie tussen werkgerelateerde factoren en infecties. Om de complexe relatie tussen werkgerelateerde factoren, infecties en vermoeidheid te bestuderen is een longitudinale aanpak een belangrijke voorwaarde. Op deze manier zou mogelijk de rol van vermoeidheid in de etiologie van infecties ontrafeld kunnen worden. Twee verschillende expressies van vermoeidheid zijn onderwerp van studie geweest. In hoofdstuk 5, is de relatie tussen vermoeidheid, gemeten met de Checklist Individuele Spankracht en infecties onderzocht. De resultaten van deze studie zijn gebaseerd op de data van de eerste zeven opeenvolgende vragenlijsten, dit betreft de eerste twee jaar van follow-up. Voor de data-analyse is gebruik gemaakt van regressie-analyse met Generalized Estimating Equations. Er werd gevonden dat vermoeidheid een frequent symptoom is tijdens infecties. Verder is er een longitudinale relatie gevonden tussen infecties als voorspeller van vermoeidheid. Voor vermoeidheid als woorspeller van een infectie hebben we ORs gevonden van 1,35 (BI 1,28-1,42) voor griep en 1.33 (BI 1,25-1,42) voor buikgriep. De hoogste incidentie van infecties is gevonden onder werknemers die op twee opeenvolgende metingen hoge vermoeidheid rapporteerden. De toegenamen incidentie van infecties kan gezien worden als een substantieel effect omdat het geassocieerd is met significant verzuim en leidt tot veel ongemak.

In hoofdstuk 6, is de rol van bumout als risicofactor voor verkoudheid, griep, en buikgriep onderzocht. Burnout is van origine geassocieerd met beroepen binnen de dienstverlenende sector, waarbij intensief contact is met hulpbehoevende mensen. Meer recent is bumout ook beschouwd als een belangrijk onderwerp binnen andere sectoren. Burnout buiten de dienstwerlenende sector omvat drie elementen: uitputting, distantie en competentie. De Maslach Burnout Invetory-General Survey (MBI-GS), is speciaal 
ontwikkeld om ook burnout te kunnen bepalen buiten de dienstverlenende sector. Er zinn maar weinig studies geweest waarin het effect van burnout als voorloper van een ziekte is onderzocht. Burnout zou mogelijk ook negatieve effecten op het immuunsysteem kunnen hebben en als gevolg daarvan een toename in de incidentie van infecties kuninen veroorzaken. De MBI-GS is gebruikt om werknemers met burnout klachten (niveau 1) en klinische burnout (niveau 2) te definiêren. De cross-sectionele relatie tussen burnout en infecties is bepaald op baseline, waarbij gebruk is gemaakt van logistische regressie-analyse. Om de longitudinale relatie tussen burnout en de subschalen van de MBI-GS als risicofactor voor infecties te bestuderen is gebruik gemaakt van survival-analyse. Voor beide niveaus van bumout is een verhoogde incidentie gevonden op baseline. Het grootste effect werd gevonden voor de relatie tussen burnout en buikgriep (OR 1,86; BI 1,57-2,21 voar niveau 1 en OR 3,$59 ; 812,09$ 6,17 voor niveau 2). De longitudinale analyses lieten vergelijkbare, maar minder uitgesproken resultaten zien. Het grootste effect werd ook hier gevonden vaor buikgriep ( $R R$ 1.55; $\mathbb{B l} 1,28-1,86$ ) voor niveau 1, en RR 2,09; BI 1,09-3,98 voor niveau 2). Voor griep en verkoudheid vonden we kleinere maar significante effecten op niveau 1 , maar niet op niveau 2. De subschaal "vermoeidheid" werd gezien als een sterke voorspeller van infecties op beide niveaus van burnout. Deze studie geeft bewijs voor burnout als risicofactor voor infecties in een grote heterogene populatie.

Een hoog percentage wan het totale verzuim wordt veroorzaakt door infecties. In het laatste onderdeel van dit proefschrift, was ziekteverzuim als gevolg van veelvoorkomende infecties onderwerp van studie. In hoofdstuk 7, is hel effect van gezondheid en werkgerelateerde factoren als voorspellers van verzuim tijdens infecties onderzocht. Werknemers die in de laatste vragenlijst (T8) aangaven dat ze een infectie hadden, zijn geselecteerd. Het effect van werkgerelateerde factoren, vermoeidheid en gezondheid op de beslissing om tijdens een infectie thuis te bliven werd bestudeerd in een mulitvariate survival-analyse. Deze analyse liet geen significante effecten van taakeisen, regelmogelijkheden of "job strain" op werzuim bij werknemers met infecties zien. Weinig commitment (RR 1,22; $\mathrm{Bl} 1,03-1,44$ ) en een laag niveau van werksatisfactie (RR 1,36; Bl 1,13-1,64) verhoogde het risico om te verzuimen tijdens een verkoudheid. Ook het hebben van een langdurige ziekte verhoogde de kans om te verzuimen tijdens een infectie. Het hebben van een leidinggevende positie verkleinde de kans om afwezig te zijn. Er werd geconcludeerd dat verzuim tijdens een verkoudheid gedeeltelijk wordt beirvloed door motivationele factorem in het werk, in tegenstelling tot ernstigere infecties zoals griep en buikgriep die meer gezondheidsgerelateerd zijn. Inzicht in factoren, gerelateerd aan verzuim, is een belangrijk startpunt voor preventieve maatregelen om ziakteverzuim te reduceren.

In de epiloog in hoofdstuk 8 , worden de resultaten in een breder perspectief geplaatst. De validiteit van de methode om het optreden van infecties te bepalen wordt bediscussieerd. Uit de resultaten van hoofdstuk, 2,3, en 4, kan geconcludeerd worden dat zowel objectieve als subjectieve werkgerelateerde factoren het optreden van infecties beinvloeden. Dit betekent dat hoewel subjectieve factoren mogelijk beinvioed worden door negatieve affectiviteil "ze vergelijkbare resultaten kunnen induceren in vergelijking met objectieve factoren. Dit wijst erop dat de perceptie van het individu over 
de werkomgeving een belangrijk punt is om mee te nemen als er preventieve maatregelen worden ontwikkeld. De rol van vermoeidheid in relatie tot infecties werd besproken op basis van de resultaten uit hoofostuk 5 en 6 , waarin twee verschillende expressies van wermaeidheid zijn gebruikt. Vanwege de relatief lage correlatie fussen de twee concepten en de kleine overlap tussen vermoeidheid en bumout cases, kan geconcludeerd worden dat vermoeidheid en burnout twee verschillende concepten representeren, beiden geassocieerd met een verhoogd risico of infecties. Op basis wan hoofdstuk 7, wordt geconcludeerd dat verzuim tijdens een verkoudheid voomamelijk wordt veroorzaakt door motivationele factoren. Absentie tijdens griep en buikgriep wordt nauwelijks beïnvloed door deze factoren.

De epiloog wordt beëindigd met conclusies en implicaties voor verder onderzoek en de praktijk, waarbij ook startpunten voor interventies worden besproken. El wordt geconcludeerd dat een slechte werkomgeving effect heeft op de prevalentie van infecties, en dus ook op het welzijn van de werknemers, en mogelijk op de productiviteit en het ziekteverzuim. Daarom dienen acute infecties zoals verkoudheid, griep en buikgriep toegewoegd te worden aan de lijst van negatieve gezondheidseffecten als gevolg van een slechte psychosociale werkomgeving. Op basis van de gevonden resultaten is het niet mogelijk om te komen met pasklare interventies. Startpunten voor interventies worden wel bediscussieerd, waarbij de bron van infecties en de gevoeligheid voor de virussen verantwoordelijk voor de infecties als uitgangspunten zijn genomen.

Infecties kunnen gezien worden als multifactorieel bepaalde gebeurtenissen. Hoewel de werksituatie maar één van de factoren is die de ontwikkeling en progressie van deze infecties beïnvloeden en niet de primaire etiologische factor is, moet deze wel gezien worden als een belangrijke factor. 


\section{Dankwoord}

Om te voorkomen dat een dankwoord geheel met melancholiek doorspekt zou worden werd me enkele maanden geleden aangeraden om hell niet op het laatste moment te schrijven. De verleiding is groot om iedereen te gaan bedanken tot aan de hond van de buren toe, omdat hij 's morgens altijd zo trouw kijkt, Maar zoals met zo veel dingen worden de puntjes op het laatste moment pas op de "i" gezet.

Het onderzoek, waar dit proefschrift het resultaat van is, was natuurlijk niet mogelijk geweest zonder de deelname van meer dan 12.000 werknemers uit 45 verschillende bedrijven. Een groot aantal deelnemers was elke keer weer bereid om de vragenlijsten in te vullen.

Graag wil ik de leden van de begeleidingsgroep bedanken die betrokken zijn geweest bij de opzet en uitvoering van het onderzoek. Als eerste wil ik Gerard Swaen bedanken, als co-promotor en dagelijkse begeleider. Beste Gerard, je hebt me binnen dit project de ruimte gegeven om het naar eigen inzicht in te vullen. Het was prettig, dat de deur van je kamer altijd open stond en ik dus ank makkelijk bij je binnen kon vallen voor vragen of advies. Verder wil ik IJmert Kant, bedanken. Beste IJmert, bedankt voor de plezierige samenwerking. Als ik het overzicht even kwijt was, was je altijd zeer behulpzaam om de belangrijke rode lijnen duidelijk te houden. Ik vind het prettig dat je in de rol van copromotor bij de verdediging zult zijn. Dan mijn promotor Joep Galama. Beste Joep, als promator ben jij altijd zeer betrokken geweest bij dit onderzoek. Ik wil je bedanken voor je uitvoerige commentaar op de manuscripten, waarbij ik altijd zeer snell je oordeel ontving. Verder heb ik het zeer gewaardeerd dat je ook nadat het project een meer epidemiologische wending ging nemen steeds enthousiast bij de discussies betrokken bent gebleven. Beste Onno, als promotor ben jij zoals je zelf zei aan boord van dit project gekomen toen de haven al in zicht was. Ik wil je bedanken voor je commentaar in de eindfase van dit project. Verder wil ik Paul Borm bedanken voor zijn rol bij de opzet van dit project en de begeleiding in de beginfase.

Gelukkig waren bij de Maastrichtse Cohort Studie veel mensen betrokken die met hun vele handen het werk regelmatig lichter maakten. Ik wil dan ook alle onderzoekers en werkgroepleden bedanken voor hun werk bij de opzet en gedurende rit van de Maastrichtse Cohort Studie. De PVA-AIO's: Nathalie Janssen. Helene Andrea en Marcus Hubers voor hun plezierige samenwerking. Ute Bültmann, het is altijd prettig geweest om werkgerelateerde maar ook vaak niet-werkgerelateerde onderwerpen de revue te laten passeren. Hopelijk komen er nog regelmatig gezellige etentjes! Jos. Slangen, jouw werk binnen het cohort is van groot belang geweest. Ik heb veel geleerd van de middagen dat we de data opgeschoond hebben. Verder was je altijd bereid te helpen. Ludovic van Amelswoort, bedankt voor de prettige samenwerking en je adviezen op statistisch vlak. Sandra Beurskens, bedank voor je adviezen op alle gebied! Marliese Saya en Sanne Imbos wil ik bedanken woor al het codeerwerk dat binnen de Maastrichtse Cohort Studie is uitgevoerd. 
Het werk wordt altijd een stuk makkelijker met aardige collega's om je heen. Co-worker social support is van groot belang geweest voor mijn welbevinden de afgelopen vier jaar. Daarom will ilk alle collega's en oud-collega's van de Capaciteitsgroep Epidemiologie bedanken. Een speciaal woord van dank aan Cobie Martens. Cobie, bedankt voor al je hulp bij het lay-outen van mijn boekje. Je was soms sneller dan het licht, je hield me goed aan het werk!

Ook buitem het werk is de social support van groot belang. Mijn "shop till you drop" maatjes Mandy en Sandra, bedankt voor de gezellige uitjes. Marleen. Eelico, Paula en

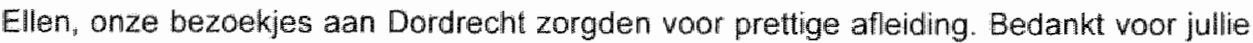
getoonde interessen, de overheerlijke salades en de schitterende tekeningen (ook al waren ze eigenlijk meestal voor Remy). En dan natuurlijk de vrienden van het eerste uur, enne ......... Inge en Ruud en Yvonne en Roger. De schitterende vergezichten (tomatensoep?) waarbij we op de meest gekke plaatsen belandden. De gezellige avonden, de onvergetelijke oud en nieuw vieringen (benieuwd welke juweeltjes we dit jaar weer krijgen?) zorgden weer woor een volle accu na het weekend (en anders in leder geval goede zin). Jansen (Nicole) \& Janssen (Yvonne) als mijn paranimfen. Nicole, omdat we in thet zelfde PVA-schuitje zaten, maar natuurlijk ook omdat alles in de afgelopen vier jaar te bespreken viel ben ik heel blij om je als paranimf te hebben. Woone, als Dr. P., ben jij natuurlijk al een ervaringsdeskundige op promotie-gebied! Het ski-uitje bij min 3 toen het buiten warm was, zorgde net voor dat beetje extra zodat ik weer genoeg inspiratie had. Bedankt voor jullie "mental support" gedurende de hele rit.

En dan heel dicht bij huis.

Ralf en Marlies, bedankt voor jullie interesse en steun. Marlies, elindelijk een creatief brein in de familie, bedankt voor je hulp bij het ontwerpen van de voorkant van het boekje. Ralf, bedankt dat je nog even een kritische blik op mijn Nedierlandstalige epistels hebt geworpen. Misschien zie je nu ook eindelijk in dat het mijn werk toch niet zo'n hoog debiteuren-crediteuren gehalte heeft.

Lieve mam, samen met pap, heb je er altijd voor gezorgd dat we onze doelen konden bereiken. Hoewel ik er soms een hele omweg voor nam, bleven jullie me altijd steunen. Het is fijn om te weten dat er iemand altijd trots op me is!

Lieve Remy, door je positieve kijk op de wereld zorg jij ervoor dat ik elke dag fluitend naar huis ga! Bedankt voor alles! 


\section{About the author}

Danielle Mohren was born on October 2, 1971 in Puth-Schinnen. In 1989 she finished secondary school at the Albert Schweitzer Scholengemeenschap in Geleen. In 1990 she started to study Biology at the Katholieke Universiteit Nijmegen. After receiving her propaedeuse, she studied Environmental Health Sciences at the Faculty of Health Sciences of Maastricht University. During her study she did a research at the Department of Health Risk Analysis and Toxicology at Maastricht University on the effects of cadmium on DNA damage and repair. After a period of six months at the department of Biochemistry at the University of Vermont (USA), where she conducted a research on the effects of oxidative stress, she graduated in 1995. In 1998 she started her scientific career at the Department of Epidemiology at Maastricht University. From 1998 titl 2002 she worked as a PhD student studying the effects of work-related factors and fatigue on the occurrence of common infections within the Maastricht Cohort Study. In May 2002 she started working as a researcher on the EUROPIT project at the same department, to study the immunotoxic effects of pesticides among bulb growers. 